\title{
Forecasting with Macro-Finance Models: Applications to United States and New Zealand
}

by

Michelle Lewis

A thesis

submitted to the Victoria University of Wellington

in fulfilment of the

requirements for the degree of

Master of Commerce

in Economics.

Victoria University of Wellington

2015 


\begin{abstract}
In this thesis, I use macro-finance models to explore the inter-relationships between the macroeconomy and the yield curve in a forecasting setting. Using the arbitrage-free Nelson-Siegel approach to model the yield curve combined with Vector Autoregression (VAR), I jointly model macroeconomic variables and the yield curve factors to produce forecasts of inflation, activity, and interest rates. In line with earlier literature I compare whether the macro-finance model is able to better capture the dynamics of the macro variables and the yield curve factors compared with a macro-only model and a yields-only model respectively. However, a key difference is I use a full real-time forecasting setting, whereas the recent literature focuses on quasi real-time forecasting.

I find there is benefit from using macro-finance models for forecasting macroeconomic variables in real-time but the gain is more significant at longer-term horizons. Indeed, the macro-finance models do not outperform traditional macroeconomic models for forecasting activity at short-term horizons. The forecasting gain is more robust for inflation and the policy rate. The theoretically motivated restrictions on the yield curve dynamics improve the forecast performance of yield curve components and generally macroeconomic variables. Using a quasi real-time environment to assess the forecast performance can overstate the usefulness of macro-finance models and understate the usefulness of placing restrictions on the yield curve dynamics.
\end{abstract}




\section{Acknowledgments}

First and foremost I would like to thank the Reserve Bank of New Zealand and colleagues, particularly Dr. John McDermott, Yuong Ha, Christie Smith, and Dr. Ben Wong, for the invaluable support and encouragement in undertaking this thesis while employed at the Bank.

I am hugely indebted to Dr. Leo Krippner who agreed to supervise this project as a Master's thesis, share his expert knowledge, experience, and has shown unwavering support and patience throughout this research. I would not have been able to finish this project without Leo's guidance. I would also like to thank Dr. Hai Lin for co-supervising this thesis, his insightful comments, and for the encouragement right from the beginning. Both supervisors have improved the quality of this thesis.

Material from this thesis was presented at the New Zealand Econometric Study Group in February 2015. I am grateful to the organisers and participants for being able to present the work and receive feedback from those attending the conference and from my discussant Dr. Jayanta Sarkar. In particular, I offer special thanks to the committee for awarding the work with the RBNZ-NZESG Award in Econometrics for best student presentation and paper.

I would also like to thank my family and friends for support and encouragement. I would particularly like to thank my parents, Clive and Lynley Lewis, for believing in me, Leigh and Paul for being absolute rocks, and Bianca for getting me over the finishing line. Lastly, thank you to my dog and football team for providing much needed sanity breaks. 


\section{Contents}

1 Introduction $\quad 1$

1.1 Overview . . . . . . . . . . . . . . . . . . 1

1.2 Literature review . . . . . . . . . . . . . . 3

1.2.1 Early macro-finance literature . . . . . . . . . . . . . 4

1.2.2 Recent advances in term structure modelling . . . . . . . . 5

1.2.3 Recent macro-finance models incorporating the term structure . . . . . . . . . . . . . . . 8

2 Yield Curve Models $\quad 14$

2.1 Generating zero-coupon data for New Zealand . . . . . . . . . . . 14

2.2 Arbitrage-free Nelson-Siegel model . . . . . . . . . . . . . . . . 22

2.2.1 Arbitrage-free Nelson-Siegel model specification . . . . . . 22

2.2.2 Arbitrage-free Nelson-Siegel model estimation . . . . . . . 29

2.2.3 Krippner arbitrage-free Nelson-Siegel model: the zero lower bound . . . . . . . . . . . . . . . . . 35

2.2.4 Krippner arbitrage-free Nelson-Siegel estimation . . . . . 39

3 Macro-Finance Model 43

3.1 VAR estimation and forecasting . . . . . . . . . . . . . 43

3.2 VAR model set up and restrictions . . . . . . . . . . . . . . . . . . 45

3.2.1 Yields-only VAR model . . . . . . . . . . . . . . . 45

3.2.2 Macro-only VAR model . . . . . . . . . . . . . . 47

3.2.3 Macro-finance VAR model . . . . . . . . . . . . . . . 47

3.3 Model estimation . . . . . . . . . . . . . . . . . . . . 52 
3.3.1 Data ........................ 52

3.4 Model evaluation . . . . . . . . . . . . . . . . . 55

4 US Model $\quad 59$

4.1 In-sample model fit . . . . . . . . . . . . . . . . 59

4.2 Real-time forecast performance . . . . . . . . . . . . 61

4.2 .1 Pre-GFC . . . . . . . . . . . . . . 61

4.2 .2 Full sample . . . . . . . . . . . . . . . 65

4.3 Results summary . . . . . . . . . . . . . . . 69

4.3.1 Pre-GFC summary results . . . . . . . . . . . 70

4.3.2 Full sample summary results . . . . . . . . . . . 72

4.4 Comparison with quasi real-time results . . . . . . . . . . . . 74

5 NZ Model $\quad 77$

5.1 In-sample model fit . . . . . . . . . . . . . . . . 77

5.2 Real-time forecast performance . . . . . . . . . . . . 78

5.3 Results summary . . . . . . . . . . . . . . . . 82

5.4 Comparison with quasi real-time results . . . . . . . . . . . 85

6 Open Economy Model $\quad 88$

6.1 In-sample model fit . . . . . . . . . . . . . . . . . 88

6.2 Real-time forecast performance . . . . . . . . . . . . . . . . 89

6.3 Results summary . . . . . . . . . . . . . . . . . 93

6.4 Comparison with quasi real-time results . . . . . . . . . . . . 95

$\begin{array}{llr}7 & \text { Conclusion } & 99\end{array}$

$\begin{array}{ll}\text { Bibliography } & 103\end{array}$

Appendices

A Arbitrage Free Nelson-Siegel Model Results 111

A.1 In sample (K)ANSM model fit . . . . . . . . . . . . . . . . . . 111

B Quasi Real-Time Forecast Performance Results 115 


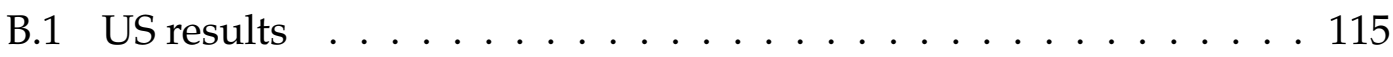

B.2 New Zealand results . . . . . . . . . . . . . . . . . 117

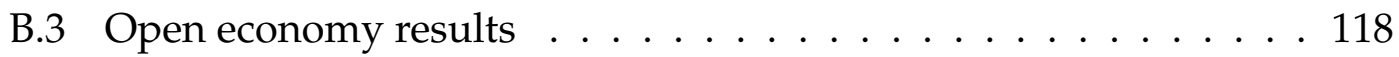

$\begin{array}{ll}\text { C Data } & 120\end{array}$

C.1 Macro-finance relationships . . . . . . . . . . . . . . . 121

C.2 Real-time data . . . . . . . . . . . . . . . . . . . . 122 


\section{List of Figures}

2.1 NZ government bond curve: actual and fitted yield curve as at 8 April 2002 . . . . . . . . . . . . . . . . . . . . . . 18

2.2 Average absolute yield pricing errors by maturity bucket . . . 19

2.3 New Zealand government bond curve in three dimensions . . 20

2.4 Nelson-Siegel factor loadings . . . . . . . . . . . . . . . . 28

2.5 US ANSM(3) and $\operatorname{ANSM}(2)$ realtime time estimates . . . . . . . 32

2.6 NZ ANSM(3) and $\operatorname{ANSM}(2)$ realtime time estimates . . . . . . 34

2.7 Zero lower bound yield curve decomposition . . . . . . . . 37

2.8 US KANSM(3) and KANSM(2) realtime time estimates . . . . . . 41

$3.1 \quad$ Unbalanced panel $\ldots \ldots \ldots \ldots \ldots$

C.1 Macro-finance linkages . . . . . . . . . . . . . . . . . 121

C.2 Real-time data . . . . . . . . . . . . . . . . . . . . 122 


\section{List of Tables}

2.1 .1 Bond yield statistics . . . . . . . . . . . . . . 21

3.2.1 Model results key . . . . . . . . . . . . . . 52

4.1 .1 US pre-GFC model fit: AIC . . . . . . . . . . . . . . . . 60

4.1 .2 US full sample model fit: AIC . . . . . . . . . . . . . . . . . 60

4.2.1 US pre-GFC: inflation RMSFE . . . . . . . . . . . . . . . . 62

4.2.2 US pre-GFC: capacity utilisation RMSFE . . . . . . . . . . . . 63

4.2.3 US pre-GFC: effective Fed funds rate RMSFE . . . . . . . . . . . . 63

4.2.4 US pre-GFC: Level RMSFE . . . . . . . . . . . . . . . . . . . . . . . . . . . . . . . 64

4.2 .5 US pre-GFC: Slope RMSFE . . . . . . . . . . . . . . . . . . 65

4.2 .6 US pre-GFC: Bow RMSFE . . . . . . . . . . . . . . . . . . . 65

4.2 .7 US full sample: inflation RMSFE . . . . . . . . . . . . . . . . . . . . . 66

4.2.8 US full sample: capacity utilisation RMSFE . . . . . . . . . . . . . 67

4.2.9 US full sample: effective Fed funds rate RMSFE . . . . . . . . . . 67

4.2.10 US full sample: Level RMSFE . . . . . . . . . . . . . . . . . . . . 68

4.2.11 US full sample: Slope RMSFE . . . . . . . . . . . . . . . . . . 68

4.2.12 US full sample: Bow RMSFE . . . . . . . . . . . . . . . . . . . . . 69

4.3.1 US pre-GFC: monitoring quarters, macro variables . . . . . . . 70

4.3.2 US pre-GFC: monitoring quarters, yield curve factors . . . . . . . 71

4.3.3 US pre-GFC: policy relevant, macro variables . . . . . . . . . 71

4.3.4 US pre-GFC: policy relevant, yield curve factors . . . . . . . . . 72

4.3.5 US full sample: monitoring quarters, macro variables . . . . . . . 73

4.3.6 US full sample: monitoring quarters, yield curve factors . . . . . 73

4.3.7 US full sample: policy relevant, macro variables . . . . . . . . . . 74 
4.3.8 US full sample: policy relevant, yield curve factors . . . . . . . . 74

4.4.1 US full sample: inflation RMSFE . . . . . . . . . . . . . . . 75

4.4.2 US full sample: capacity utilisation RMSFE . . . . . . . . . . . . . 76

5.1.1 NZ full sample model fit: AIC . . . . . . . . . . . . . . 78

5.2.1 NZ: inflation RMSFE . . . . . . . . . . . . . . . . . . . . . . . 79

5.2 .2 NZ: output gap RMSFE . . . . . . . . . . . . . . . . . . . . . 79

5.2 .3 NZ: 90-day interest rate RMSFE . . . . . . . . . . . . . . . . . . 80

5.2.4 NZ: TWI exchange rate RMSFE . . . . . . . . . . . . . . . . . . . . . . . . . . . 80

5.2 .5 NZ: Level RMSFE . . . . . . . . . . . . . . . . . . . . . . . 81

5.2 .6 NZ: Slope RMSFE . . . . . . . . . . . . . . . . . . . . 82

5.2 .7 NZ: Bow RMSFE . . . . . . . . . . . . . . . . . . 82

5.3.1 NZ: monitoring quarters, macro variables . . . . . . . . . . 83

5.3.2 NZ: monitoring quarters, yield curve factors . . . . . . . . . . . 83

5.3.3 NZ: policy relevant, macro variables . . . . . . . . . . . . 84

5.3.4 NZ: policy relevant, yield curve factors . . . . . . . . . . . . 85

$5.4 .1 \quad$ NZ: inflation RMSFE . . . . . . . . . . . . . . . . . . . . 86

5.4 .2 NZ: output gap RMSFE . . . . . . . . . . . . . . . 86

5.4 .3 NZ: TWI exchange rate RMSFE . . . . . . . . . . . . . 87

6.1.1 Open economy full sample model fit: AIC . . . . . . . . . . . . 89

6.2.1 Open econ: inflation RMSFE . . . . . . . . . . . . . . . . . 90

6.2 .2 Open econ: output gap RMSFE . . . . . . . . . . . . . . . . . . . 90

6.2.3 Open econ: 90-day interest rate RMSFE . . . . . . . . . . . . . . . 91

6.2.4 Open econ: NZD/USD exchange rate RMSFE . . . . . . . . . . . 91

6.2 .5 Open econ: Level RMSFE . . . . . . . . . . . . . . . . . . . . . . . . . . . . . . . . . . . . . 92

6.2 .6 Open econ: Slope RMSFE . . . . . . . . . . . . . . . . . . . . . . 92

6.3.1 Open econ: monitoring quarters, macro variables . . . . . . . . . 93

6.3.2 Open econ: monitoring quarters, yield curve factors . . . . . . . 94

6.3.3 Open econ: policy relevant quarters, macro variables . . . . . . . 95

6.3.4 Open econ: policy relevant quarters, yield curve factors . . . . . 95

6.4 Open econ: inflation RMSFE . . . . . . . . . . . . . . . . 96

6.4 .2 Open econ: output gap RMSFE . . . . . . . . . . . . . . . . . . . . . 97

6.4.3 Open econ: NZD/USD exchange rate RMSFE . . . . . . . . . . . 97 
A.1.1 US ANSM(3) parameters . . . . . . . . . . . . . . . . 111

A.1.2 US ANSM(3) model fit . . . . . . . . . . . . . . . . . . . . . . 112

A.1.3 US ANSM(2) parameters . . . . . . . . . . . . . . . . . 112

A.1.4 US ANSM(2) model fit . . . . . . . . . . . . . . . . . . . . . . . . . 112

A.1.5 NZ ANSM(3) parameters . . . . . . . . . . . . . . . . . . . . . . . . . . . . . . . . . . . . . . 113

A.1.6 NZ ANSM(3) model fit . . . . . . . . . . . . . . . . . . 113

A.1.7 NZ ANSM(2) parameters . . . . . . . . . . . . . . . . . 113

A.1.8 NZ ANSM(2) model fit . . . . . . . . . . . . . . . . . . 114

B.1.1 US full sample: effective Fed funds rate RMSFE . . . . . . . . . . 115

B.1.2 US full sample: Level RMSFE . . . . . . . . . . . . . . . . . . . . . 116

B.1.3 US full sample: Slope RMSFE . . . . . . . . . . . . . . . . . 116

B.1.4 US full sample: Bow RMSFE . . . . . . . . . . . . . . . . . . . 116

B.2.1 NZ: 90-day rate RMSFE . . . . . . . . . . . . . . . . . . . 117

B.2.2 NZ: Level RMSFE . . . . . . . . . . . . . . . . . . . . . . 117

B.2.3 NZ: Slope RMSFE . . . . . . . . . . . . . . . . . . . . . 117

B.2.4 NZ: Bow RMSFE . . . . . . . . . . . . . . . . . . . . . . . . . 118

B.3.1 Open econ: 90-day rate RMSFE . . . . . . . . . . . . . . . . 118

B.3.2 Open econ: Level RMSFE . . . . . . . . . . . . . . . . . . . . . 118

B.3.3 Open econ: Slope RMSFE . . . . . . . . . . . . . . . . . . . . . 119 


\section{Chapter 1}

\section{Introduction}

\subsection{Overview}

In this thesis I investigate the use of macro-finance models for forecasting in real-time. It is motivated by a large body of literature that indicates empirically useful relationships between macroeconomic and financial market variables, which I review in Section 1.2. However, the usefulness of these relationships in real-time, as faced by practitioners, is an area that is largely untested for recent macro-finance models. The real-time environment simulates the environment faced by a practitioner and provides a degree of confidence for the practical gain from augmenting macroeconomic models with yield curve information.

The general approach I take is to combine arbitrage-free Nelson and Siegel (1987) latent factors (Level, Slope, and Bow) from government bond yield curves with macroeconomic variables (CPI inflation, real activity, and the exchange rate) within a Vector Autoregressive (VAR) model. From the resulting macro-finance model, I test in-sample model fit and forecast performance.

The analysis focuses on the United States and New Zealand. From 2008, the US model incorporates the zero lower bond, using the Kripper $(2011,2015)$ approach. A small open economy model is also developed, where a New Zealand macroeconomic model is augmented with New Zealand and US yield 
curve information. This captures the idea that incorporating financial links with the US could provide a parsimonious method for distilling information from US yields.

This research has at least three contributions to the literature, which I list in order of importance:

- I use real-time data and evaluate the models' real-time forecasting ability. This simulates the environment faced by a forecaster in real-time and provides a practical test on the usefulness of including macro economic and yield curve data together in forecasting models. Much of the literature that looks at the gain from macro-finance models focuses on either full-sample analysis or quasi-realtime (truncating the latest vintage of data available), ignoring the data revisions seen in real-time. I repeat the analysis using quasi real-time data to compare with past literature and to contrast with the real-time results.

- For the US, I use a yield curve model that allows for the zero-lower-bound policy environment. To date, the literature has focused on the ability of zero-lower-bound yield curve models, occasionally combined with macro-economic variables, to model and forecast yields. This research adds to this body of work, using the yield curve information to help inform macro economic forecasts.

- I have created a database for New Zealand zero-coupon government bonds using techniques widely used in the literature. Up-to-date data will be available on request from the Reserve Bank of New Zealand. Krippner and Thorsrud (2009) also generated zero-coupon government bond data for New Zealand, but their programme is no longer readily updatable.

The in-sample and quasi real-time forecasting results show that macro-finance models generally outperform economic-only models. This result is consistent with the literature. However, taking data-revisions into account weakens the result. The forecast improvement from using the term structure almost disappears for activity, with gains remaining only for longer forecast horizons. Nevertheless, the information gain at the longer-horizons should still be of 
use to policy makers given this horizon is consistent with medium-term objectives. The forecast improvement is more robust for inflation, even when incorporating real-time economic activity in the forecasting model. The theoretically motivated restrictions on the yield curve dynamics improve the forecast performance of yield curve components and generally macroeconomic variables.

\subsection{Literature review}

The field of macro-finance takes an interdisciplinary approach to understanding the inter-relationships between the macroeconomy and the term structure of interest rates. As Rudebusch (2010) notes, there is a disconnect between the traditional macroeconomic and finance literatures for how to model interest rates.

The traditional finance literature uses a factor structure to model interest rates, with the factors typically interpreted as Level, Slope, and Bow (or Curvature). Long-term interest rates are a function of the short-term interest rate plus a term premium. However, these factors do not have clear economic connections or interpretation.

The traditional macroeconomic literature models short-term interest rates as controlled by the central bank. The expectations hypothesis is invoked to derive long-term interest rates, despite its poor empirical performance ${ }^{1}$, where the long-term interest rates depend on expectations of the future economic activity, inflation, and how the central bank responds, but risk premiums are generally ignored.

The macro-finance literature combines aspects of the two literatures using various approaches in an attempt to understand interest rates and the macroeconomy. Indeed, as Gurkaynak and Wright (2012) explain, when

\footnotetext{
${ }^{1}$ See Campbell and Shiller (1991), Gurkaynak and Wright (2012) for updated results using the Campbell and Schiller methods, Fama and Bliss (1987), Backus et al. (2001), Duffee (2002), and Cochrane and Piazzesi (2005) for studies showing the failure of the expectations hypothesis.
} 
analysing movements in interest rates, particularly long-term interest rates, it is important to distinguish between changes in expectations about macroeconomic fundamentals and risk premiums since this can have important policy implications. Macro-finance models offer a way of making this distinction.

\subsubsection{Early macro-finance literature}

The literature linking the yield curve and the macro-economy began in the late 1980s. This literature focused on the information content in the yield curve spread i.e. the difference between a long-term rate and short-term rate, such as the 10-year government bond and the three-month Treasury Bill. Estrella and Hardouvelis (1991) provided the first comprehensive statistical study into the relationship for the US, finding the government bond spread is useful for forecasting activity, consumption and investment particularly 4-6 quarters ahead. This work sparked an extensive literature investigating the relationship further and for other countries, focusing on the ability of the yield curve slope to predict economic growth ${ }^{2}$.

There is also no unified theory for why a relationship exists. Rather, as Benati and Goodhart (2008) note, the relationship is a 'stylised fact in search of a theory'. The general intuition behind the relationship is that the yield curve will move as investors' expectations about the future path of the economy changes. For example, if the economy is expected to expand then the yield curve is upward slopping. If the economy is expected to slow or contract then the yield curve flattens or possibly inverts.

However, there is not a general consensus in the literature about how well the slope of the yield curve predicts economic activity (see Benati and Goodhart (2008) and Stock and Watson (2003), for example). As Wheelock and Wohar (2009) note in their recent review of this literature, many studies find the

\footnotetext{
${ }^{2}$ See www.newyorkfed.org/research/capital_markets/ycfaq.html for an extensive bibliography of literature for the US. Krippner and Thorsrud (2009) analyse the relationship for New Zealand.
} 
slope is a good predictor of economic activity at one-year horizons but many studies also find the results are not robust to different sample periods or across countries. Studies also find that ability of the spread to forecast activity has weakened since the mid-1980s (see, for example, D'Agostino, Giannone, and Surico (2006)). Nevertheless, the literature does find stronger evidence of the yield curve slope being useful for predicting recessions across different countries (see, for example, Bernard and Gerlach (1998), Stock and Watson (2003), and Moneta (2005)). As an application for the US, Rudebusch and Williams (2009) show that the simple forecasting model with the yield curve slope is better than predicting recessions a few quarters ahead compared to the survey of professional forecasters.

In light of the instability using the yield curve slope for forecasting economic activity, the macro-finance literature has begun to use term structure modelling techniques used in the finance literature. These models offer richer dynamics for explaining movements in the yield curve, while also parsimoniously capturing almost 100 percent of the variation in the yield curve. Indeed, pointing to the importance of using the entire yield curve, albeit not using real-time data, Ang, Piazzesi, and Wei (2006) show using term structure modelling techniques, discussed below, provide superior forecasting power compared to using interest rate spreads for US GDP growth.

\subsubsection{Recent advances in term structure modelling}

The modern finance literature uses more sophisticated term-structure modelling methods to analyse yield curve dynamics. The most common approach is to employ a factor structure, which is a popular approach for modelling asset prices in general in the finance literature (see Diebold and Rudebusch (2012), Duffie (2001), Singleton (2006), and Piazzesi (2010) for comprehensive reviews of the term structure modelling literature). Dai and Singleton (2000) show these modelling techniques are able to explain around 98 percent of the variation across the yield curve using two or three latent 
factors ${ }^{3}$. This means information from essentially the entire yield curve can be decomposed into a few factors, rather than only using a specific component of the yield curve (i.e. the slope). This is the approach I use in this thesis and a fuller discussion of the models are in Chapter 2. In this section I provide an overview of such models and discuss how they are used.

The workhorse model is the Gaussian affine term structure model, where bond yields are modelled as a linear function of state variables and a constant. The resulting dynamics ensure there are no arbitrage opportunities in how the bonds are priced, which makes the estimated bond yields consistent cross-sectionally (i.e. bond yields across the yield curve) at any point in time as well as across time. However, practical implementation can be problematic, where parametrisation can result in flat likelihoods during estimation (see Duffee (2002) and Dai and Singleton (2002)). Duffee (2002) shows the canonical affine arbitrage-free models have poor empirical performance, especially for forecasting future bond yields, although this can be improved with more flexible market prices of risk. Recent practical advances have been made; for example, Joshlin, Singleton, and Zhu (2011) and Hamilton and Wu (2012) use a discrete time version of the affine term structure model and develop robust estimation methods that prevent flat likelihoods.

Another approach has been to use the Nelson and Siegel (1987) model, where bond yields are a linear function of three latent factors that govern the yield curve dynamics. Diebold and Li (2006) introduced the dynamic Nelson-Siegel model, and showed the first three latent factors were interpretable as the Level, Slope, and Bow (or Curvature) of the yield curve. This class of model is simple to estimate but suffers theoretically because it is not arbitrage free. Krippner (2006) and Christensen, Diebold, and Rudebusch (2011) show the Nelson-Siegel model can be made arbitrage-free and is a sub-class in the Gaussian affine term structure modelling family once certain restrictions are imposed. This overcomes the theoretical criticism in Filipovic (1999 and 2000) that Nelson-Siegel models, in the original form, cannot be

\footnotetext{
${ }^{3}$ Litterman and Scheinkman (1991) originally illustrated that using three factors captures the key dynamics in the yield curve.
} 
intertemporally consistent or arbitrage-free. Christensen et al. (2011) highlight that the arbitrage-free Nelson-Siegel model is theoretically rigorous, empirically tractable, provides a good fit to the yield curve, and has good forecast performance. The Nelson-Siegel and arbitrage-free version are widely used in the literature given its theoretical and empirical appeal.

The zero lower bound environment is problematic for traditional term structure models, including those discussed above, because these models do not rule out the possibility of negative interest rates. This has become more of an issue in practice and in the literature given the number of countries at or near the zero lower bound since 2008. Krippner (2011) models options on physical currency within a Gaussian affine term structure model for interest rates to provide a modeled zero lower bound constraint that matches observed yields, while also extracting a shadow interest rate and associated metrics to gauge the effective stance of monetary policy. This model is a natural extension of the Gaussian affine term-structure modelling approach and the arbitrage-free Nelson-Siegel representation can also be recovered. Alternative approaches to modelling the zero lower bound term structure models are discussed in Krippner (2015) but these alternatives do not offer a natural extension to the arbitrage-free Nelson-Siegel model, which is convenient for this analysis given the conceptual continuity with the yield curve components (Level, Slope, and Bow) ${ }^{4}$. This approach was used in Christensen and Rudebusch (2013) for similar reasons. From an empirical point of view, Kim and Singleton (2012) compare models that use a quadratic term structure model to fit yields and a shadow rate model similar to Krippner (2011) and find the latter model sightly outperforms.

\footnotetext{
${ }^{4}$ As discussed in Krippner (2015), these alternative models also have inconsistencies with empirical data.
} 


\subsubsection{Recent macro-finance models incorporating the term structure}

\section{Inter-relationships between the yield curve and the macro economy}

The recent macro-finance literature focuses on examining the relationship between the entire yield curve and macroeconomic variables using either a Gaussian affine term structure model or the Nelson-Siegel model ${ }^{5}$. This allows a parsimonious way of extracting all the information from the yield curve, rather than a segment of the curve. The literature is further motivated by an apparent observable link between the yield curve factors (Level, Slope, and Bow) and economic concepts such as real activity and inflation.

In the seminal article of Ang and Piazzesi (2003), the authors investigate the relationship from macro variables to the yield curve using arbitrage-free latent factors of the yield curve and a VAR, finding that a large proportion of the variation in yields can be explained with output and inflation. However, the model restrictions implies that changes in the policy rate, which are reflected in the yield curve, cannot affect future inflation or real activity since a unidirectional relationship is assumed.

Diebold, Rudebusch, and Aruoba (2006) were the first to consider a bi-directional relationship between the macroeconomy and the yield curve. Diebold et al. (2006) estimate a model that summarises the yield curve using Nelson-Siegel latent factors (Level, Slope, and Bow) and macroeconomic data (capacity utilisation, inflation, and the Fed funds rate) within a VAR. They show macroeconomic variables explain a significant proportion of variance in yield curves. While yield curves are informative for macroeconomic variables it is to a lesser degree. In particular, the Level component is related to inflation and the Slope is related to economic activity, while the Bow appears unrelated to any key macroeconomic variables.

Extending the work of Diebold et al. (2006), Ang, Bekaert, and Wei (2007)

\footnotetext{
${ }^{5}$ See Rudebusch (2010) and Gurkaynak and Wright (2012) for recent reviews of the broader macro-finance literature.
} 
also study the dynamic relationship between the yield curve and the economy but they also impose no-arbitrage conditions, which provides an estimation challenge. When the relationship is constrained to be unidirectional from macroeconomic to yield factors, macroeconomic factors only explain a small proportion of long-term yields. When the system is fully dynamic, over half of the variance in long-term yields can be attributed to macro factors. Related research that looks at the empirical linkages between the macro economy and yield curves includes Kozicki and Tinsley (2001), Piazzesi (2005), Ang, Piazzesi, and Wei (2006), Dewachter and Lyrio (2006), Balfoussia and Wickens (2007), and Joslin, Priebsch, and Singleton (2009).

A popular setup in these empirical macro-finance VAR models is using recursive ordering to identify shocks and do variance-explained analysis. However, it is not clear how the variables should be ordered. Convention is for the yield curve factors to be ordered first, meaning yield curve factors do not contemporaneously effect macroeconomic variables, but Bibkov and Chernov (2010) show that ordering of the variables matters for results. Nevertheless, Bibkov and Chernov (2010) find, in a more robust environment, that yield curve factors and economic variables are each important for explaining variation in macroeconomic variables and the yield curve.

Another approach to the macro-finance literature has been to embed yield curve factors into structural economic models, which allows for clearer understanding of the inter-relationships.

Rudebusch and Wu (2008) combine an affine arbitrage-free term structure model with a small New Keynesian rational expectations model. The central bank's reaction function connects the short-term interest rate and the macroeconomy, while the affine term structure model allows for a departure from the expectations hypothesis for long-term interest rates. The authors are able to interpret the yield curve latent factors in terms of macroeconomic variables, where the Level is interpreted as the inflation target and the Slope is the cyclical monetary policy response to the economy (the Bow component is not included in the model). Unlike standard macroeconomic models, the authors' model is also able to generate persistent macroeconomic 
effects on the long-term interest rates. This empirical feature was stressed in Gurkaynak, Sack, and Swanson (2005), where long-rates empirically respond to macroeconomic surprises.

Krippner $(2008,2015)$ uses a continuous-time general equilibrium model of Cox, Ingersoll, and Ross (1985) to develop a formal economic foundation for an arbitrage-free Nelson-Siegel model. Krippner shows the Level is related to long-term expected inflation and potential output growth, while the Slope and Bow components are related to the cyclical components of inflation and output growth. An application in Krippner (2008) with US data finds evidence that the relationships between the yield curve and macroeconomic variables has been influenced by time-varying potential growth and occasional but highly persistent changes to the yield curve term-premia ${ }^{6}$. Similar results were found in Joshin, Priebsch, and Singleton (2014), where the authors find evidence of a regime switch in term premia in 1985.

Some studies have used macro variables as latent factors in the yield curve. Bernanke, Reinhart, and Sack (2004) use an affine model where the factors are GDP growth, inflation, the Fed funds rate, and survey expectations of inflation and GDP growth. Smith and Taylor (2009) use inflation and the output gap as the factors. In these models, yields of all maturities are a function of the economic factors which allows economic shocks to the yield curve to be analysed. However, as Gurkaynak and Wright (2012) note, this class of model does not fit the observed yield curve well.

\section{Forecasting exercises}

From a forecasting perspective, the literature largely focuses on quasi real-time forecast performance (truncating the latest vintage of data available, ignoring data revisions). This allows the analysis to be focused on which model has the better performance, given reliable information (final vintage data). However, this approach neglects the problems a forecaster is faced with in practice,

\footnotetext{
${ }^{6}$ For other research using structural models see Dewachter and Lyrio $(2006,2008)$, Wright (2011), Joslin et al. (2009), and Hordahl et al. (2008)
} 
notably access to just the information available to investors at the time of pricing bonds.

The seminal article by Ang and Piazzesi (2003), previously mentioned, only looked at the forecasting performance gain for yield curves from incorporating macroeconomic variables for the United States. The unidirectional model meant the forecasting exercise could not be conducted in reverse. The authors find significant improvement in forecasting yield curves when adding macroeconomic information. The exercise is done in quasi real-time.

Ang and Piazzesi (2006) include GDP growth in an arbitrage-free term structure model as the basic model for the United States. In a quasi real-time forecasting environment (1990Q1-2001Q4), as previously mentioned, the authors find that using a factor structure of the yield curve outperforms the slope for forecasting GDP out to 12 quarters ahead. The authors also find using two latent yield curve factors is preferred to three factors.

Moench (2008) uses an arbitrage-free term structure model along with a large number of macroeconomic series in a factor augmented VAR (FAVAR) model to forecast US bond yields in a macro-data-rich environment. The macro-finance FAVAR developed outperforms other forecasting methods such as the affine three factor model in Duffee (2002) and the dynamic Nelson-Siegel model in Diebold and $\mathrm{Li}$ (2006) up to 12 quarters ahead. The analysis uses quasi real-time data and the sample period is 1983:01 - 2003:09.

Moench (2012) uses the data-surprise methodology to show the Level, Slope, and Bow components each provide valuable information. Despite the low explanatory power of the Bow factor, Moench (2012) finds surprises to the Bow precede changes to the Slope of the yield curve as well as output more than a year in advance.

The majority of recent papers that analyse the predictive relationship between the yield curve and macroeconomic data find that macro factors have significant predictive power for government bond yields. However, the majority of these studies use final vintage data, which investors did not have access to 
as the time ${ }^{7}$. Ghysels, Horan, and Moench (2012) use real-time data vintages and find a significant share of the predictive power of macro-data for bond yields is due to subsequent data revisions. In a genuine real-time forecasting environment, the degree of predictability is moderate albeit still statistically significant. Similar analysis in Christoffersen, Ghysels, and Swanson (2002) show the importance of using real-time data for assessing the performance of tracking portfolios. From the monetary policy perspective, Orphanides (2001) emphasises the importance of using real-time data when examining monetary policy decisions. Indeed, the importance of using real-time data in the macroeconomic forecasting literature is extensive (see, for example, Stark and Croushore (2002), Orphanides and van Norden (2002), Koenig, Dolmas, and Piger (2003), Croushore and Evans (2006), and Croushore (2006)).

Hordahl, Tristani, and Vestin (2006) also use real-time data vintages. The authors combine a small structural model with an arbitrage-free model of bond yields, relaxing the assumption in Ang and Piazzesi (2003) that inflation and output are independent of the monetary policy rate. Hordahl et. al. (2006) find that macro factors affect the term structure of interest rates in different ways. Monetary policy shocks have a significant impact at the short-term yields but has little impact on long-term yields. Inflation and output shocks affect medium-term yields, which is the Bow factor of the yield curve, and changes in the perceived inflation target affect long-term yields. The authors do a forecasting exercise using German data, mainly focusing on forecasting yields. They find macroeconomic information improves the forecast performance of bond yields compared to a yields-only model. Conversely, yield curve information marginally improves inflation forecasts but not forecasts for economic activity. However, due to the computational burden the authors do not re-estimate the model for each forecast vintage (use the estimation pre-forecast window estimation) and the macroeconomic forecast evaluation period is small (January 1995 - December 1998).

The recent macro-finance literature has also used information from the

\footnotetext{
${ }^{7}$ In addition to the previously mentioned studies, other examples include Ludvigson and Ng (2009), Joslin, Priebsch, and Singleton (2010), and Wright (2011).
} 
entire yield curve to forecast recessions. Chauvet and Senyuz (2012) use a Markov-switching model to forecast the beginning and end of recessions. The authors find strong predictability, using real-time and truncated data. Nyholm (2007) uses a three-state regime-switching version of the three-factor Nelson-Siegel yield curve model to predict recessions. 


\section{Chapter 2}

\section{Yield Curve Models}

This section outlines how the yield curve models used in this thesis are constructed and estimated. Firstly, for New Zealand, constant maturity zero-coupon government bond yields need to be estimated. Then the arbitrage-free Nelson-Siegel and zero-lower-bound Nelson-Siegel models are used to estimate yield curves based on generic yields. The factors that underpin these models are used in the macro-finance model.

\subsection{Generating zero-coupon data for New Zealand}

For New Zealand, at any point in time, there are a limited number of bonds on issue. Furthermore, the infrequency of issuance means these bonds can pay materially different coupons. To make bond yields comparable at a point in time, the prices of the bonds need to be adjusted for different coupon payments over the time until maturity. To make bond yields comparable over time, a set of bonds with standard maturities needs to be calculated i.e. a bond with exactly five years to maturity if not available every day, so a five-year bond yield needs to be implied from the available data. Yield curve estimation may be used to adjust for coupons and interpolate between existing maturities and calculate constant maturity bonds (also known as generic bonds). 
There are generally two methods for generating zero coupon yield curve data. The first approach uses techniques such as splines to fit as many points as possible points on the yield curve. This approach is desirable for traders that want to closely replicate actual bond prices. The other approach is parametric. This is preferable when the aim to understand fundamental components of the yield curve, with less regard to the exact prices of individual securities. Reflecting the need to understand yield curve fundamentals, the majority of central banks that report generic bond data use the Nelson and Siegel (1987) approach, or a variant of the method (see BIS $\left.(2005)^{1}\right)$. With this in mind, and following convention, I estimate zero-coupon generic bond yields for New Zealand using the Nelson-Siegel (NS) model ${ }^{2,3}$. This approach is flexible enough to fit a variety of shapes that the yield curve takes, while smoothing out the anomalies caused by specific securities.

The NS model calculates the cross-section of yields for a given point in time using the latent factor approach with four parameters. Equation 2.1 shows the NS functional form for continuously compounding zero-coupon interest rates:

$$
R_{N S}(t, \tau)=\beta_{1}(t)+\beta_{2}(t)\left(\frac{1-e^{-\phi \tau}}{\phi \tau}\right)+\beta_{3}(t)\left(\frac{1-e^{-\phi \tau}}{\phi \tau}-e^{-\phi \tau}\right)
$$

where $t$ is the observation date, $\tau$ is remaining time to maturity, and $\phi$ is the decay parameter, representing how the shape of the yield curve decays.

\footnotetext{
${ }^{1}$ Belgium, Canada, Finland, France, Germany, Italy, Japan, Norway, Spain, Sweden, Switzerland, UK, and US all provide zero-coupon yield data to the BIS and all, except for Japan, use the Nelson-Siegel method or some variant.

${ }^{2}$ Krippner and Thorsrud (2009) calculate and use generic bond yield data based on the same method used here, however the model was not in a format that could be readily integrated into the Reserve Bank's modelling suite. The notation from the authors' paper is used here.

${ }^{3}$ The preferred approach would be to be to have one step estimation, where the yield curve models detailed in the next section were able to process coupon-paying bonds. Krippner (2006) and Pancost (2013) directly estimate Gaussian affine term structure models from coupon-paying data. However, computationally this is demanding and requires non-linear estimation techniques such as the Iterated Extended Kalman Filter. I leave this for future research. Convention in the literature and practice is to use generated zero-coupon data as the data set.
} 
$\beta_{1}(t), \beta_{2}(t)$, and $\beta_{3}(t)$ are factor coefficients and the terms that multiply these factor coefficients are the factor loadings. The economic interpretation of the factors and loadings will be discussed below but Equation 2.1 shows the fitted yield curve can take a number of shapes at different points in time, where the curve can be flat, sloping, and have 'humped' or 'U' shapes. The NS model also ensures that forward rates are positive at all times and the non-Level components approach zero as the maturity increases.

The data required for fitting the yield curve are: bond yields from the secondary market for New Zealand government bonds, issuance dates, maturity dates, settlement date convention (two days for bonds and same-day settlement for Treasury bills), coupon rates, and coupon payment frequencies ${ }^{4}$. All bonds on issue at any point in time are used although bonds with less than three months to maturity are discarded for liquidity reasons. Three- and six-month Treasury bill data are also used. Daily data from 1 April 1992 until 1 July 2014 are used, with 27 securities having been issued over the sample period. The data are collected from the Reserve Bank of New Zealand and Krippner and Thorsrud $(2009)^{5}$.

The first step is to calculate the bond cashflows, based on the time to maturity, the coupon, the frequency that the coupon is paid, the yield on the bond in the secondary market, and the settlement convention. Once the cashflows for each bond on issue at each point in time are available, the model net price for the bond is calculated ${ }^{6}$.

Equation 2.1 is estimated by minimising the squared residuals of net fitted prices over the entire sample of yield curve data, where the difference between the price of the bond, $P_{k}$, and the cash flows is minimised:

\footnotetext{
${ }^{4}$ Government bond data are used in this analysis to abstract from additional risk components that would be required in modelling other interest rate securities. It would be interesting in future work to test the relationships explored here using securities such as interest rate swaps or corporate bonds.

${ }^{5}$ The New Zealand Debt Management Office website has information about each specific bond and treasury bill on issue www. nzdmo. govt. nz.

${ }^{6}$ The price of a bond at time $t$ is the sum of discounted cashflows.
} 


$$
\text { Minimise : } \sum_{t=1}^{T} \sum_{k=1}^{K(t)}\left(\omega_{k t} \cdot \epsilon_{k t}\right)^{2}
$$

Where:

$$
\epsilon_{k t}=\sum_{j=1}^{J[k]} a_{j k t} \cdot \exp \left[-\tau_{j k t} \cdot R_{N S}\left(t, \tau_{j k t}\right)\right]
$$

$T$ is the number of yield curve observations in the sample, $K(t)$ is the number of bonds available at each point in time (with more than three months to maturity), and $\omega_{k t}$ is the weighting factor. The weighting factor for each bond is the inverse of the basis point value, which measures the price sensitivity of a bond to a one basis point change in the yield. $J(k)$ is the number of cashflows for bond $k, a_{j k t}$ is the cashflow for each bond, $\tau_{j k t}$ is the maturity of the cashflow $j$ of bond $k$ at time $t$, and $R_{N S}\left(t, \tau_{j k t}\right)$ is the NS interest rate for time to maturity $\tau_{j k t}$. Note that the first cashflow is negative since it is the initial cash outlay from purchasing the bond. The parameters $\beta_{1}(t), \beta_{2}(t)$, and $\beta_{3}(t)$ are estimated for each yield curve observation based on a given value for $\phi$.

The full estimation is done in two steps, where $\phi$ is optimized over the full sample. A starting value of $\phi$ is given (set at 0.8 ), and the NS coefficients are estimated for each yield curve in the sample. The squared error of estimated bond prices is minimised. The sum of squared residuals is used to calculate a new value of $\phi$ based on the Newton method. This process continues until $\phi$ converges $^{7}$. The global optimisation of $\phi$ means the zero-coupon bond data are consistent across time as well as cross-sectionally, making the NS model dynamic. Figure 2.1 illustrates how the fitted yield curve smooths through individual bonds, particularly the anomaly the short end of the curve in this particular example.

\footnotetext{
${ }^{7}$ The Matlab algorithm used is fminsearch, which solves non-linear optimisation. I also use csminwell to help ensure global convergence as well as testing the sensitivity to starting values.
} 
Figure 2.1: NZ government bond curve: actual and fitted yield curve as at 8 April 2002

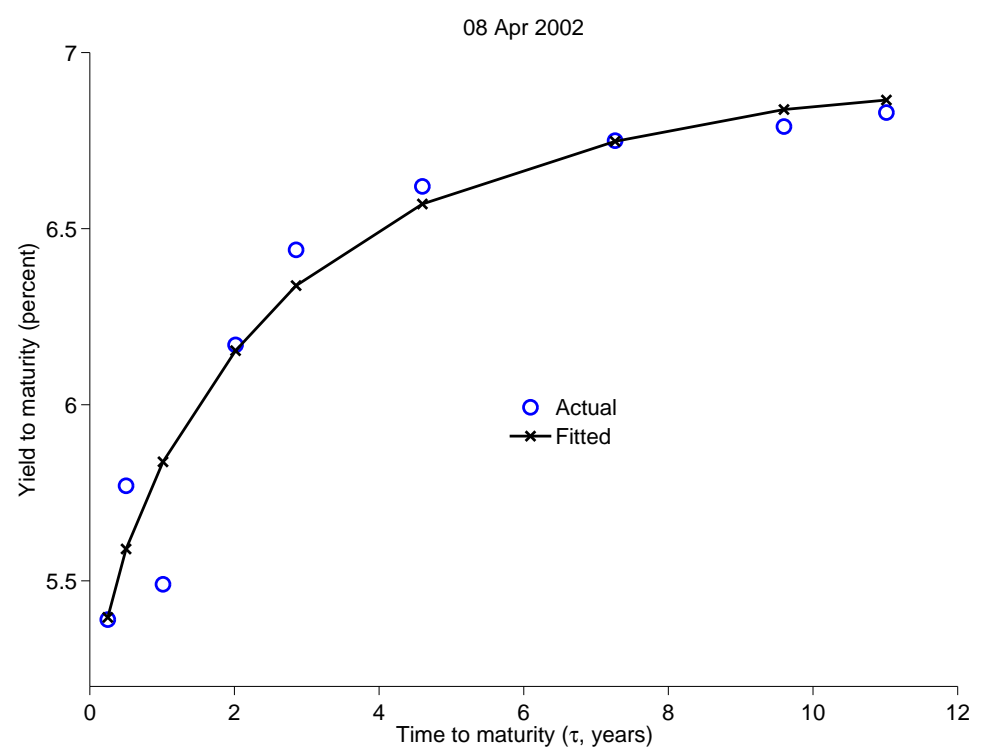

Note: The solid line is the fitted yield curve from the NS(3) and the crosses indicate the fitted yields (with coupons added back). The circles are the actual bond yields (including coupons).

The fitted yields are generated with the NS coefficients $L(t)=7.06 \%, S(t)=-1.83 \%, B(t)=$ $-0.30 \%$, and $\phi=0.79$.

Overall the model provides a good fit to the yield curve, with an absolute pricing error of 13 basis points across all the bonds, which compares well with the US data set developed by Gurkaynak, Sack, and Wright (2007). Figure 2.2 shows the average absolute yield pricing error in different maturity buckets over time. The short-end of the yield curve has slightly larger pricing errors compared to the long-end, although those errors have been trending lower in recent years. This could reflect greater liquidity in the market, which could reduce pricing anomalies. 
Figure 2.2: Average absolute yield pricing errors by maturity bucket

$0-2$ years

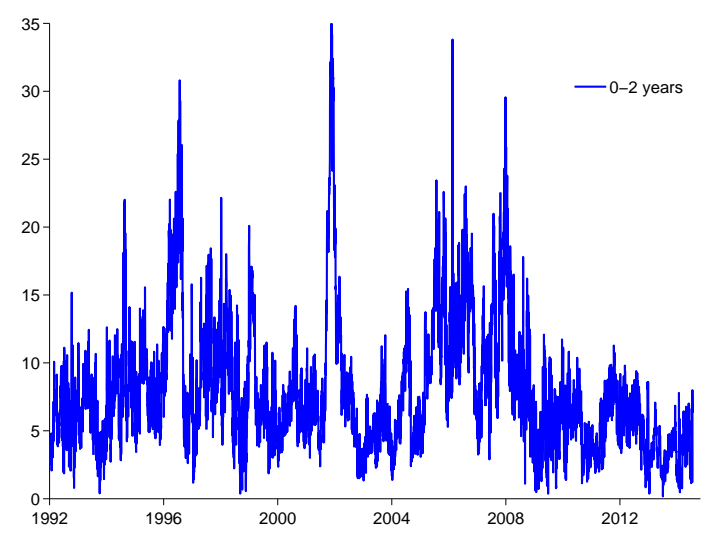

2-5 years

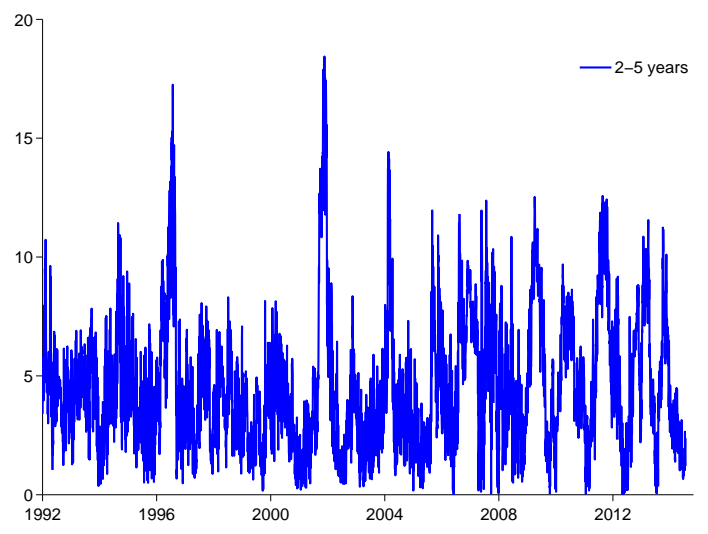

5-10 years

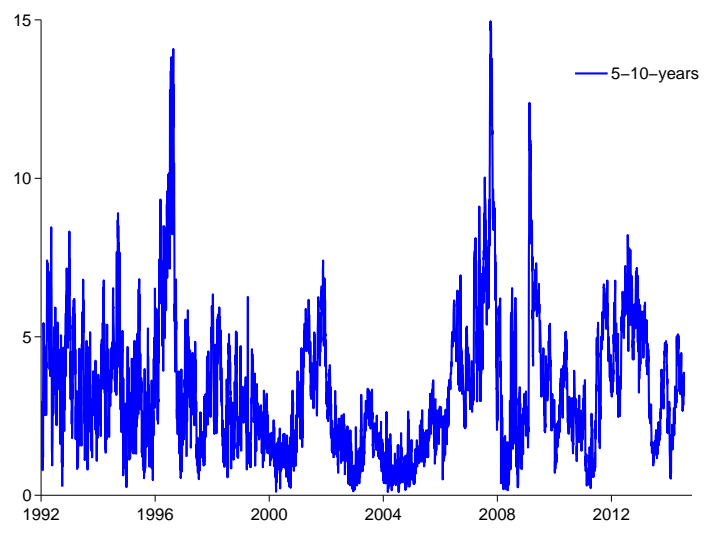

Note: The pricing error is the difference between the fitted yield from the NS(3) and the actual bond yield. The maturities are split to represent the short-, medium-, and long-end of the yield curve.

Generic bond yields are calculated using Equation 2.1 for maturities of 3-months, 6-months, 1, 2, 3, 5, 7, and 10 years. Doing this calculation for each time $t$ gives a time series of generic continuously compounding government bond yields. This gives a data set that is comparable across time and across countries.

The New Zealand government bond curve fits several stylized facts for how 
bond yields behave over time (see Diebold and Rudebusch (2012) for a discussion on stylized yield curve facts, using the US as an example). Figure 2.3 gives a three-dimensional view of how the curve has evolved since April 1992. There is a lot of movement in yields over time, and the curve takes on positive, inverted, and humped shapes.

Figure 2.3: New Zealand government bond curve in three dimensions

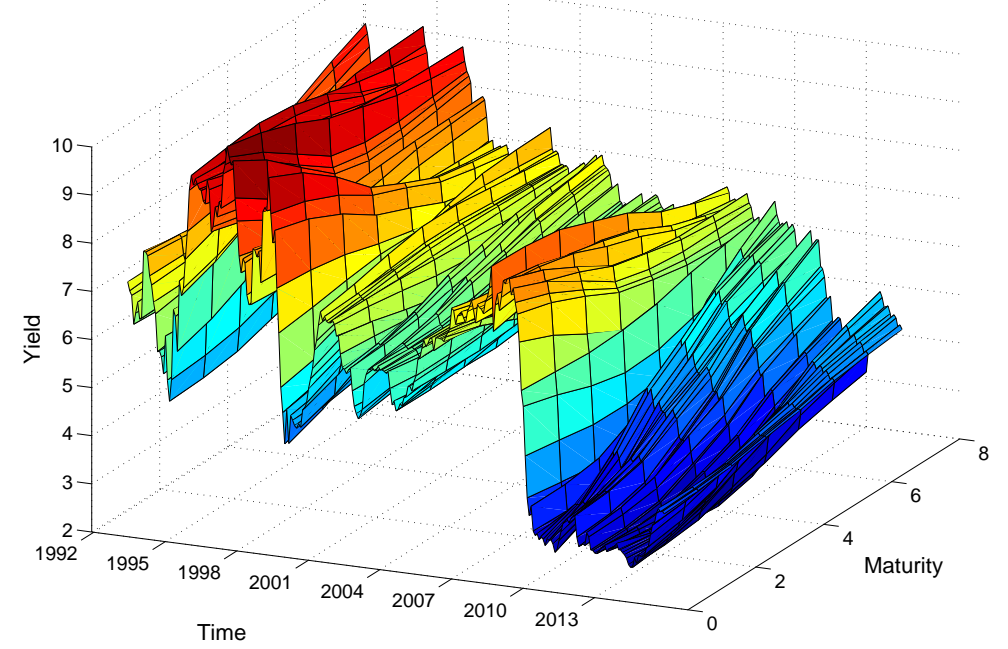

Note: NS(3) fitted bond yields for New Zealand, with maturities between 3-months and 10-years.

Table 2.1.1 provides summary statistics for the zero-coupon bonds, which also fit with the stylised facts outlined in Diebold and Rudebusch (2012). Firstly, the average yield increases with maturity, suggesting a term-premium priced in the bonds. Secondly, the volatility of yields decreases as the maturity increases. Thirdly, yields are highly persistent, as seen by the autocorrelations for one- and 12-month bond yields. 
Table 2.1.1: Bond yield statistics

\begin{tabular}{|c|c|c|c|c|c|c|c|c|}
\hline & \multicolumn{4}{|c|}{ United States } & \multicolumn{4}{|c|}{ New Zealand } \\
\hline $\begin{array}{r}\text { Maturity } \\
\text { (years) }\end{array}$ & $\bar{y}$ & $\hat{\sigma}$ & $\hat{\rho_{y}}(1 m)$ & $\hat{\rho_{y}}(12 m)$ & $\bar{y}$ & $\hat{\sigma}$ & $\hat{\rho_{y}}(1 m)$ & $\hat{\rho_{y}}(12 m)$ \\
\hline 0.25 & 3.8 & 2.5 & 0.99 & 0.78 & 5.6 & 2.1 & 0.98 & 0.64 \\
\hline 0.5 & 3.9 & 2.5 & 0.99 & 0.79 & 5.6 & 2.0 & 0.98 & 0.66 \\
\hline 1 & 4.1 & 2.6 & 0.99 & 0.80 & 5.6 & 1.9 & 0.98 & 0.68 \\
\hline 2 & 4.4 & 2.6 & 0.99 & 0.82 & 5.7 & 1.7 & 0.98 & 0.68 \\
\hline 3 & 4.6 & 2.5 & 0.99 & 0.83 & 5.8 & 1.5 & 0.98 & 0.67 \\
\hline 5 & 5.0 & 2.3 & 0.98 & 0.83 & 5.9 & 1.4 & 0.97 & 0.65 \\
\hline 7 & 5.3 & 2.2 & 0.98 & 0.84 & 6.0 & 1.3 & 0.96 & 0.62 \\
\hline 10 & 5.6 & 2.1 & 0.98 & 0.84 & 6.1 & 1.2 & 0.96 & 0.58 \\
\hline
\end{tabular}

Zero-coupon government bond data for the United States are readily available. Many researchers use the database available from the Board of Governors of the Federal Reserve System, based on Gurkaynak et al (2007). The authors use the Svensson (1995) extended NS model, which includes a fourth factor (an additional Bow) to provide extra flexibility when fitting the yield curve for long-maturity bonds. The data set for the US includes bonds with maturity out to 30-years ${ }^{8}$. Following Krippner (2015), I also splice US overnight indexed swap data, which are from Bloomberg (code S0042Z). From 2006, these data are included because the interest rates are closely linked to the US monetary policy rate but are not available prior to this date.

\footnotetext{
${ }^{8}$ In New Zealand the longest maturity is typically around 10-years, so the added flexibility provided by Svensson (1995) is not needed.
} 


\subsection{Arbitrage-free Nelson-Siegel model}

\subsubsection{Arbitrage-free Nelson-Siegel model specification}

In finance, term-structure modelling has two overall strands. The first is theoretically rigorous and focuses on ensuring conditions are met such as no-arbitrage opportunities result from the model. These models fit in the Gaussian affine term structure literature. The second strand is atheoretical, focusing on developing functional forms to fit and forecast yield curves. This strand typically suffers from not being theoretically founded and is not necessarily consistent with the no-arbitrage condition but does well fitting and forecasting the yield curve.

The NS model fits initially in the atheoretical strand but can be made arbitrage free, as Christensen et al (2011a) and Krippner (2006) show, and is thus consistent with the theoretically appealing Gaussian Affine Term Structure class of models. This makes the NS class a popular choice when modelling the yield curve and extending the analysis to macro-finance (see Diebold and Rudebusch (2012) for a full discussion).

The NS model introduced in the previous section is extended to make it arbitrage-free when modelling zero-coupon bond yields. Following Krippner $(2006,2015)$ a 'volatility effect' is introduced, which accounts for the Jensen's inequality effects (Christensen et al (2011a) refer to this as a time-invariant 'yield-adjustment' term). Jensen's inequality is often ignored in macroeconomics and in atheoretical yield curve fitting models, but it can become quite large with long maturities. Intuitively, the volatility effect represents that the expected compounded return from investing in a volatile short rate from $t$ to $t+\tau$ is less than the expected compounded return from investing in the expected short rate at each point in time over the same period. A key aspect to this effect is that it is time-invariant, depending only on the volatilities of the state variables (Level, Slope, and Bow in the case of the NS(3) model). The arbitrage-free NS model also has a risk-premium component, which distinguishes between the observed P-measure and market-priced 
Q-measure. Diebold and Rudebusch (2013) and Krippner (2015) provide rigorous and intuitive explanations on how these models are derived. I present the key concepts but leave the proofs and explanations to Diebold and Rudebusch (2012) and Krippner (2015).

A Gaussian affine term structure model has a generic functional form, where the short-rate is a function of a constant and the state variables at time $t$ :

$$
r(t)=a_{0}+b_{0}^{\prime} x(t)
$$

where $x(t)$ is a $N \times 1$ vector of state variables, the coefficients $a_{0}$ is a constant, and $b_{0}$ is a constant vector.

Under the P-measure, the state variable $x(t)$ evolves a vector with Ornstein-Uhlenbeck process:

$$
d x(t)=\kappa(\theta-x(t))+\sigma d W(t)
$$

where $\kappa$ is a constant $N \times N$ matrix, representing the mean reversion of $x(t)$ to $\theta, \sigma$ represents the variance of innovations, and $d W(t) \sim N(0,1) \sqrt{(d t)}$.

The key element for arbitrage-free models is distinguishing between the P-measure, which represents actual expectations held by economic agents, and the Q-measure, which represents how bonds are priced in financial markets with a suitable adjustment for risk.

A specification for the market price of risk is required to adjust for risk, producing the Q-measure process which bonds are priced under. The price of risk is a linear function of the state variables:

$$
\Pi(t)=\sigma^{-1}[\gamma+\Gamma x(t)]
$$

where $\Pi(t)$ is the market price of risk for each state variable, $\gamma$ is the constant component of the market price of risk, and $\Gamma$ is how the market price of risk varies with the state variable. 
Under the Q-measure, the state variable $x(t)$ also evolves as a vector Ornstein-Uhlenbeck process.

$$
d x(t)=\tilde{\kappa}(\tilde{\theta}-x(t))+\sigma d \tilde{W(t)}
$$

where $\tilde{\kappa}=\kappa+\Gamma, \tilde{\theta}=\tilde{\kappa}^{-1}(\kappa \theta-\gamma)$, and $d \tilde{W}(t)=d W(t)+\Pi(t) d t$

The dynamics of the state variables $x(t)$ under the risk-adjusted $\mathrm{Q}$ measure are:

$$
x(t+\tau)=\tilde{\theta}+\exp (-\tilde{\kappa} \tau)[x(t)-\tilde{\theta}]+\int_{t}^{t+\tau} \exp (-\tilde{\kappa}[t-u]) \sigma d W(u)
$$

where $u$ is a dummy variable for $t$, in accordance with mathematical convention. The expected future evolution of the state variables, given the state at time $t$ is:

$$
\tilde{E}_{t}[x(t+\tau) \mid x(t)]=\tilde{\theta}+\exp (-\tilde{\kappa} \tau)[x(t)-\tilde{\theta}]
$$

The expected path of the short-rate under the $Q$ measure, given the state variables at time $t$ is:

$$
\begin{aligned}
\tilde{E}_{t}[r(t+\tau) \mid x(t)] & =a_{0}+b_{0}^{\prime} \tilde{E}_{t}\left[x_{t+\tau} \mid x(t)\right] \\
& =a_{0}+b_{0}^{\prime}\{\tilde{\theta}+\exp (-\tilde{\kappa} \tau)[x(t)-\tilde{\theta}]\}
\end{aligned}
$$

The volatility effect for a given maturity is:

$$
V E(\tau)=\frac{1}{2}\left[\int_{0}^{\tau} b_{0}^{\prime} \exp (-\tilde{\kappa u}) d u\right] \sigma \sigma^{\prime}\left[\int_{0}^{\tau} \exp \left(-\tilde{\kappa}^{\prime} u\right) b_{0} d u\right]
$$

The Gaussian affine forward rate, explicitly expressing the volatility effect, is:

$$
f(t, \tau)=\tilde{E}_{t}[r(t+\tau) \mid x(t)]-V E(\tau)
$$

The corresponding interest rate is: 


$$
\begin{aligned}
R(t, \tau) & =\frac{1}{\tau} \int_{0}^{\tau} f(\tau, u) d u \\
& \left.=\frac{1}{\tau} \int_{0}^{\tau} \tilde{E}_{t}[r(t+u)] \mid x(t)\right] d u-\frac{1}{\tau} \int_{0}^{\tau} V E(\tau) \\
& =a(\tau)+[b(\tau)]^{\prime} x(t)
\end{aligned}
$$

The explicit treatment of the risk component and the volatility effect makes the Gaussian Affine Term Structure class of models theoretically rigorous.

The Arbitrage Free Nelson-Siegel model (ANSM) is recovered from the Gaussian affine term structure once restrictions are imposed on the model's specifications. As discussed in Christensen et al (2011) the ANSM is easier to implement in practice.

The ANSM(3) has three state variables (Level, Slope, and Bow), 19 free parameters, and 18 fixed parameters:

$$
\begin{aligned}
& x(t)=(L(t) \quad S(t) \quad B(t))^{\prime} ; a_{0}=0 ; b_{0}=\left(\begin{array}{lll}
1 & 1 & 0
\end{array}\right)^{\prime} ; \\
& \kappa=\left(\begin{array}{lll}
\kappa_{11} & \kappa_{12} & \kappa_{13} \\
\kappa_{21} & \kappa_{22} & \kappa_{23} \\
\kappa_{31} & \kappa_{32} & \kappa_{33}
\end{array}\right) ; \theta=\left(\begin{array}{lll}
\theta_{1} & \theta_{2} & \theta_{3}
\end{array}\right)^{\prime} ; \\
& \sigma=\left(\begin{array}{ccc}
\sigma_{1} & 0 & 0 \\
\sigma_{2} \rho_{12} & \sigma_{2} \sqrt{1-\rho_{12}^{2}} & 0 \\
\sigma_{3} \rho_{13} & \sigma_{3} \frac{\rho_{23}-\rho_{12} \rho_{13}}{\sqrt{1-\rho_{12}^{2}}} & \sigma_{3} \sqrt{1-\rho_{12}^{2}-\frac{\left(\rho_{23}-\rho_{12} \rho_{13}\right)^{2}}{1-\rho_{12}^{2}}}
\end{array}\right) ; \\
& \tilde{\kappa}=\left(\begin{array}{ccc}
0 & 0 & 0 \\
0 & \phi & -\phi \\
0 & 0 & \phi
\end{array}\right) ; \tilde{\theta}=\left(\begin{array}{ccc}
0 & 0 & 0
\end{array}\right)^{\prime} ;
\end{aligned}
$$

Free parameters are:

$$
B=\left\{\phi, \kappa_{11}, \kappa_{12}, \kappa_{13}, \kappa_{21}, \kappa_{22}, \kappa_{23}, \kappa_{31}, \kappa_{32}, \kappa_{33}, \theta_{1}, \theta_{2}, \theta_{3}, \sigma_{1}, \sigma_{2}, \sigma_{3}, \rho_{12}, \rho_{13}, \rho_{23}\right\}
$$


Below I outline the key aspects of the ANSM, focusing on the three factor model, highlighting the restrictions that will be applied in the macro-finance model. I use the Level (L), Slope (S), and Bow (B) notation that is widely used in the literature, as well as explaining the the intuition behind these labels.

The instantaneous short rate for the three-factor model is:

$$
\begin{aligned}
r(t) & =b_{0}^{\prime} x(t) \\
& =\left(\begin{array}{lll}
1 & 1 & 0
\end{array}\right)\left(\begin{array}{c}
L(t) \\
S(t) \\
B(t)
\end{array}\right) \\
& =L(t)+S(t)
\end{aligned}
$$

Recall that the Bow factor in the NS model has a zero loading for the instantaneous interest rate, while the Level and Slope have a loading of one.

The matrix exponential of $\tilde{\kappa}$, the constant matrix that determines the deterministic mean reversion of state variables, is adjusted for the market price of risk. This equation forms one of the restrictions that will be applied to the macro-finance model.

$$
\exp (-\tilde{\kappa} \tau)=\left(\begin{array}{ccc}
1 & 0 & 0 \\
0 & \exp (-\phi \tau) & \phi \tau \exp (-\phi \tau) \\
0 & 0 & \exp (-\phi \tau)
\end{array}\right)
$$

The expected path of the short interest rate given the state variables at time $t$ is:

$$
\begin{aligned}
\tilde{E}_{t}[r(t+\tau) \mid x(t)] & =\left(\begin{array}{ll}
1, & \exp (-\phi \tau), \quad \phi \tau \exp (-\phi \tau)]
\end{array}\right)\left(\begin{array}{c}
L(t) \\
S(t) \\
B(t)
\end{array}\right) \\
& =L(t)+S(t) \cdot \exp (-\phi \tau)+B(t) \cdot \phi \tau \exp (-\phi \tau)
\end{aligned}
$$

The forward rate is: 


$$
f(t, \tau)=[1, \exp (-\phi \tau), \phi \tau \exp (-\phi \tau)]\left(\begin{array}{c}
L(t) \\
S(t) \\
B(t)
\end{array}\right)-V E_{f}(\tau)
$$

The ANSM interest rate is ${ }^{9}$ :

$$
\begin{aligned}
R(t, \tau)= & \frac{1}{\tau} \int_{0}^{\tau} f(t, u) d u \\
& =\left[1, \frac{1-e^{-\phi \tau}}{\phi \tau}, \frac{1-e^{-\phi \tau}}{\phi \tau}-e^{-\phi \tau}\right]\left(\begin{array}{c}
L(t) \\
S(t) \\
B(t)
\end{array}\right)-V E(\tau) \\
& =L(t)+S(t)\left(\frac{1-e^{-\phi \tau}}{\phi \tau}\right)+B(t)\left(\frac{1-e^{-\phi \tau}}{\phi \tau}-e^{-\phi \tau}\right)-V E(\tau)
\end{aligned}
$$

Note that ignoring the volatility effect, $V E(\tau)$ would recover the non-arbitrage-free NS model discussed in section 2.1.

The intuition behind calling the factors Level, Slope, and Bow comes from the dynamics of the factor loadings. The first loading is one, which is interpreted as reflecting the Level of the yield curve since it does not change with the maturity of bonds. The second loading starts at one when $\tau=0$ and goes to zero as $\tau \rightarrow \infty$, this is typically described as a short-term factor and represents the Slope of the yield curve. The third factor starts at zero when $\tau=0$ and increases at as $\tau$ increases before approaching zero as $\tau \rightarrow \infty$. The factor is typically referred to as the medium-term factor, where a change in the third factor has little impact on short or long term interest rates, and is called the Bow (or Curvature) factor. Figure 2.4 illustrates the Level, Slope, and Bow components as a function of time to maturity.

\footnotetext{
${ }^{9}$ See Krippner (2013) for derivation of the volatility effect
} 
Figure 2.4: Nelson-Siegel factor loadings

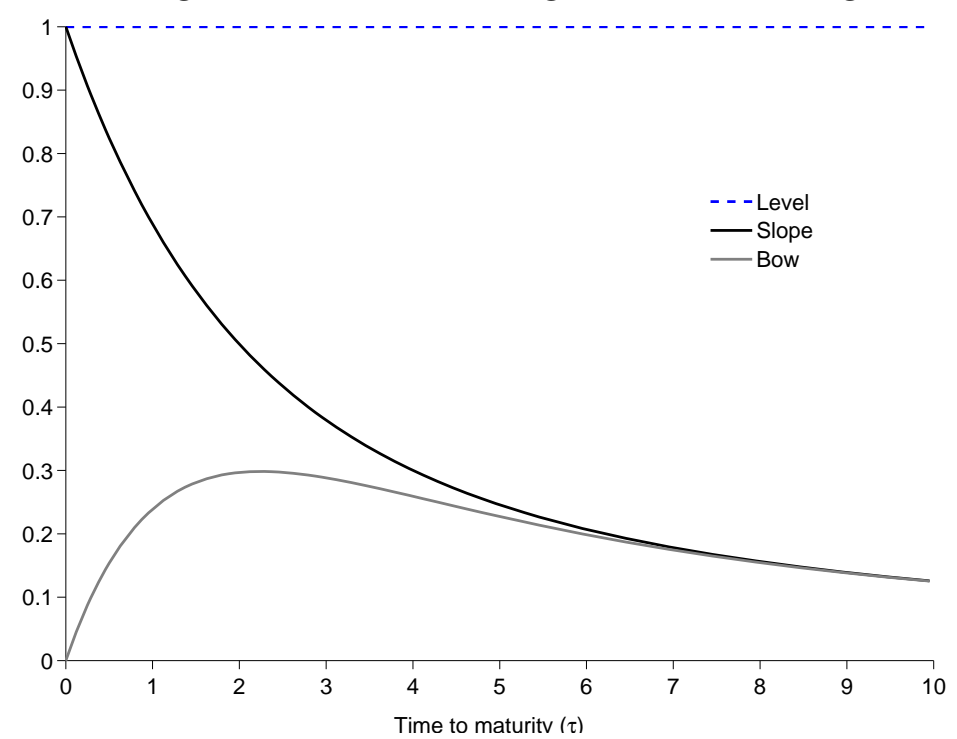

Note: Example of NS(3) factor loadings, generated with the NS coefficients $L=7.06 \%, S=$ $-1.83 \%, B=-0.30 \%$, and $\phi=0.79$.

I also estimate two-factor ANSMs for the United States and New Zealand to test the importance of including the Bow factor in macro-finance models. In the interests of conserving space I will not go into the amount of detail above. It is sufficient to illustrate that the $\operatorname{ANSM}(2)$ is a restricted version of the $\operatorname{ANSM}(3)$, where the third state variable (the Bow) is restricted to be zero. Diebold and Rudebusch (2012) and Krippner (2015) provide fully worked examples with the $\operatorname{ANSM}(2)$.

The ANSM(2) has 10 free parameters to estimate:

$$
B=\left\{\phi, \kappa_{11}, \kappa_{12}, \kappa_{21}, \kappa_{22}, \theta_{1}, \theta_{2}, \sigma_{1}, \sigma_{2}, \rho_{12}\right\}
$$

The fixed and free parameters in matrix form are: 


$$
\begin{aligned}
x(t) & =\left(\begin{array}{ll}
L(t) & S(t)
\end{array}\right) ; a_{0}=0 ; b_{0}=\left(\begin{array}{ll}
1 & 1
\end{array}\right)^{\prime} ; \\
\kappa & =\left(\begin{array}{ll}
\kappa_{11} & \kappa_{12} \\
\kappa_{21} & \kappa_{22}
\end{array}\right) ; \theta=\left(\begin{array}{ll}
\theta_{1} & \theta_{2}
\end{array}\right) ; \\
\sigma & =\left(\begin{array}{cc}
\sigma_{1} & 0 \\
\sigma_{2} \rho_{12} & \sigma_{2} \sqrt{1-\rho_{12}^{2}}
\end{array}\right) ; \\
\tilde{\kappa} & =\left(\begin{array}{ll}
0 & 0 \\
0 & \phi
\end{array}\right) ; \tilde{\theta}=\left(\begin{array}{ll}
0 & 0
\end{array}\right)^{\prime} ;
\end{aligned}
$$

\subsubsection{Arbitrage-free Nelson-Siegel model estimation}

The ANSM is a state space model, which naturally lends itself to the Kalman filter for estimation. Indeed, this is the most common approach in the literature, where the maximum likelihood estimation with the Kalman filter is used. In this exercise, the difference between the fitted and observed bond yields are minimised.

The Kalman filter is a way of linking the state equation and data at each point in time. From the ANSMs above, the Level, Slope, and Bow are the state variables, the measurement equation is the ANSM equation that shows how the state variables evolve over time, and the data are zero-coupon bond yields. Krippner (2015) provides a step-by-step guide for applying the Kalman filter with the ANSMs. The ANSM(2) estimation is on page $66-83$ and the ANSM(3) is on page 86 - 93.

I illustrate the state and measurement equations used in the Kalamn Filter for the $\operatorname{ANSM}(2)$.

The state equation is:

$$
\left(\begin{array}{l}
L(t) \\
S(t)
\end{array}\right)=\left(\begin{array}{l}
\theta_{1} \\
\theta_{2}
\end{array}\right)+\exp \left[-\left(\begin{array}{ll}
\kappa_{11} & \kappa_{12} \\
\kappa_{21} & \kappa_{22}
\end{array}\right) \Delta t\right]\left(\begin{array}{c}
L(t-1) \\
S(t-1)
\end{array}\right)+\varepsilon(t)
$$

where $\Delta t$ is the time increment. 
The measurement equation is:

$$
\left(\begin{array}{c}
R\left(t, \tau_{1}\right) \\
\vdots \\
\left.R\left(t, \tau_{k}\right)\right)
\end{array}\right)=\left(\begin{array}{cc}
1 & \left.\frac{1-\exp \left(-\phi \tau_{1}\right.}{\phi \tau_{1}}\right) \\
\vdots & \vdots \\
1 & \frac{1-\exp \left(-\phi \tau_{k}\right.}{\left.\phi \tau_{k}\right)}
\end{array}\right)\left(\begin{array}{c}
L(t) \\
S(t)
\end{array}\right)-\left(\begin{array}{c}
V E\left(\tau_{1}\right) \\
\vdots \\
V E\left(\tau_{k}\right)
\end{array}\right)+\left(\begin{array}{c}
\varepsilon\left(t, \tau_{1}\right) \\
\vdots \\
\varepsilon\left(t, \tau_{k}\right)
\end{array}\right)
$$

\section{Arbitrage-free Nelson-Siegel model results}

For the US and New Zealand, the $\operatorname{ANSM}(2)$ and $\operatorname{ANSM}(3)$ are estimated using end-of-month zero coupon bond data. The US models are estimated from the end of 1985 until the end of 2007, just prior to the Global Financial Crisis hitting (the ANSMs with the zero lower bound are discussed below). The choice for this sample period reflects inflation stability in the US and the great moderation following the banking reform ${ }^{10}$. Eight maturities are used, with $\tau_{U S}=\{0.25,0.5,1,2,3,5,7,10\}$ years. For New Zealand the estimation period is from April 1992 until July 2014, reflecting the beginning of the generic zero-coupon bond data base, which also coincides with the achievement of inflation targeting. Eight maturities are used, with $\tau_{N Z}=$ $\{0.25,0.5,1,2,3,5,7,10\}$.

Results for each of the full sample ANSMs are in Appendix A. The results are similar to Krippner (2015), where the ANSM(3) model provides a superior fit to the data compared to the $\operatorname{ANSM}(2)$, with the log-likelihood significantly improving. This suggests that, although the Bow factor in the NS model explains only one to three percent of the variation in bond yields, the additional factor has an important role in fitting the entire yield curve. This will be further explored in the macro-finance model, where ANSM(2) and ANSM(3) models will be used in conjunction with real economic variables.

A key aspect of this analysis is based on real-time data vintages. The ANSMs are also estimated in real-time, with the US recursive estimation starting from

\footnotetext{
${ }^{10}$ Krippner (2008) and Joshin, Priebsch, and Singleton (2014) both find a structural change around this date.
} 
1996Q4 and the New Zealand recursive estimation starting from 2000Q11. These start times reflect the availability of macroeconomic data vintages as well as ensuring sufficient data for reliable estimation.

The US ANSM(3) real-time estimates of the Level, Slope, and Bow show little real-time variation (see Figure 2.5). For the Level factor, the largest difference relative to the last vintage is 24 basis points and the absolute mean difference is three basis points. The Slope and Bow factors also show little real-time variation, with absolute mean differences of four and 12 basis points respectively.

The US ANSM(2) real-time estimates of the Level and Slope show more variation in the real-time estimates compared to the ANSM(3). However, the variation still remains small, with absolute mean differences of 12 and eight basis points for each of the factors.

Given the stability in the real-time estimates, the final vintage (full-sample) estimates of the yield curve factors are used to evaluate real-time forecast performance $^{12}$. This is consistent with how the macroeconomic data are evaluated. An alternative approach would be to calculate the zero-coupon yield curve at each point in time over the forecast horizon but since this an exercise of relative forecast performance nothing is lost from evaluating against the yield curve factors themselves. Indeed, analysing the factors individually can give insight into which yield curve components are easiest to forecast.

\footnotetext{
${ }^{11}$ The generated zero-coupon data are not generated in real-time, however the NS data are very stable in recursive estimates. Results demonstrating this for New Zealand are available on request.

${ }^{12}$ The real-time estimation exercise was also done for the yield curve out to 30 years. These estimates showed more real-time variation, with the largest difference peaking at 111 basis points. To minimise the real-time variation, for consistency with the literature, and consistency between the New Zealand and United States applications, the yield curve out to 10 years is used.
} 
Figure 2.5: US ANSM(3) and ANSM(2) realtime time estimates

$\operatorname{ANSM}(3)$ Level

ANSM(3) Slope
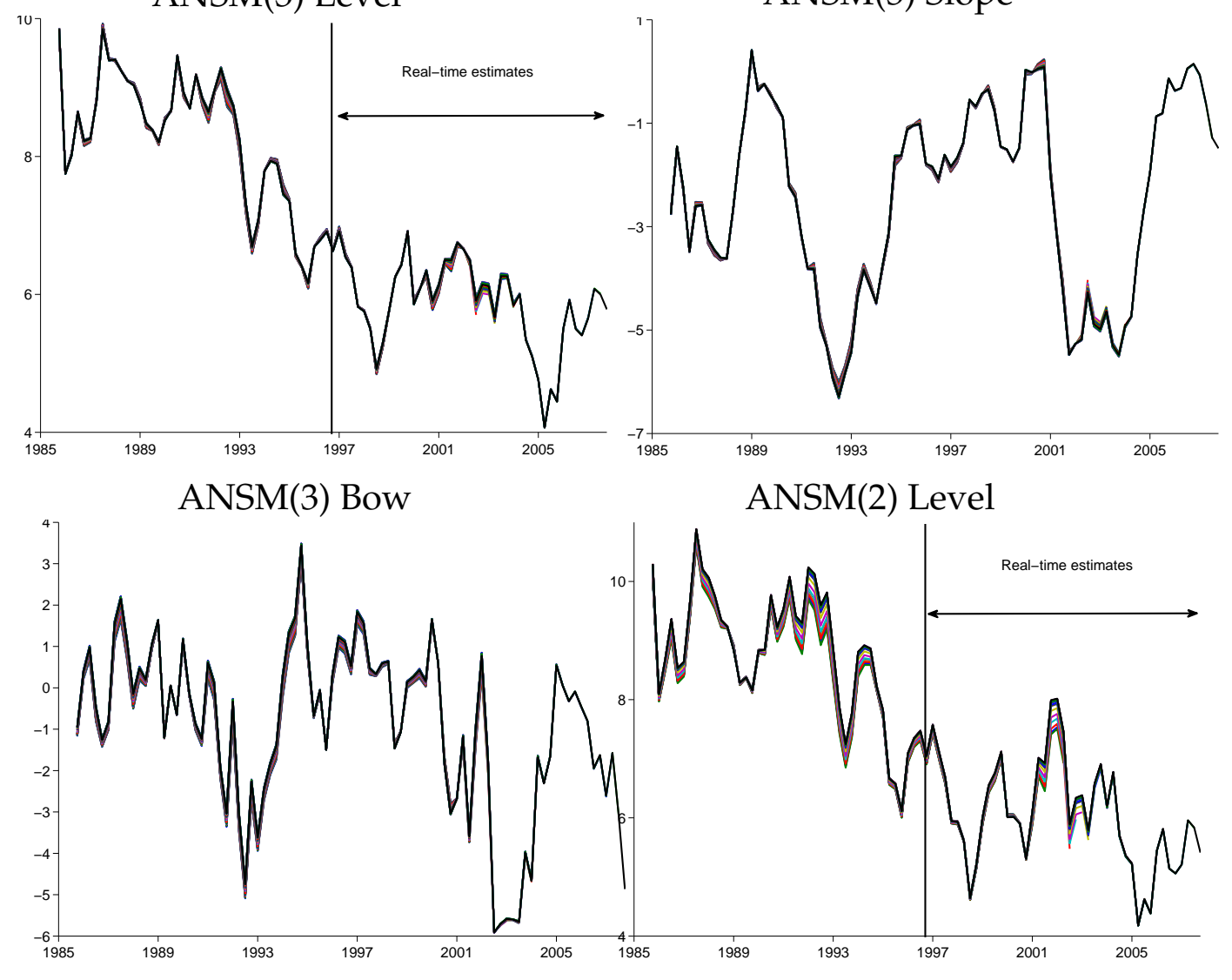

ANSM(2) Level

$\operatorname{ANSM}(2)$ Slope

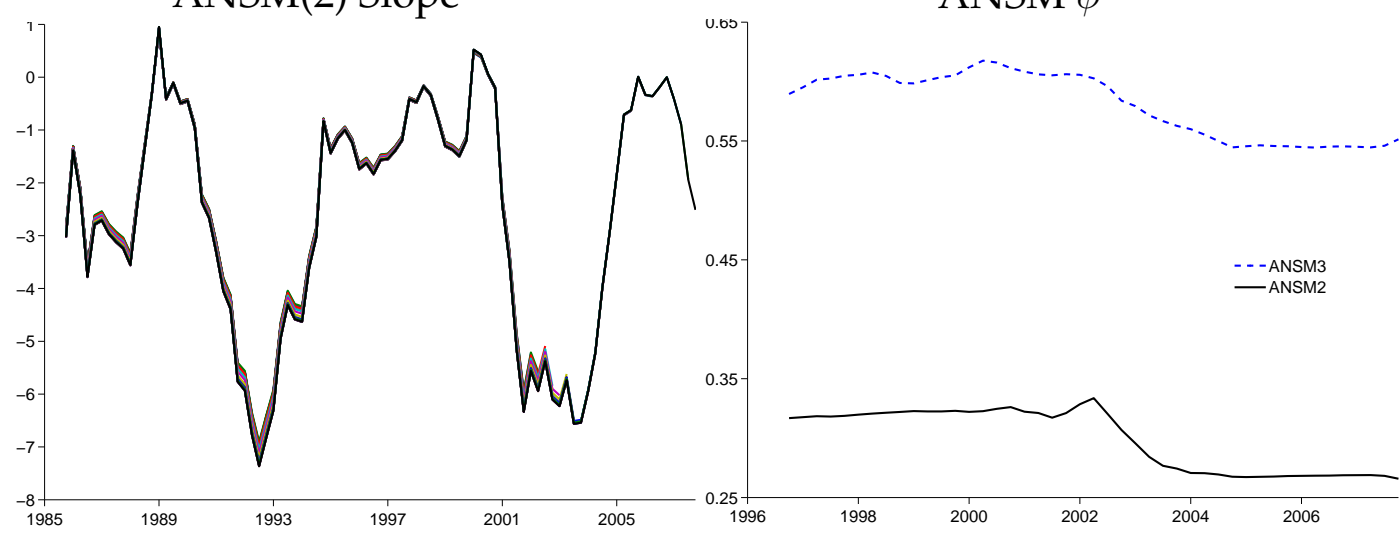

Note: Realtime estimates of ANSM state variables. The sample starts 1985Q4 and the real-time vintages start in 1996Q4. The sample ends in 2007Q4, reflecting the onset of the GFC.

The New Zealand ANSM(3) model also provides stable real-time estimates of 
the yield curve factors. The absolute mean difference from the final vintage is 0.2 basis points for each the Level, Slope, and Bow. The ANSM(2) shows more variation compared to the $\operatorname{ANSM}(3)$, with the absolute mean differences of four and one basis point respectively for the level and Slope factors, but the variation is economically small. The real-time estimate of $\phi$ shows variation at the fourth decimal point. A reason for the stability in the real-time estimates could be that the ANSMs are recovering the NS model that generated the data series, with the arbitrage-free restriction proving to be a weak additional restriction in the New Zealand case. Recall the US data set are generated using an augmented NS model, with two decay parameters changing at each point in time, thus the ANSM may not have been able to fully recover the data generating process. 
Figure 2.6: NZ ANSM(3) and ANSM(2) realtime time estimates

ANSM(3) Level

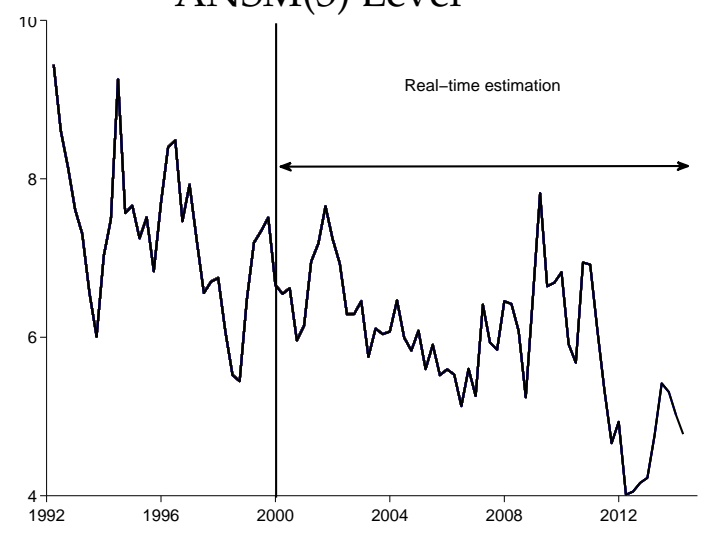

$\operatorname{ANSM}(3)$ Bow

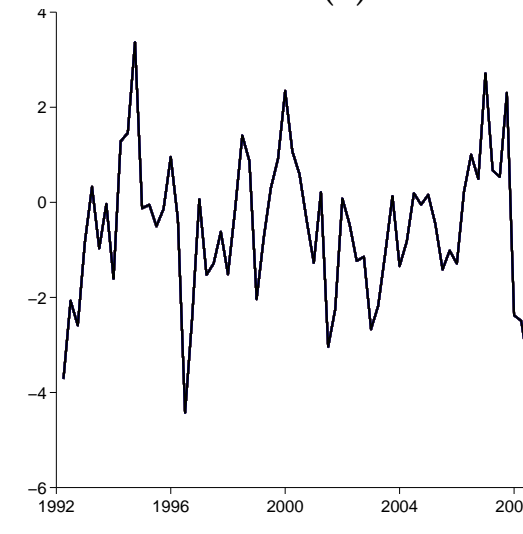

ANSM(2) Slope
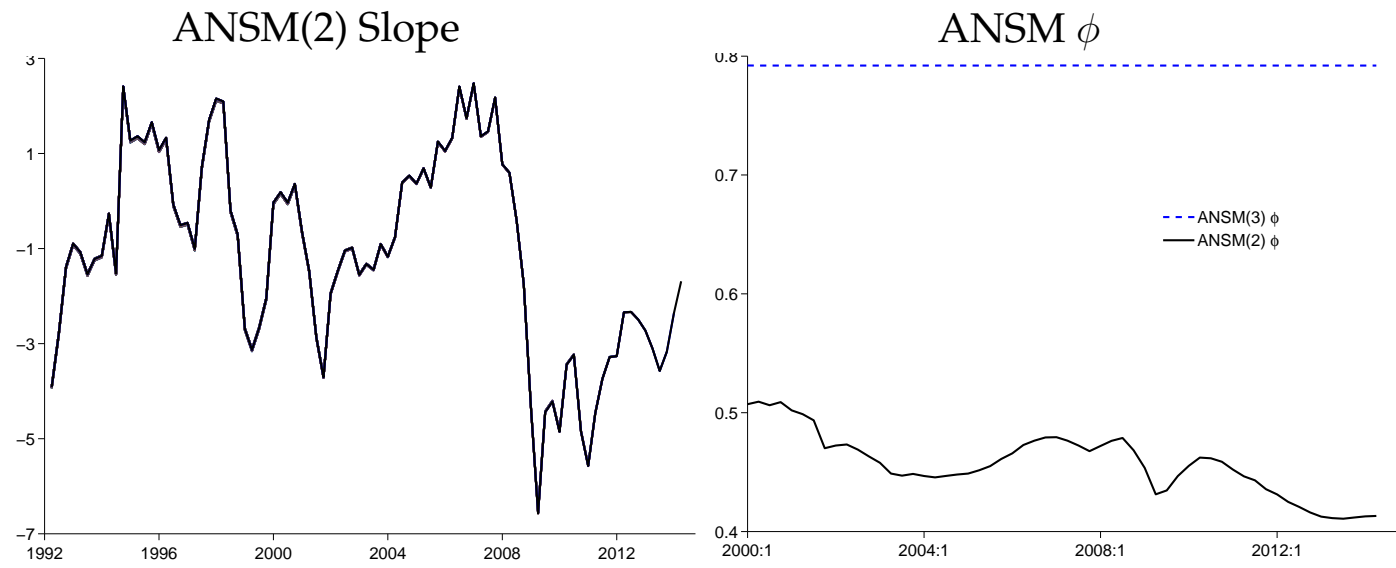

Note: Realtime estimates of ANSM state variables. The sample starts 1992Q2 and the real-time vintages start in 2000Q1. The sample ends in 2014Q1. 


\subsubsection{Krippner arbitrage-free Nelson-Siegel model: the zero lower bound}

In 2008, short-term US interest rates hit the zero lower bound. This poses problems for traditional yield curve modelling techniques because they are not bounded. To build a macro-finance model for the United States that includes the post-GFC period, the yield curve modelling technique needs to be augmented.

The Krippner (2011) approach to modelling yield curves with a lower bound uses the Gaussian affine term structure model to represent a shadow term structure $^{13}$. More specifically, Krippner argues to use the ANSM as a shadow term structure, which, noted previously, maintains the interpretation of the Level, Slope, and Bow factors. This enables a consistent transition of the ANSM used in the pre-GFC period to the ZLB period. Hereafter I refer to the Krippner model as the KANSM for notational convenience. In the detail that follows I use notation from Krippner (2015).

To enforce the zero lower bound in the model, to match the data, Krippner uses an option payoff for holding physical currency relative to a shadow short rate that would exist in the absence of physical currency. Equation 2.23 shows this option payoff. The observed interest rate, $\underline{r}(t)$, takes on the greater value between zero, which represents holding physical currency, and the shadow short rate, $r(t)$, which is the interest rate that would exist in the absence of cash. The valuation of this option payoff over all maturities on the yield curve, which is discussed below, is key to representing the yield curve at the zero lower bound.

$$
\underline{r}(t)=\max \{0, r(t)\}
$$

Krippner values the option using a shadow yield curve, which results in a more tractable version of Black (1995). The intuition is that when the shadow short rate falls below the zero lower bound, investors would prefer to hold physical

\footnotetext{
${ }^{13}$ The Krippner framework has also been used in Christensen and Rudebusch (2013). Wu and Xia (2013) provide and equivalent model to the Krippner approach but it is in discrete time.
} 
currency (and earn no interest on the investment) rather than receive a negative interest rate on investments.

Figure 2.7 decomposes examples of zero lower bound yield curves into the shadow yield curve and the option effect. As panel 1 illustrates, when interest rates are sufficiently far away from the lower bound, the option effect is close to zero, reflecting low probability of a pay-off from the currency option, and the shadow yield curve is the same as the observed yield curve ${ }^{14}$. As interest rates approach zero, the option effect grows, reflecting the higher probability of a payoff from the option to hold physical currency, and the zero lower bound yield curve diverges from the observed yield curve (see panel 2). Panel 3 shows a large option effect for short maturities, with the shadow yield curve becoming significantly negative, that reduces as the maturity increases. This reflects the market pricing an expectation that interest rates are likely to move away from the zero lower bound over time, which reduces the value of the option effect and sees the shadow yield curve begin to converge to the observed yield curve.

\footnotetext{
${ }^{14}$ The 'observed' yield curve is the estimated zero coupon yield curve.
} 
Figure 2.7: Zero lower bound yield curve decomposition
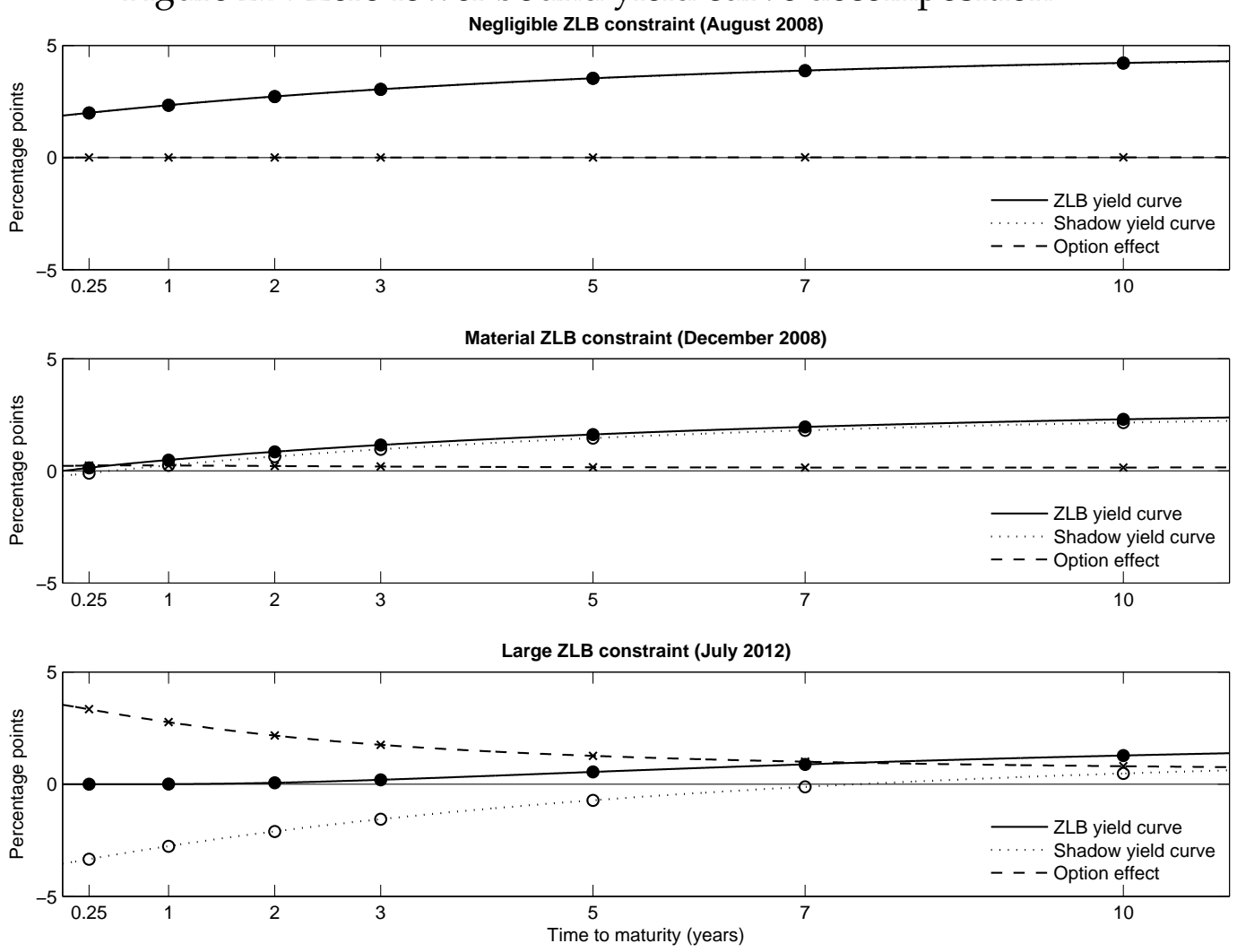

Note: Examples of the zero lower bound yield curve are decomposed into a shadow yield curve and option effect. The figure is from Krippner (2015) page 37.

The KANSM also allows for the non-zero lower bound. In practice the lower bound for policy may not be strictly zero. Indeed, the US Federal Reserve has had a policy setting of $0-0.25$ percent since December 2008. In the application below I set the lower bound to zero. I do this in the real-time and in-sample estimations to ensure consistency, where estimating a zero lower bound in real-time would mean I would need to take a stand on when the lower bound environment became binding so that an effective lower bound can be estimated. I take an agnostic stance around the timing on when the lower bound would have started to take an effect and instead impose the lower bound for interest rates is zero at all times. 
Using the Gaussian affine term structure notation, the short rate is:

$$
\begin{aligned}
\underline{r}(t) & =r(t)+\max \{0,-r(t)\} \\
& =a_{0}+b_{0} x(t)+\max \left\{0,-\left[a_{0}+b_{0} x(t)\right]\right\}
\end{aligned}
$$

The forward rate under the risk-adjusted $\mathrm{Q}$ measure is:

$$
\begin{aligned}
\underline{f}(t, \tau) & =\tilde{E}_{t+\tau}[r(t+\tau) \mid x(t)]+\tilde{E}_{t+\tau}[\max \{-r(t+\tau), 0\} \mid x(t)] \\
& =f(t, \tau)+z(t, \tau)
\end{aligned}
$$

where $\tilde{E}_{t}[\cdot]$ is expectations under the Q-measure, $f(t, \tau)$ is the shadow forward rate, and $z(t, \tau)$ is the forward rate option effect. For mathematical convenience the KANSM is derived using forward rates, where the future payoff at time $t+\tau$ (including the probability of the option being exercised) is evaluated and then discounted back to time $t$.

The forward rate option effect $z(t, \tau)$ has a closed form solution of:

$$
z(t, \tau)=[-f(t, \tau)] \cdot\left(1-\Phi \frac{f(t, \tau)}{\omega(\tau)}+\omega(\tau) \cdot \phi \frac{f(t, \tau)}{\omega(\tau)}\right)
$$

where $\phi[\cdot]$ is the unit normal probability density function for $r(t+\tau) \mid x(t), \Phi[\cdot]$ is the cumulative unit normal probability density, and $\omega(\tau)$ is the variance of $r(t+\tau) \mid x(t)^{15}$.

Combining Equations 2.25 and 2.26 gives the generic KANSM forward rate expression used:

$$
\begin{aligned}
\underline{f}(t, \tau) & =f(t, \tau)+z(t, \tau) \\
& =[f(t, \tau)] \cdot \Phi \frac{f(t, \tau)}{\omega(\tau)}+\omega \tau \cdot \phi \frac{f(t, \tau)}{\omega(\tau)}
\end{aligned}
$$

The KANSM interest rate is:

\footnotetext{
${ }^{15}$ See Krippner (2015) for derivation.
} 


$$
\underline{R}(t, \tau)=\frac{1}{\tau} \int_{0}^{\tau} \underline{f}(t, u) d u
$$

The state equation for the KANSM and ANSM is the same, with both models using the same state variables and parameters. The KANSM(3) uses the same parameters from Equations 2.14 and the KANS(2) uses the parameters from Equations 2.20, but there is a difference in the measurement questions.

\subsubsection{Krippner arbitrage-free Nelson-Siegel estimation}

The adjustment that the KANSM makes to the ANSM means non-linear filtering techniques are required because interest rates are non-linear functions of the state variables $x(t)$ in the measurement equation. Following Krippner (2012, 2015) I use the Iterated Extended Kalman Filter for maximum likelihood estimation. This method involves taking a Taylor-series approximation of the measurement equation and iterating the approximation for the linear form. However, the overall estimation of the KANSM is still similar to the ANSM since the state equation is the same. Krippner (2015) provides step-by-step example of estimating the KANS(2) on page 136 - 143 and the KANS(3) on page $144-145$.

The state equation is the same as before in the ANSM estimation. However, the measurement equation becomes non-linear as there is a nonlinear relationship between interest rates and the state variables given the presence of the option effect.

The KANSM(2) state equation is:

$$
\left(\begin{array}{l}
L(t) \\
S(t)
\end{array}\right)=\left(\begin{array}{l}
\theta_{1} \\
\theta_{2}
\end{array}\right)+\exp \left[-\left(\begin{array}{ll}
\kappa_{11} & \kappa_{12} \\
\kappa_{21} & \kappa_{22}
\end{array}\right) \Delta t\right]\left(\begin{array}{c}
L(t-1) \\
S(t-1)
\end{array}\right)+\varepsilon(t)
$$

where $\Delta t$ is the time increment.

The measurement equation is: 


$$
\left(\begin{array}{c}
R\left(t, \tau_{1}\right) \\
\vdots \\
\left.R\left(t, \tau_{k}\right)\right)
\end{array}\right)=\left(\begin{array}{c}
R\left[x(t), \tau_{1}\right] \\
\vdots \\
R\left[x(t), \tau_{k}\right]
\end{array}\right)+\left(\begin{array}{c}
\varepsilon\left(t, \tau_{1}\right) \\
\vdots \\
\varepsilon\left(t, \tau_{k}\right)
\end{array}\right)
$$

\section{Krippner arbitrage-free Nelson-Siegel model results}

The KANSMs provide stable estimates of the state variables in real-time, consistent with the ANSM. Indeed, comparing the ANSM and KANSM, the Level, Slope, and Bow estimates are almost identical over the 1996-2007 period. Thus the KANSM models provide a robust estimate for the state variables and theoretically and empirically smooth transition to the observed lower bound period in the post-GFC sample. 
Figure 2.8: US KANSM(3) and KANSM(2) realtime time estimates KANSM(3) Level
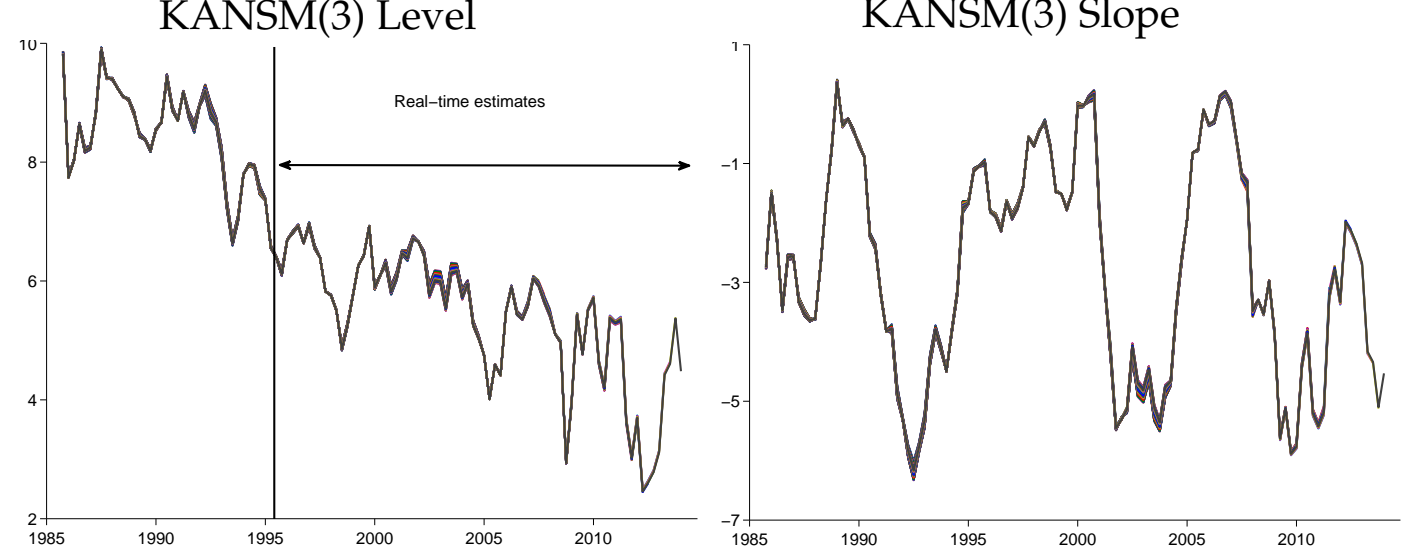

KANSM(3) Bow

KANSM(2) Level
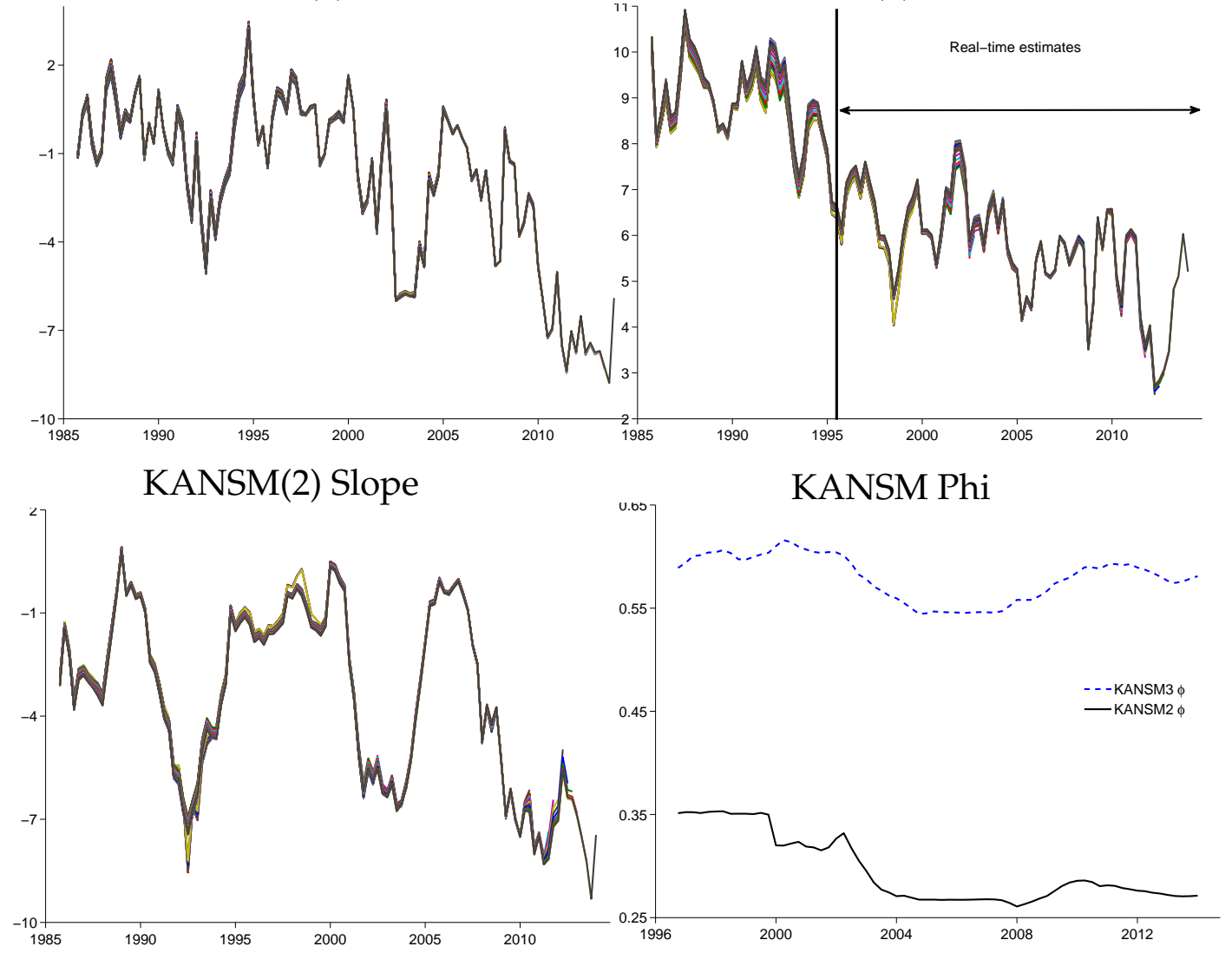

Note: Realtime estimates of KANSM state variables. The sample starts 1985Q4 and the real-time vintages start in 1996Q4. The sample ends in 2014Q1.

To summarise, the Nelson-Siegel class of models is a popular choice because it 
fits the yield curve well, offers superior forecast performance of the yield curve, and the components have well-established macro-economic links. Typical Nelson-Siegel models, or Gaussian affine term structure models, can not adequately model the zero lower bond since there is not a mechanism to prevent interest rates from going below a lower bound. To overcome this, Krippner $(2011,2015)$ derives an options based adjustment to the Nelson-Siegel model and shows it is also consistent with the broader Gaussian affine term structure class of models. These models all provide a good fit to the yield curve and real-time estimation shows the state variable estimates are stable. 


\section{Chapter 3}

\section{Macro-Finance Model}

In this section the estimated yield curve factors are combined with macroeconomic variables ${ }^{1}$. Two tests will be carried out. The first is in sample fit, where the models will be assessed using information criteria. The second test is a horse-race between the models, simulating the environment a forecaster faces in real-time.

\subsection{VAR estimation and forecasting}

This section outlines how the VARs are estimated and used for forecasting using generalised notation, based on Hamilton (1994).

Assume the variables of interest are $\left\{y_{1}, y_{2}, \ldots, y_{n}\right\}$ and we want to produce forecasts from time $t=1$ to time $t+\tau$. A VAR with $\mathrm{p} \geq 1$ lags takes the following form:

$$
Y_{t}=C+A(L) Y_{t-1}+\varepsilon_{t}
$$

\footnotetext{
${ }^{1}$ One-step estimation would be more efficient, and is left for future work, but could be computationally burdensome. Indeed, Ang and Piazzesi (2006) estimate a similar model in two steps for similar reasons given the out-of-sample forecast exercises
} 
where $Y_{t}=\left[y_{1, t}, y_{2, t}, \ldots, y_{n}\right]^{\prime}, \varepsilon_{t}=\left[\varepsilon_{1, t}, \varepsilon_{2, t}, \ldots, \varepsilon_{n, t}\right]^{\prime}, L$ is the lag operator, and $A(L)=\sum_{p} \sum_{j=1}^{\Sigma(t)} A_{j} L^{j}$ for $n \times 1$ and $n \times p$ parameter matrices $C$ and $A_{j}, j=$ $1, \ldots, p$ respectively.

The VARs are estimated using Ordinary Least Squares (OLS), with each model recursively estimated in the real-time forecasting environment. Another common approach used in the VAR forecast literature is Bayesian estimation. Since I am interested in the relative forecast performance among the models, testing whether the macro-finance model improves on the yields-only or macro-only models, there is little to be gained from the additional complexity of Bayesian estimation.

The appropriate lag length for the VARs are selected using the Bayesian Information Criterion (BICs) ${ }^{2}$. BICs are a metric for assessing a model's fit, where the criteria penalises models as the number of parameters increases and/or the sample size decreases. This means more parsimonious models are typically preferred, which is an aspect that is particularly important for real-time estimation. As discussed in Lütkepohl (2005), BICs are the appropriate test when the aim is to pick the correct VAR order.

$$
B I C=-2 \ln (\hat{L})+\ln (N) k
$$

where $\hat{L}$ is the likelihood, $N$ is the number of observations, and $k$ is the degrees of freedom.

The forecasts are constructed using recursion. The forecast $k$ periods ahead is:

$$
\hat{Y}_{t+k}=C+A_{1} \hat{Y}_{t+k-1}+\ldots+A_{p} \hat{Y}_{t+k-p}
$$

The forecast error is calculated comparing the prediction for $\hat{Y}_{t+k}$ to the actual outturn form the final vintage of data, $Y t(k)$.

The estimation, lag selection, and forecast error are calculated for each model recursively over the respective samples for the United States and New Zealand.

\footnotetext{
${ }^{2}$ The BIC results are not reported here but are available upon request.
} 
In all cases I find the optimal VAR lag length is one. For clarity and given the BIC results, the macro-finance VARs in the following section are presented in $\operatorname{VAR}(1)$ equation form.

\subsection{VAR model set up and restrictions}

The aim of this analysis is to improve macroeconomic and yield curve forecast performance. This is done by including economic variable and yield curve factors in a single VAR system. The model is further augmented by using various theoretically motivated restrictions, which also improves the parsimony, to help further improve model fit and forecast performance. For the US and New Zealand, three yield curve models and seven macro finance models are compared. These models are detailed below.

The open economy model connects New Zealand to the US through financial links (the yield curve factors and the bilateral exchange rate). These results are an initial approach to modelling the open economy within the spirit of the set-up in this paper. Another avenue for future research would be to use the two-country yield curve model as in Diebold, Li, and Yue (2008) and augment the yield curve model with a lower bound and macroeconomic variables.

In the notation below, $y$ is economic activity, $\pi$ is inflation, $r$ is the policy rate, twi is the New Zealand Trade Weighted Index for the New Zealand dollar, $N Z D / U S D$ is the bilateral New Zealand and US exchange rate, $L$ is the Level component of the yield curve, $S$ is the Slope, and $B$ is the Bow.

\subsubsection{Yields-only VAR model}

The VARs and restrictions are presented in matrix form, with one lag, to illustrate the restrictions used.

1) Unrestricted yields-only VAR model 
The yields-only VAR contains the three yield curve factors and no restrictions are placed on the parameters. This models serves as a benchmark for forecasting the yield curve, where the questions are 'do restrictions or the addition of economic variables improve forecast performance?'

$$
\left[\begin{array}{l}
L_{t} \\
S_{t} \\
B_{t}
\end{array}\right]=\left[\begin{array}{l}
c_{10} \\
c_{20} \\
c_{30}
\end{array}\right]+\left[\begin{array}{lll}
a_{11} & a_{12} & a_{13} \\
a_{21} & a_{22} & a_{23} \\
a_{31} & a_{32} & a_{33}
\end{array}\right]\left[\begin{array}{c}
L_{t-1} \\
S_{t-1} \\
B_{t-1}
\end{array}\right]+\left[\begin{array}{l}
e_{1 t} \\
e_{2 t} \\
e_{3 t}
\end{array}\right]
$$

\section{2) Full restrictions yields-only VAR Model}

The fully restricted yields-only VAR uses the mean-reverting process embedded in the ANSM/KANSM to restrict parameters in the VAR. The restrictions reflect the risk-adjusted $\mathrm{Q}$-measure mean reversion matrix for the yield curve factors shown in Equation 2.16. This restriction implies constant risk-premiums, although the premiums do vary with the state variables in the yield curve estimation. Therefore, this restrictions tests whether the time-varying risk premia inherent in the estimated yield curve factors are important in a forecasting context.

$$
\left[\begin{array}{c}
L_{t} \\
S_{t} \\
B_{t}
\end{array}\right]=\left[\begin{array}{c}
\mathbf{0} \\
c_{20} \\
c_{30}
\end{array}\right]+\left[\begin{array}{ccc}
\mathbf{1} & \mathbf{0} & \mathbf{0} \\
\mathbf{0} & \boldsymbol{e x p}(-\boldsymbol{\phi} \boldsymbol{\tau}) & \boldsymbol{\phi} \boldsymbol{\tau} \exp (-\boldsymbol{\phi} \boldsymbol{\tau}) \\
\mathbf{0} & \mathbf{0} & \boldsymbol{e x p}(-\phi \boldsymbol{\tau})
\end{array}\right]\left[\begin{array}{c}
L_{t-1} \\
S_{t-1} \\
B_{t-1}
\end{array}\right]+\left[\begin{array}{c}
e_{1 t} \\
e_{2 t} \\
e_{3 t}
\end{array}\right]
$$

\section{3) Partial restrictions yields-only VAR model}

The partial restrictions yields-only VAR weakens the restrictions used in the full-restrictions VAR. Rather than imposing the non-zero parameter values, which are derived from the Q-measure, only the zero-restrictions are used. These restrictions make the dynamics more consistent with the P-measure.

$$
\left[\begin{array}{l}
L_{t} \\
S_{t} \\
B_{t}
\end{array}\right]=\left[\begin{array}{l}
c_{10} \\
c_{20} \\
c_{30}
\end{array}\right]+\left[\begin{array}{ccc}
a_{11} & \mathbf{0} & \mathbf{0} \\
\mathbf{0} & a_{22} & a_{23} \\
\mathbf{0} & \mathbf{0} & a_{33}
\end{array}\right]\left[\begin{array}{c}
L_{t-1} \\
S_{t-1} \\
B_{t-1}
\end{array}\right]+\left[\begin{array}{l}
e_{1 t} \\
e_{2 t} \\
e_{3 t}
\end{array}\right]
$$




\subsubsection{Macro-only VAR model}

The macro-only VAR is a traditional model, containing activity, inflation, the policy rate, and, in the case of New Zealand, the exchange rate. This model is the benchmark model for comparing the performance of macro-finance models for forecasting macroeconomic variables ${ }^{3}$.

$$
\left[\begin{array}{c}
y_{t} \\
\pi_{t} \\
r_{t} \\
t w i_{t}
\end{array}\right]=\left[\begin{array}{c}
C_{10} \\
C_{20} \\
C_{30} \\
C_{40}
\end{array}\right]+\left[\begin{array}{llll}
a_{11} & a_{12} & a_{13} & a_{14} \\
a_{21} & a_{22} & a_{23} & a_{24} \\
a_{31} & a_{32} & a_{33} & a_{34} \\
a_{41} & a_{42} & a_{43} & a_{44}
\end{array}\right]\left[\begin{array}{c}
y_{t-1} \\
\pi_{t-1} \\
r_{t-1} \\
t w i_{t-1}
\end{array}\right]+\left[\begin{array}{c}
e_{1 t} \\
e_{2 t} \\
e_{3 t} \\
e_{4 t}
\end{array}\right]
$$

\subsubsection{Macro-finance VAR model}

The macro-finance VAR embeds a traditional macroeconomic VAR (real activity, inflation, policy rate, and in the case of New Zealand the exchange rate) and the yields-only VAR discussed above. Imposing restrictions would recover each separate model specification ${ }^{4}$. The bolded parameters in the top quadrant of Equation 3.8 represents the macro-only VAR, where only traditional macro-economic variables are analysed. The bolded parameters in the bottom right quadrant represent the yields-only VAR discussed above.

\section{4) Unrestricted macro-finance VAR model}

The unrestricted macro-finance VAR is the most flexible of the macro-finance VARs considered and provides a comparison for whether the restrictions on the yield curve mean-reversion matrix provide further gains to forecasting the macro-finance variables.

\footnotetext{
${ }^{3}$ An alternative benchmark model could have been a DSGE but the simple three-equation DSGE reduced-form representation is equivalent to the model presented here, which is simpler to estimate.

${ }^{4}$ In the interests of space, I present the VAR specifications for New Zealand however the US specifications are identical when the exchange rate is removed from the model.
} 


$$
\left[\begin{array}{c}
y_{t} \\
\pi_{t} \\
r_{t} \\
t w i_{t} \\
L_{t} \\
S_{t} \\
B_{t}
\end{array}\right]=\left[\begin{array}{c}
C_{10} \\
C_{20} \\
C_{30} \\
C_{40} \\
C_{50} \\
C_{60} \\
C_{70}
\end{array}\right]+\left[\begin{array}{lllllll}
\boldsymbol{a}_{\mathbf{1 1}} & \boldsymbol{a}_{\mathbf{1 2}} & \boldsymbol{a}_{\mathbf{1 3}} & \boldsymbol{a}_{\mathbf{1 4}} & a_{15} & a_{16} & a_{17} \\
\boldsymbol{a}_{\mathbf{2 1}} & \boldsymbol{a}_{\mathbf{2 2}} & \boldsymbol{a}_{\mathbf{2 3}} & \boldsymbol{a}_{\mathbf{2 4}} & a_{25} & a_{26} & a_{27} \\
\boldsymbol{a}_{\mathbf{3 1}} & \boldsymbol{a}_{\mathbf{3 2}} & \boldsymbol{a}_{\mathbf{3 3}} & \boldsymbol{a}_{\mathbf{3 4}} & a_{35} & a_{36} & a_{37} \\
\boldsymbol{a}_{\mathbf{4 1}} & \boldsymbol{a}_{\mathbf{4 2}} & \boldsymbol{a}_{\mathbf{4 3}} & \boldsymbol{a}_{\mathbf{4 4}} & a_{45} & a_{46} & a_{47} \\
a_{51} & a_{52} & a_{53} & a_{54} & \boldsymbol{a}_{\mathbf{5 5}} & \boldsymbol{a}_{\mathbf{5 6}} & \boldsymbol{a}_{\mathbf{5 7}} \\
a_{61} & a_{62} & a_{63} & a_{64} & \boldsymbol{a}_{\mathbf{6 5}} & \boldsymbol{a}_{\mathbf{6 6}} & \boldsymbol{a}_{\mathbf{6 7}} \\
a_{71} & a_{72} & a_{73} & a_{74} & \boldsymbol{a}_{\mathbf{7 5}} & \boldsymbol{a}_{\mathbf{7 6}} & \boldsymbol{a}_{\mathbf{7 7}}
\end{array}\right]\left[\begin{array}{c}
y_{t-1} \\
\pi_{t-1} \\
r_{t-1} \\
t w i_{t-1} \\
L_{t-1} \\
S_{t-1} \\
B_{t-1}
\end{array}\right]+\left[\begin{array}{c}
e_{1 t} \\
e_{2 t} \\
e_{3 t} \\
e_{4 t} \\
e_{5 t} \\
e_{6 t} \\
e_{7 t}
\end{array}\right]
$$

\section{5) Full restrictions macro-finance VAR model:}

The full restrictions macro-finance VAR imposes the restrictions on the yield-curve from Equation 3.5. Zero restrictions are also imposed on the policy rate, where the policy rate does not affect other variables, but can affect itself. This reflects the idea that information from the entire yield curve, including the short-rate, is in the Level, Slope, and Bow, so restricting the policy rate makes the model more parsimonious without losing additional information. Zero restrictions are also imposed on the Bow factor, where the Bow factor does not effect the macro-economic variables. This restriction reflects the lack of theoretical and empirical evidence about a relationship between the Bow and macro-economic variables ${ }^{5}$.

$$
\left[\begin{array}{c}
y_{t} \\
\pi_{t} \\
r_{t} \\
t w i_{t} \\
L_{t} \\
S_{t} \\
B_{t}
\end{array}\right]=\left[\begin{array}{c}
C_{10} \\
C_{20} \\
C_{30} \\
C_{40} \\
\mathbf{0} \\
C_{60} \\
C_{70}
\end{array}\right]+\left[\begin{array}{ccccccc}
a_{11} & a_{12} & \mathbf{0} & a_{14} & a_{15} & a_{16} & \mathbf{0} \\
a_{21} & a_{22} & \mathbf{0} & a_{24} & a_{25} & a_{26} & \mathbf{0} \\
a_{31} & a_{32} & a_{33} & a_{34} & a_{35} & a_{36} & \mathbf{0} \\
a_{41} & a_{42} & \mathbf{0} & a_{44} & a_{45} & a_{46} & \mathbf{0} \\
a_{51} & a_{52} & \mathbf{0} & a_{54} & \boldsymbol{a}_{\mathbf{5 5}} & \boldsymbol{a}_{\mathbf{5 6}} & \boldsymbol{a}_{\mathbf{5 7}} \\
a_{61} & a_{62} & \mathbf{0} & a_{64} & \boldsymbol{a}_{\mathbf{6 5}} & \boldsymbol{a}_{\mathbf{6 6}} & \boldsymbol{a}_{\mathbf{6 7}} \\
a_{71} & a_{72} & \mathbf{0} & a_{74} & \boldsymbol{a}_{\mathbf{7 5}} & \boldsymbol{a}_{\mathbf{7 6}} & \boldsymbol{a}_{\mathbf{7 7}}
\end{array}\right]\left[\begin{array}{c}
y_{t-1} \\
\pi_{t-1} \\
r_{t-1} \\
t w i_{t-1} \\
L_{t-1} \\
S_{t-1} \\
B_{t-1}
\end{array}\right]+\left[\begin{array}{c}
e_{1 t} \\
e_{2 t} \\
e_{3 t} \\
e_{4 t} \\
e_{5 t} \\
e_{6 t} \\
e_{7 t}
\end{array}\right]
$$

where the lower quadrant restrictions are:

\footnotetext{
${ }^{5}$ Imposing these restrictions step-by-step were also analysed and are available on request. The key results of the macro-finance models are reported here.
} 


$$
\left[\begin{array}{lll}
a_{55} & a_{56} & a_{57} \\
a_{65} & a_{66} & a_{67} \\
a_{75} & a_{76} & a_{77}
\end{array}\right]=\left[\begin{array}{ccc}
1 & 0 & 0 \\
0 & \exp (-\phi \tau) & \phi \tau \exp (-\phi \tau) \\
0 & 0 & \exp (-\phi \tau)
\end{array}\right]
$$

\section{6) Partial restrictions macro-finance VAR model:}

The partial restrictions macro-finance VAR imposes the weaker restrictions on the yield-curve from Equation 3.6. The policy rate and Bow restrictions are also imposed, following the same arguments outline above. The key difference in the models is testing the specifications of the risk-premium.

$$
\left[\begin{array}{c}
y_{t} \\
\pi_{t} \\
r_{t} \\
t w i_{t} \\
L_{t} \\
S_{t} \\
B_{t}
\end{array}\right]=\left[\begin{array}{c}
C_{10} \\
C_{20} \\
C_{30} \\
C_{40} \\
C_{50} \\
C_{60} \\
C_{70}
\end{array}\right]+\left[\begin{array}{ccccccc}
a_{11} & a_{12} & \mathbf{0} & a_{14} & a_{15} & a_{16} & \mathbf{0} \\
a_{21} & a_{22} & \mathbf{0} & a_{24} & a_{25} & a_{26} & \mathbf{0} \\
a_{31} & a_{32} & a_{33} & a_{34} & a_{35} & a_{36} & \mathbf{0} \\
a_{41} & a_{42} & \mathbf{0} & a_{44} & a_{45} & a_{46} & \mathbf{0} \\
a_{51} & a_{52} & \mathbf{0} & a_{54} & a_{55} & \mathbf{0} & \mathbf{0} \\
a_{61} & a_{62} & \mathbf{0} & a_{64} & \mathbf{0} & a_{66} & a_{67} \\
a_{71} & a_{72} & \mathbf{0} & a_{74} & \mathbf{0} & \mathbf{0} & a_{77}
\end{array}\right]\left[\begin{array}{c}
y_{t-1} \\
\pi_{t-1} \\
r_{t-1} \\
t w i_{t-1} \\
L_{t-1} \\
S_{t-1} \\
B_{t-1}
\end{array}\right]+\left[\begin{array}{c}
e_{1 t} \\
e_{2 t} \\
e_{3 t} \\
e_{4 t} \\
e_{5 t} \\
e_{6 t} \\
e_{7 t}
\end{array}\right]
$$

$\operatorname{ANSM}(2)$ versions of the macro-finance models are also tested, which removes the Bow factors from the above VARs. This case is included because it provides an additional check on the importance of the Bow factor.

\section{7) Open macro-only VAR model:}

The open economy macro-only VAR model uses a traditional open economy framework. The variables included are New Zealand and US real activity, inflation, policy rates, and the bilateral exchange rate NZD/USD. 


$$
\left[\begin{array}{l}
y_{t}^{N Z} \\
\pi_{t}^{N Z} \\
r_{t}^{N Z} \\
n z d_{t} \\
y_{t}^{U S} \\
\pi_{t}^{U S} \\
r_{t}^{U S}
\end{array}\right]=\left[\begin{array}{l}
C_{10} \\
C_{20} \\
C_{30} \\
C_{40} \\
C_{50} \\
C_{60} \\
C_{70}
\end{array}\right]+\left[\begin{array}{lllllll}
a_{11} & a_{12} & a_{13} & a_{14} & a_{15} & a_{16} & a_{17} \\
a_{21} & a_{22} & a_{23} & a_{24} & a_{25} & a_{26} & a_{27} \\
a_{31} & a_{32} & a_{33} & a_{34} & a_{35} & a_{36} & a_{48} \\
a_{41} & a_{42} & a_{43} & a_{44} & a_{45} & a_{46} & a_{47} \\
a_{51} & a_{52} & a_{53} & a_{54} & a_{55} & a_{56} & a_{57} \\
a_{61} & a_{62} & a_{63} & a_{64} & a_{65} & a_{66} & a_{67} \\
a_{71} & a_{72} & a_{73} & a_{74} & a_{75} & a_{76} & a_{77}
\end{array}\right]\left[\begin{array}{c}
y_{t-1}^{N Z} \\
\pi_{t-1}^{N Z} \\
r_{t-1}^{N Z} \\
n z d_{t-1} \\
y_{t-1}^{U S} \\
\pi_{t-1}^{U S} \\
r_{t-1}^{U S}
\end{array}\right]+\left[\begin{array}{c}
e_{1 t} \\
e_{2 t} \\
e_{3 t} \\
e_{4 t} \\
e_{5 t} \\
e_{6 t} \\
e_{7 t}
\end{array}\right]
$$

\section{8) Open economy macro-finance VAR model:}

The open economy version of the macro-finance model adds US yield curve factors to the New Zealand model and the exchange rate is changed to the bilateral NZD/USD. Movements in US interest rates often have a material impact on the interest rates of smaller open economies. Including US yield curve factors in a model of a small open economy could help capture a key transmission mechanism, where global yield curve movements flow through to the domestic economy.

In particular, only the Level and Slope yield curve factors are included in the open-economy VAR model. This reflects the desire to minimise the number of variables in the model, to keep it as parsimoneous as possible, and the fact that the Level and Slope components of the yield curve explain the largest proportion of the variation in yield curves. This is also consistent with the approach taken by Diebold, Li, and Yu (2008) in their yield curve estimation. 


$$
\left[\begin{array}{c}
y_{t} \\
\pi_{t} \\
r_{t} \\
n z d_{t} \\
L_{t}^{N Z} \\
S_{t}^{N Z} \\
L_{t}^{U S} \\
S_{t}^{U S}
\end{array}\right]=\left[\begin{array}{c}
C_{10} \\
C_{20} \\
C_{30} \\
C_{40} \\
C_{50} \\
C_{60} \\
C_{70} \\
C_{80}
\end{array}\right]+\left[\begin{array}{cccccccc}
a_{11} & a_{12} & \mathbf{0} & a_{14} & a_{15} & a_{16} & a_{17} & a_{18} \\
a_{21} & a_{22} & \mathbf{0} & a_{24} & a_{25} & a_{26} & a_{27} & a_{28} \\
a_{31} & a_{32} & a_{33} & a_{34} & a_{35} & a_{36} & a_{48} & a_{38} \\
a_{41} & a_{42} & \mathbf{0} & a_{44} & a_{45} & a_{46} & a_{47} & a_{48} \\
a_{51} & a_{52} & \mathbf{0} & a_{54} & \boldsymbol{a}_{\mathbf{5 5}} & \boldsymbol{a}_{\mathbf{5 6}} & \boldsymbol{a}_{\mathbf{5 7}} & \boldsymbol{a}_{\mathbf{5 8}} \\
a_{61} & a_{62} & \mathbf{0} & a_{64} & \boldsymbol{a}_{\mathbf{6 5}} & \boldsymbol{a}_{\mathbf{6 6}} & \boldsymbol{a}_{\mathbf{6 7}} & \boldsymbol{a}_{\mathbf{6 8}} \\
a_{71} & a_{72} & \mathbf{0} & a_{74} & \boldsymbol{a}_{\mathbf{7 5}} & \boldsymbol{a}_{\mathbf{7 6}} & \boldsymbol{a}_{\mathbf{7 7}} & \boldsymbol{a}_{\mathbf{7 8}} \\
a_{81} & a_{82} & \mathbf{0} & a_{84} & \boldsymbol{a}_{\mathbf{7 5}} & \boldsymbol{a}_{\mathbf{7 6}} & \boldsymbol{a}_{\mathbf{7 7}} & \boldsymbol{a}_{\mathbf{8 8}}
\end{array}\right]\left[\begin{array}{c}
y_{t-1} \\
\pi_{t-1} \\
r_{t-1} \\
n z d_{t-1} \\
L_{t-1}^{N Z} \\
S_{t-1}^{N Z} \\
L_{t-1}^{U S} \\
S_{t-1}^{U S}
\end{array}\right]+\left[\begin{array}{c}
e_{1 t} \\
e_{2 t} \\
e_{3 t} \\
e_{4 t} \\
e_{5 t} \\
e_{6 t} \\
e_{7 t} \\
e_{8 t}
\end{array}\right]
$$

where the lower quadrant restrictions for the fully restricted macro-finance model are:

$$
\left[\begin{array}{llll}
\boldsymbol{a}_{\mathbf{5 5}} & \boldsymbol{a}_{\mathbf{5 6}} & \boldsymbol{a}_{\mathbf{5 7}} & \boldsymbol{a}_{\mathbf{5 8}} \\
\boldsymbol{a}_{\mathbf{6 5}} & \boldsymbol{a}_{\mathbf{6 6}} & \boldsymbol{a}_{\mathbf{6 7}} & \boldsymbol{a}_{\mathbf{6 8}} \\
\boldsymbol{a}_{\mathbf{7 5}} & \boldsymbol{a}_{\mathbf{7 6}} & \boldsymbol{a}_{\mathbf{7 7}} & \boldsymbol{a}_{\mathbf{7 8}} \\
\boldsymbol{a}_{\mathbf{8 5}} & \boldsymbol{a}_{\mathbf{8 6}} & \boldsymbol{a}_{\mathbf{8 7}} & \boldsymbol{a}_{\mathbf{8 8}}
\end{array}\right]=\left[\begin{array}{cccc}
\mathbf{1} & \mathbf{0} & a_{57} & a_{58} \\
\mathbf{0} & \boldsymbol{e x p}\left(-\phi^{N Z} \boldsymbol{\tau}\right) & a_{67} & a_{68} \\
a_{75} & a_{76} & \mathbf{1} & \mathbf{0} \\
a_{85} & a_{86} & \mathbf{0} & \boldsymbol{e x p}\left(-\phi^{U S} \boldsymbol{\tau}\right)
\end{array}\right]
$$

and the lower quadrant restrictions for the partially restricted macro-finance model are:

$$
\left[\begin{array}{llll}
a_{55} & a_{56} & a_{57} & a_{58} \\
a_{65} & a_{66} & a_{67} & a_{68} \\
a_{75} & a_{76} & a_{77} & a_{78} \\
a_{85} & a_{86} & a_{87} & a_{88}
\end{array}\right]=\left[\begin{array}{cccc}
a_{55} & 0 & a_{57} & a_{58} \\
\mathbf{0} & a_{66} & a_{67} & a_{68} \\
a_{75} & a_{76} & \boldsymbol{a}_{\mathbf{7 6}} & \mathbf{0} \\
a_{85} & a_{86} & \mathbf{0} & \boldsymbol{a}_{\mathbf{7 7}}
\end{array}\right]
$$

\section{Model results key:}

Table 3.2.1 provides a reference list for the models that will be shown in the results tables in the coming sections. 
Table 3.2.1: Model results key

\begin{tabular}{llr}
\hline Abbreviation & Model & Equation reference \\
\hline Yield curve models & & 3.4 \\
\hline Yields-only & Unrestricted (K)ANSM(3) & 3.5 \\
Full & Fully restricted (K)ANSM(3) & 3.6 \\
Partial & Partially restricted (K)ANSM(3) & 3.7 \\
\hline Macro-finance models & Macroeconomic VAR & 3.8 \\
\hline Macro-only & Unrestricted macro-finance with (K)ANSM(3) & 3.9 \\
MF unrestricted & Fully restricted macro-finance with (K)ANSM(3) & 3.10 \\
MF full & Partially restricted macro-finance with (K)ANSM(3) & $3.8 \ddagger$ \\
MF partial & Unrestricted macro-finance with (K)ANSM(2) & $3.10 \ddagger$ \\
MF two factor & Partially restricted macro-finance with (K)ANSM(2) & 3.11 \\
MF two factor partial & 3.12 \\
\hline Open economy models & & 3.14 \\
\hline Macro Open BM & Small open economy, macro-only & 3.13 \\
FL unrestricted & Unrestricted financial links macro-finance model with (K)ANSM(3) & $3.12 \S$ \\
FL full & Fully restricted financial links macro-finance model with (K)ANSM(3) & $3.13 \S$ \\
FL partial & Partially restricted financial links macro-finance model with (K)ANSM(3) \\
FL 2F & Unrestricted financial links macro-finance model with (K)ANSM(2) & \\
FL 2F partial & Partially restricted financial links macro-finance model with (K)ANSM(2) & \\
\hline \hline † These models use the two-factor yield curve models, hence the Bow is component is removed from the VAR. \\
§ The yield curve models are estimated using two factors.
\end{tabular}

\subsection{Model estimation}

\subsubsection{Data}

The estimation and forecast exercises require two different data sets but based on the same economic variables. The first is full sample, using the latest vintage of data available as at the end of 2014Q2. The second set is the real-time vintage data - the data available to the forecaster at each point in time.

\section{US full sample data}

For the United States, core CPI is used as the inflation measure, which is quarterly $\log$ differences and multiplied by $400 .^{6}$ Economic activity is

\footnotetext{
${ }^{6}$ For robustness, alternative measures were also used (core PCE, PCE, and CPI) and results were similar, although not as strong for headline CPI. The use of core CPI inflation fits with
} 
measured using two different series. The first is the output gap, which is calculated using the official Congressional Budget Office (CBO) 2014 measure of potential output and 2014Q1 GDP data. The second measure used is demeaned capacity utilisation, which is a similar concept to the output gap. The reasons two measures are used is for robustness given various studies use different measures of economic activity and because calculating the output gap in real-time is problematic (discussed below). The policy rate is measured using the effective Fed Funds rate. All data are quarterly and are from the Federal Reserve Bank of St. Louis FRED website wwww.research.stlouisfed. org/fred2/.

\section{US real-time data}

US real-time vintage data are from the Federal Reserve Bank of St. Louis ALFRED website wwww.alfred.stlouisfed.org/, which is a database of real-time data vintages. Core CPI is seasonally adjusted so has some variation over releases and as methodology changes, which is incorporated in this analysis. Economic activity data are also revised. As mentioned previously, it would be preferable to use the output gap in the real-time analysis but this is problematic. The CBO's measure of potential output is released annually (sometimes semi-annually) but GDP data can have substantial revisions throughout the year. It is not clear how much of the revisions to GDP would feed into estimates for potential output, particularly following substantial revisions. There is a lively debate in the literature about output gap measurement, particularly in real-time (Orphanides and Norden (1999) discuss the unreliability of real-time output gap estimates). Rather than add the complexity of real-time output gap estimation, I use capacity utilisation as a measure of economic activity, as is used in much of the literature ${ }^{7}$. Capacity utilisation is demeaned in real-time, capturing the amount of capacity pressure as would have been seen in real-time. See Appendix C.2 for figures of real-time

much of the literature and fits with intuition that financial market prices would reflect the trend component of inflation rather than the idiosyncratic components.

${ }^{7}$ US GDP growth was also used. The results were similar, although not as strong. This fits with the closer observed relationship between capacity utilisation/output gap. 
data used. Real-time data vintages are used from 1996Q4 and the final vintage is 2014 Q2.

\section{NZ full sample data}

For New Zealand, core CPI is measured using the Sectoral Core Factor that is published by the Reserve Bank of New Zealand and is based on Kirker (2010). The seasonality in New Zealand data means this measure was estimated on annual data and are used here on quarterly basis ${ }^{8}$. Real activity is measured using the Reserve Bank of New Zealand's output gap estimates ${ }^{9}$. The policy rate is measured using the 90-day bank bill rate, in-keeping with the forecast methodology of the Reserve Bank of New Zealand. For the New Zealand model, the exchange rate is measured by the Trade Weighted Index, which is a trade-weighted basket of currencies. For the open economy version model, which takes US economic variables and yield curve factors into account, the bilateral USD/NZD is used. Interest rate data, including the yield curve factors, are in level terms. The exchange rate data are in log difference terms. All data are quarterly and are from the Reserve Bank of New Zealand. Real-time data vintages are used from 2000Q1 and the final vintage is 2014Q2.

\section{NZ real-time data}

The Sectorial Core Factor model for core CPI is estimated using dynamic factors and hence shows real-time variation in estimation. The real-time estimated vintages are available from the Reserve Bank of New Zealand on request. The real-time estimates of the output gap are also obtained from the Reserve Bank of New Zealand. These revisions can be substantial and reflect revisions to GDP national accounts data, revisions to potential output and methodological changes to the estimation of the output gap. See Appendix C.2 for figures of real-time data used.

\footnotetext{
${ }^{8}$ The trimmed and weighted median measures of quarterly inflation were also used and while there broad results were similar to the results discussed below were not as strong. Headline quarterly CPI inflation was also tested but measures of core inflation are preferred conceptually since it abstracts from idiosyncratic movements.

${ }^{9}$ Likewise with the US study, GDP growth data were also considered. The overall results still hold but are less strong
} 


\section{Conceptual considerations}

Many of the data series considered are unobservable by definition (the output gap, capacity utilisation, core inflation, and the yield curve factors), but these are typical variables that central banks spend much time discussing and forecasting during policy rounds. The forecast performance tests with real-time data vintages provide a reliable evaluation using these series for forecasting, using information as available at particular points in time. The forecast of observable variables (policy rates and exchange rates) also provides a cross-check on the information content in the unobservable variables, especially since the naive $\operatorname{AR}(1)$ model is also used for generating forecasts.

To simulate the real-time forecasting environment, I also incorporate publication lags. In particular, activity and price measures are available with a one quarter lag. This creates two issues for the forecast exercise. Firstly, not all the data are available at each point in time and the data are subject to revision. These are the conditions faced by a forecaster in the real-world and hence the conditions replicated here.

\subsection{Model evaluation}

\section{In-sample evaluation}

The macro-finance models are evaluated in two ways. The first is in-sample estimation, where information criteria are used to test which model provides the best explanation of the data. Models are ranked based on Akaike's information criteria (AIC). Lütkepohl (2005) illustrates that AIC are more successful at picking the models that forecast well because the criteria is related to minimising the mean squared forecast error. Since this paper investigates the forecast ability of the macro-finance models, AIC is a natural choice for model evaluation. In this scenario, the 'best' model is the one with the lowest AIC score. The AIC score is calculation is in Equation 3.15. 


$$
A I C=-2 \ln (\hat{L})+2 k
$$

where $\hat{L}$ is the likelihood and $k$ is the degrees of freedom.

\section{Out-of-sample evaluation}

The second evaluation is real-time forecasting. The real-time environment has two key features aside from recursive estimation and forecasting used in this thesis ${ }^{10}$. The initial release of quarterly macroeconomic data is often released at least a quarter after the observation period. This means that any given point in time the panel of data available is unbalanced. Secondly, when this data is released it is typically preliminary and subject to substantial revision over time. The subsequent data revisions could reflect, for example, a fuller set of information, changes in methodology, or technical reasons such as seasonal adjustment.

The missing observations are handled using each model's structure. At each point in time $t$, the macro-finance model is estimated until $t-1$, reflecting missing activity and inflation data. The model structure is then used to 'now-cast' the missing observations. Figure 3.1 illustrates the unbalanced panel, where inflation and activity data are missing at time $t$. At each point in time the VAR model is estimated until time $t-1$ and then the VAR structure is used to create 'now-casts' for inflation and activity at time $t^{11}$.

\footnotetext{
${ }^{10} \mathrm{~A}$ recursive forecasting strategy is used, as is often the case in the literature, given the short sample sizes involved. However, for robustness the procedure could be done using a rolling window. This is left for future work.

${ }^{11}$ An alternative method would have to use a Kalman Filter to estimate the missing data. This practical improvement is left for future research. However, given the relative forecast exercise considered here, the key requirement is that all models are treated the same.
} 
Figure 3.1: Unbalanced panel

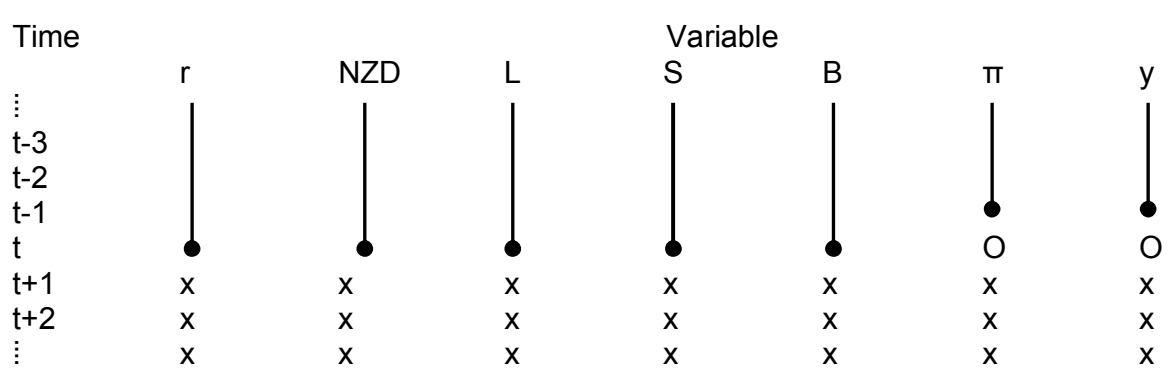

Note: Figure illustrates the missing data in real-time, where inflation and output data are not available in at time $t$. ' $\mathrm{O}$ ' is the nowcast and ' $\mathrm{x}$ ' is the forecast.

From there, forecasts are created from $t+1$ until $t+16$. The forecasts for each vintage are compared against the data from 2014Q2, which is the 'final vintage'. The root mean squared forecast error (RMSFE) is calculated and the forecast performance is evaluated relative to a benchmark model using their ratio. A ratio smaller than one means the alternative model provides a better forecast than the benchmark model. From this ratio it is possible to calculate the percentage gain in using the alternative model. For example if the relative RMSFE is 0.80 then the alternative model is 20 percent better at forecasting than the benchmark model.

For macroeconomic variables, the benchmark model is the macro-only model. For yield curve factors, the benchmark model is the yields-only model. AR(1) forecasts of all variables are also calculated, as a way of further assessing whether the additional information in the VAR is valuable to the forecast process relative to a single-equation approach for each variable. Indeed, given an $\mathrm{AR}(1)$ model is so parsimonious, it is often difficult to beat for producing forecasts.

The RMSFE equation is:

$$
R M S F E=\sqrt{\frac{1}{n} \sum_{i=1}^{n}\left(y_{i}-\hat{y}_{i}\right)^{2}}
$$


where $y_{i}$ is the realised value of $y$ and $\hat{y}_{i}$ is the forecast of $y$.

Statistical significance of forecast performance is tested using the Diebold and Mariano (1995) test, and the altered Clark and West (2007) test is used for nested models. In the case of the macro and yields-only models, the unrestricted macro-finance and AR models are nested. Since the $h$ step ahead forecasts use overlapping data, the Newey-West estimator with a $h-1$ window is used to correct for the autocorrelation. One-sided tests are used with predictive accuracy tested at the one, five, and 10 percent levels. Using the one-sided test, rather than two sided, reflects the research questions:

1. can yield curve information improve macro economic forecasts?

2. can macroeconomic information improve yield curve forecasts?

The Diebold-Mariano mean squared forecast error (MSFE) is:

$$
f_{t+k}=\left(y_{t+k}-\hat{y}_{t+k}\right)^{2}-\left(y_{t+k}-\tilde{y}_{t+k}\right)^{2}
$$

where $f$ is is the MSFE statistic, $y$ is the variable outturn $k$ periods ahead, $\hat{y}$ is the forecast from model 1 , and $\tilde{y}$ is the prediction from model 2 . The time series of $f$ is regressed on a constant, for each forecast horizon, and the one-sided p-value for a one-sided test is calculated with the standard normal distribution. The Newey West estimator is used to correct for serial correlation in forecast errors beyond the first forecast period.

The Clark-West MSFE-adjusted statistic is:

$$
\left.f_{t+k}^{a d j}=\left(y_{t+k}-\hat{y}_{t+k}\right)^{2}-\left[\left(y_{t+k}-\tilde{y}_{t+k}\right)^{2}-\left(\hat{y}_{t+k}-\tilde{y}_{t+k}\right)^{2}\right]\right)
$$

The critical values are calculated using the same method as Diebold-Mariano. 


\section{Chapter 4}

\section{US Model}

The results are presented as 'pre-GFC' and 'full-sample', where the pre-GFC period is 1986Q4-2007Q4 and the full-sample period is 1986Q4-2014Q1. There are two reasons for splitting the sample period. The first is that essentially two different models are being used, albeit the ANSM is a nested version of the KANSM. Splitting the sample makes the pre-GFC results comparable to the rest of the literature. The second reason is that the transmission mechanism from monetary policy may have sufficiently changed once the zero lower bound was reached, making information from the yield curve less informative compared to the pre-ZLB period.

\subsection{In-sample model fit}

Table 4.1.1 reports the in-sample fit results for the pre-GFC period. The five macro-finance models considered all give lower AIC scores relative to the macro-only model. This suggests the additional information in the yield curve, in any of the forms considered, improves the description of the economic model. The results are consistent between the output gap and capacity utilisation versions of the model. The top three models are the unrestricted, partially restricted, and fully restricted macro-finance models. For robustness, the BIC 
results are also presented.

For the yields-only model, the parameter restrictions have little effect, although the $\mathrm{P}$-measure restrictions provide a small gain while the $\mathrm{Q}$-measure restrictions slightly deteriorate the model's fit relative to the benchmark unrestricted yield curve model.

Table 4.1.1: US pre-GFC model fit: AIC

\begin{tabular}{lcc|lcccc}
\hline \multicolumn{3}{c|}{ Yields-only } & \multicolumn{5}{c}{ Macro-finance } \\
\hline & & & & \multicolumn{5}{c}{ Output gap } & \multicolumn{3}{c}{ Capacity utilisation } \\
& AIC & BIC & & AIC & BIC & AIC & BIC \\
Yields-only & -2.30 & -1.97 & Macro-only & -3.50 & -3.17 & -2.72 & -2.38 \\
Partial & -2.38 & -2.18 & MF unrestricted & -7.70 & -6.52 & -6.83 & -5.65 \\
Full & -2.25 & -2.20 & MF partial & -7.51 & -6.69 & -6.76 & -5.94 \\
& & & MF full & -7.17 & -6.50 & -6.19 & -5.52 \\
& & & MF two factor & -6.45 & -5.72 & -5.51 & -4.77 \\
& & & MF two factor partial & -6.49 & -5.81 & -5.54 & -4.86 \\
\hline \hline
\end{tabular}

See Table 3.2.1 for model name references. The bolded numbers indicate the top models.

The full sample results are consistent with the pre-GFC results (see Table 4.1.2). The macro-finance models consistently score lower AIC measures compared to the macro-only model. The same three macro-finance models are ranked the top three. The yields-only models are also consistent with the pre-GFC period, where the P-measure restrictions slightly improve the model fit and the Q-measure restrictions deteriorate the fit.

Table 4.1.2: US full sample model fit: AIC

\begin{tabular}{lcc|lcccc}
\hline \multicolumn{3}{c|}{ Yields-only } & \multicolumn{5}{c}{ Macro-finance } \\
\hline & & & & \multicolumn{5}{c}{ Output gap } & \multicolumn{2}{c}{ Capacity utilisation } \\
& AIC & BIC & & AIC & BIC & AIC & BIC \\
Yields-only & -1.65 & -1.36 & Macro-only & -3.22 & -2.92 & -2.05 & -1.76 \\
Partial & -1.67 & -1.50 & MF unrestricted & -6.66 & -5.64 & -5.52 & -4.50 \\
Full & -1.51 & -1.46 & MF partial & -6.53 & -5.82 & -5.37 & -4.67 \\
& & & MF full & -6.04 & -5.46 & -4.82 & -4.24 \\
& & & MF two factor & -5.29 & -4.65 & -4.11 & -3.48 \\
& & & MF two factor partial & -5.30 & -4.71 & -4.13 & -3.54 \\
\hline \hline
\end{tabular}

See Table 3.2.1 for model name references. The bolded numbers indicate the top models. 


\subsection{Real-time forecast performance}

The results in the tables below show the forecast performance, measured in root mean squared forecast errors (RMSFE), relative to the benchmark model (BM). The macro-only model is the benchmark model for the economic forecasts. The yields-only model is the benchmark model for the yield curve component forecasts. The forecast error for the benchmark models are reported as they were estimated in the VARs, i.e. CPI inflation is quarterly annualised, capacity utilisation is in gap terms, the Effective Feds Funds rate and the yield curve factors are in percentage point terms. The forecast horizon for inflation and capacity utilisation start at zero, where the models also compute the now-cast. The forecast horizon for other variables start at one quarter ahead.

\subsubsection{Pre-GFC}

\section{Inflation forecasts}

Table 4.2.1 reports the results for the inflation forecasts. The macro-finance models significantly improve the forecast performance for inflation, with the significance of the improvement growing as the forecast horizon is extended. The macro-finance models improve the now-cast forecast performance by 5 percent, although this is not statistically significant. The improvement grows to almost 40 percent at 16 quarters ahead when using the macro-finance model with partial-restrictions. In terms of statistical significance of the forecast improvement, the unrestricted macro-finance model is the best. However, economic significance of the forecast improvement suggests the macro-finance models with the partial restrictions are the strongest performers. These results are consistent with the in-sample results. 
Table 4.2.1: US pre-GFC: inflation RMSFE

\begin{tabular}{|c|c|c|c|c|c|c|c|}
\hline Forecast & Macro BM & $\mathrm{MF} \mathrm{Un}^{\dagger}$ & MF Partial & MF Full & $\mathrm{MF} 2 \mathrm{~F}$ & MF 2F Partial & $\mathrm{AR}^{\dagger}$ \\
\hline 0 & 0.73 & 1.01 & 0.94 & 0.95 & 0.95 & 0.95 & 1.05 \\
\hline 1 & 0.80 & $0.91^{* * *}$ & 0.84 * & $0.85 *$ & $0.85 *$ & $0.85 *$ & 1.10 \\
\hline 2 & 0.85 & $0.83^{* *}$ & $0.81 *$ & 0.80 & 0.79 * & $0.79^{* *}$ & 1.11 \\
\hline 3 & 0.91 & $0.84^{* *}$ & 0.82 & 0.84 & $0.87^{*}$ & $0.87 *$ & 1.16 \\
\hline 4 & 0.93 & $0.90 * *$ & 0.87 & 0.93 & 0.95 & 0.94 & 1.19 \\
\hline 8 & 1.19 & $0.89^{* * *}$ & $0.80^{* *}$ & 0.86 & $0.85^{* * *}$ & $0.84^{* * *}$ & 1.04 \\
\hline 12 & 1.34 & $0.88^{* *}$ & $0.73^{* * *}$ & $0.80 *$ & $0.83^{* * *}$ & $0.82^{* * *}$ & 0.93 \\
\hline 16 & 1.38 & $0.82^{* * *}$ & $0.64^{* * *}$ & $0.66^{* * *}$ & $0.81^{* * *}$ & $0.80^{* * *}$ & 0.97 \\
\hline
\end{tabular}

Note: the first column is the benchmark model (BM). The numbers reported are quarterly RMSFE. Bold text shows where the relative RMSFE is less than one (the model outperforms the benchmark model). The significance of the result is given by the asterisks. ${ }^{* \prime}$ is significant at the 10 percent level, ${ }^{* * \prime}$ is significant at the 5 percent level and ${ }^{* * * * \prime}$ is significant at the 1 percent level. Diebold-Mariano one-sided tests were used, with the Clark-West correction for nested models. Nested models are identified with ${ }^{\dagger}$.

See Table 3.2.1 for model name references.

\section{Capacity utilisation forecasts}

For capacity utilisation forecasts (see Table 4.2.2), the macro-finance models can outperform the macro-only model at long forecast horizons but not at other horizons ${ }^{1}$. This contrasts to the literature, which uses quasi-real forecast performance tests, although the different sample period could play a role too. Nevertheless, the forecast improvement at longer-horizons could be particularly useful for policymakers since this is a horizon of importance when setting policy.

\footnotetext{
${ }^{1}$ The result holds for forecasting quarterly GDP growth.
} 
Table 4.2.2: US pre-GFC: capacity utilisation RMSFE

\begin{tabular}{|c|c|c|c|c|c|c|c|}
\hline Forecast & Macro BM & $\mathrm{MF}^{\mathrm{U}}{ }^{\dagger}$ & MF Partial & MF full & MF 2F & MF 2F Partial & $\mathrm{AR}^{\dagger}$ \\
\hline 0 & 1.88 & 1.11 & 1.10 & 1.12 & 1.14 & 1.14 & 1.15 \\
\hline 1 & 1.98 & 1.17 & 1.16 & 1.19 & 1.20 & 1.20 & 1.20 \\
\hline 2 & 2.16 & 1.19 & 1.19 & 1.24 & 1.25 & 1.25 & 1.23 \\
\hline 3 & 2.33 & 1.20 & 1.19 & 1.26 & 1.27 & 1.27 & 1.24 \\
\hline 4 & 2.51 & 1.21 & 1.17 & 1.26 & 1.26 & 1.26 & 1.24 \\
\hline 8 & 3.04 & 1.24 & 1.11 & 1.22 & 1.20 & 1.19 & 1.28 \\
\hline 12 & 3.41 & 1.07 & 0.93 & 0.89 & 1.00 & 0.99 & 1.37 \\
\hline 16 & 3.59 & 1.02 & $0.94^{* * *}$ & 0.90 & 0.94 & 0.94 & 1.40 \\
\hline
\end{tabular}

See Table 4.2.1 for table details.

Effective Fed funds rate forecasts

The results in Table 4.2.3 show that the macro-finance model significantly improves the forecast performance for the Effective Fed funds rate. The gain reaches almost 30 percent when using either the partially or fully restricted macro-finance models. This is an intuitive result since the yield curve contains information about the expected path of the policy rate ${ }^{2}$.

Table 4.2.3: US pre-GFC: effective Fed funds rate RMSFE

\begin{tabular}{|c|c|c|c|c|c|c|c|}
\hline Forecast & Macro BM & MF Un ${ }^{\dagger}$ & MF Partial & MF full & MF $2 F$ & MF 2F Partial & $\mathrm{AR}^{\dagger}$ \\
\hline 1 & 0.46 & $0.73^{* * *}$ & $0.83^{* * *}$ & $0.82 * * *$ & $0.76^{* * *}$ & $0.76^{* * *}$ & 1.05 \\
\hline 2 & 0.85 & $0.89^{* *}$ & 0.94 & 0.90 & $0.87 *$ & $0.87 *$ & 1.03 \\
\hline 3 & 1.22 & 0.95 * & 0.98 & 0.95 & 0.92 & 0.92 & 1.00 \\
\hline 4 & 1.56 & 0.99 & 1.00 & 0.99 & 0.97 & 0.97 & $0.98^{* *}$ \\
\hline 8 & 2.48 & 1.14 & 1.03 & 1.13 & 1.08 & 1.08 & 0.99 \\
\hline 12 & 3.19 & 1.08 & $0.86^{* *}$ & 0.97 & 0.99 & 0.98 & $0.98^{* *}$ \\
\hline 16 & 3.58 & 1.02 & $0.76^{* * *}$ & 0.73 * & 0.93 & 0.93 & $0.94 *$ \\
\hline
\end{tabular}

See Table 4.2.1 for table details.

\footnotetext{
${ }^{2}$ The forecast for the Fed funds rate is not bounded by zero. In practice a threshold in the forecast would be used to account for the effective lower bound. However, in this exercise the relative forecast performance is of interest.
} 


\section{Yield curve component forecasts}

The macro-finance models improve the forecast performance of the Level component of the yield curve relative to the yields-only benchmark model (see Table 4.2.4). The partially restricted macro-finance model improves the forecast performance up to 20 percent at the longer horizons. The improvement in the forecast performances of inflation and the Level is consistent with the empirical and theoretical link between the two variables.

Given the Level component explains around 90 percent of the variation in the yield curve, this result highlights the usefulness of incorporating macro-economic information in the curve forecasts. This result is consistent with the literature on forecasting the yield curve. Further improvement in forecasting the Level component comes from the restricted yields-only models. The gain reaches 28 percent when using the fully restricted yields-only model. This result is new to the literature, where the theoretical restrictions on yield curve dynamics supersede the gain from using macro-finance models for forecasting the yield curve.

Table 4.2.4: US pre-GFC: Level RMSFE

\begin{tabular}{|c|c|c|c|c|c|c|c|}
\hline Forecast & Yields BM & LSB Partial & LSB Full & $\mathrm{MF} \mathrm{Un}^{\dagger}$ & MF Partial & MF Full & $\mathrm{AR}^{\dagger}$ \\
\hline 1 & 0.45 & $0.96^{* *}$ & 0.97 & 1.00 & $0.95^{* * *}$ & 0.97 & $0.99 *$ \\
\hline 2 & 0.64 & $0.93 *$ & 0.93 & 1.00 & $0.93 *$ & 0.95 & 0.98 \\
\hline 3 & 0.79 & 0.93 & 0.92 & 0.98 & 0.92 & 0.96 & 0.99 \\
\hline 4 & 0.93 & 0.93 & 0.92 & $0.98 *$ & 0.93 & 0.98 & 1.00 \\
\hline 8 & 0.96 & 0.97 & 0.93 & $0.91^{* * *}$ & 0.94 & 1.11 & 1.06 \\
\hline 12 & 1.16 & 0.93 & $0.80^{* *}$ & 0.82 ** & $0.86^{* *}$ & 1.01 & 1.01 \\
\hline 16 & 1.32 & $0.91^{* * *}$ & $0.72 * * *$ & $0.86^{* *}$ & $0.79^{* * *}$ & 0.83 * & $0.99 * *$ \\
\hline
\end{tabular}

See Table 4.2.1 for table details.

The Slope and Bow component forecasts are in Tables 4.2.5 and 4.2.6. Economic information improves the forecast performance for the Slope component at long-horizons, which is consistent with the capacity utilisation results. The forecast performance for the Bow improves when yield curve restrictions are imposed as well as when economic information is added to the model. 
Table 4.2.5: US pre-GFC: Slope RMSFE

\begin{tabular}{|c|c|c|c|c|c|c|c|}
\hline Forecast & Yields BM & LSB Partial & LSB Full & MF Un $^{\dagger}$ & MF Partial & MF Full & \\
\hline 1 & 0.64 & 1.00 & 1.01 & 1.03 & 1.11 & 0.99 & 1.12 \\
\hline 2 & 1.06 & 0.99 & 0.99 & 1.06 & 1.16 & 1.03 & 1.11 \\
\hline 3 & 1.46 & 0.98 & 0.98 & 1.07 & 1.16 & 1.06 & 1.07 \\
\hline 4 & 1.84 & 0.96 & 0.97 & 1.07 & 1.13 & 1.09 & 1.03 \\
\hline 8 & 2.73 & $0.90 *$ & 0.97 & 1.09 & 1.02 & 1.16 & 0.90 \\
\hline 12 & 3.38 & $0.81^{* * *}$ & $0.89^{* * *}$ & 0.95 * & $0.85^{* * *}$ & 1.05 & 0.88 * \\
\hline 16 & 3.34 & $0.76^{* * *}$ & $0.87^{* * *}$ & $0.87^{* *}$ & $0.73^{* * *}$ & $0.93^{* *}$ & 0.88 * \\
\hline
\end{tabular}

See Table 4.2.1 for table details.

Table 4.2.6: US pre-GFC: Bow RMSFE

\begin{tabular}{|c|c|c|c|c|c|c|c|}
\hline Forecast & Yields BM & LSB Partial & LSB Full & MF Un ${ }^{\dagger}$ & MF Partial & MF Full & $\mathrm{AR}^{\dagger}$ \\
\hline 1 & 1.46 & $0.96^{*}$ & $0.94^{* *}$ & 1.01 & 1.00 & 0.96 & $0.96^{* *}$ \\
\hline 2 & 1.95 & $0.94 *$ & $0.93^{* *}$ & $0.97^{*}$ & 0.96 & 0.98 & $0.94^{* *}$ \\
\hline 3 & 2.18 & $0.94 *$ & $0.91^{* * *}$ & $0.95 *$ & 0.92 & 0.97 & $0.94^{* *}$ \\
\hline 4 & 2.38 & 0.94 & $0.91^{* * *}$ & 0.96 * & $0.91 *$ & 0.98 & $0.94^{* *}$ \\
\hline 8 & 2.86 & $0.90^{* * *}$ & $0.91^{* * *}$ & 1.00 & $0.90^{* *}$ & 1.02 & $0.90^{* * *}$ \\
\hline 12 & 3.05 & $0.89^{* * *}$ & $0.93^{* * *}$ & 0.99 & $0.89^{* * *}$ & 1.00 & $0.89^{* * *}$ \\
\hline 16 & 3.10 & 0.93 & 0.99 & 1.00 & 0.95 & 1.02 & $0.93^{* *}$ \\
\hline
\end{tabular}

See Table 4.2.1 for table details.

\subsubsection{Full sample}

Inflation forecasts

As shown in Table 4.2.7, the yield curve factors are able to still add value for inflation forecasts when the forecasts are extended to include the zero lower bound period. The economic strength of the improvement is a little less in the post-GFC period but is nonetheless economically and statically significant.

The unrestricted macro-finance model consistently improves forecasts for inflation from three quarters ahead, while the partially restricted macro-finance model provides the largest gains at longer horizons (albeit economically outperforms from 2 quarters ahead). The other macro-finance model specifications also improve forecast performance for longer-term forecasts. 
Table 4.2.7: US full sample: inflation RMSFE

\begin{tabular}{|c|c|c|c|c|c|c|c|}
\hline Forecast & Macro BM & MF $\mathrm{Un}^{\dagger}$ & MF Partial & MF Full & MF 2F & MF 2F Partial & $\mathrm{AR}^{\dagger}$ \\
\hline 0 & 0.74 & 1.06 & 1.04 & 1.03 & 1.01 & 1.01 & 1.08 \\
\hline 1 & 0.78 & 1.03 & 1.02 & 1.04 & 1.05 & 1.05 & 1.15 \\
\hline 2 & 0.82 & $0.98^{* *}$ & 0.96 & 1.02 & 1.00 & 0.99 & 1.19 \\
\hline 3 & 0.87 & $0.99 * *$ & 0.95 & 1.05 & 1.03 & 1.01 & 1.25 \\
\hline 4 & 0.89 & $0.99 * *$ & 0.93 & 1.05 & 1.03 & 1.00 & 1.27 \\
\hline 8 & 1.24 & $0.86^{* * *}$ & $0.80^{* * *}$ & $0.81 * *$ & $0.82 * * *$ & $0.81^{* * *}$ & 1.02 \\
\hline 12 & 1.39 & $0.84^{* * *}$ & $0.76^{* * *}$ & $0.78^{* *}$ & $0.79^{* * *}$ & $0.78^{* * *}$ & 0.93 * \\
\hline 16 & 1.44 & $0.78^{* * *}$ & $0.67^{* * *}$ & $0.70^{* * *}$ & $0.74^{* * *}$ & $0.74^{* * *}$ & 0.95 * \\
\hline
\end{tabular}

See Table 4.2.1 for table details.

\section{Capacity utilisation forecasts}

The forecast performance for capacity utilisation improves in the full sample, with greater statistical and economic significance for forecasts from eight quarters ahead (see Table 4.2.8). Indeed, all the macro-finance model specifications considered improve forecast performance, with the gain reaching around 25 percent. This is consistent with literature showing yield curve factors improve activity forecast performance during economic downturns. A possible explanation for this could be the type of investors that are attracted to bonds during economic downturns. A 'flight-to-safety' could depress bond yields and signal the length of time that economic activity is likely to remain depressed ${ }^{3}$.

\footnotetext{
${ }^{3}$ Exploring non-linearities in forecast performance, focusing on recessions and recoveries, could be an interesting extension for future research.
} 
Table 4.2.8: US full sample: capacity utilisation RMSFE

\begin{tabular}{|c|c|c|c|c|c|c|c|}
\hline Forecast & Macro BM & $\mathrm{MF} \mathrm{Un}^{\dagger}$ & MF Partial & MF full & MF 2F & MF 2F Partial & $\mathrm{AR}^{\dagger}$ \\
\hline 0 & 1.78 & 1.06 & 1.06 & 1.06 & 1.08 & 1.08 & 1.10 \\
\hline 1 & 2.25 & 1.06 & 1.05 & 1.06 & 1.07 & 1.07 & 1.11 \\
\hline 2 & 2.86 & 1.04 & 1.03 & 1.04 & 1.05 & 1.05 & 1.09 \\
\hline 3 & 3.48 & 1.02 & 1.03 & 1.04 & 1.04 & 1.03 & 1.08 \\
\hline 4 & 3.95 & 1.01 & 1.01 & 1.04 & 1.03 & 1.02 & 1.07 \\
\hline 8 & 4.89 & 0.96 & 0.94 & 1.00 & 0.98 & 0.98 & 1.11 \\
\hline 12 & 5.38 & $0.85^{* *}$ & $0.82^{* *}$ & $0.85 *$ & $0.85^{* *}$ & $0.86^{* *}$ & 1.15 \\
\hline 16 & 5.77 & $0.79 * *$ & $0.77^{* *}$ & $0.70 *$ & $0.75^{* *}$ & $0.76^{* *}$ & 1.13 \\
\hline
\end{tabular}

See Table 4.2.1 for table details.

\section{Effective Fed funds rate forecasts}

The results in Table 4.2.9 show that forecasts of the policy rate improve when yield curve data are added to the economic model. Statistically, the unrestricted macro-finance model is the strongest performing model, with improved forecast performance at all horizons. Economically, the largest forecast gains are from using the restricted macro-finance models.

Table 4.2.9: US full sample: effective Fed funds rate RMSFE

\begin{tabular}{|c|c|c|c|c|c|c|c|}
\hline Forecast & Macro BM & MF Un ${ }^{\dagger}$ & MF Partial & MF Full & MF 2F & MF 2F Partial & $\mathrm{AR}^{\dagger}$ \\
\hline 1 & 0.52 & $0.81^{* * *}$ & $0.88^{* *}$ & $0.86^{* * *}$ & $0.87^{* *}$ & $0.85^{* *}$ & $0.94^{* * *}$ \\
\hline 2 & 0.95 & $0.88^{* * *}$ & 0.94 * & $0.89^{* *}$ & $0.90 *$ & $0.88^{*}$ & $0.91^{* * *}$ \\
\hline 3 & 1.34 & $0.90^{* * *}$ & 0.95 & 0.90 & $0.90 *$ & $0.89 *$ & $0.90^{* * *}$ \\
\hline 4 & 1.72 & $0.92^{* * *}$ & 0.97 & 0.92 & 0.92 & $0.91 *$ & $0.89^{* * *}$ \\
\hline 8 & 2.79 & $0.98 *$ & 0.95 & 0.94 & 0.97 & 0.96 & $0.88^{* * *}$ \\
\hline 12 & 3.53 & $0.91^{* *}$ & $0.81^{* * *}$ & $0.81 *$ & $0.87^{* *}$ & $0.86^{* *}$ & $0.86^{* *}$ \\
\hline 16 & 4.05 & $0.84^{* *}$ & $0.71^{* * *}$ & $0.63^{* * *}$ & $0.79 * * *$ & $0.78^{* * *}$ & $0.80 * * *$ \\
\hline
\end{tabular}

See Table 4.2.1 for table details.

Overall, information from the three factor yield curve models improve the forecast for economic variables relative to the macro-only model. However, the strength of the result differs for individual variables. Forecasts for inflation and the policy rate show significant improvement, while capacity utilisation forecasts improve only for longer-horizon forecasts. 
Yield curve component forecasts

Consistent with the inflation forecast performance, the macro-finance models forecast performance deteriorate in the full sample (see Table 4.2.10). The best forecast performance comes from the restricted yields-only models, with the forecast gain reaching 25 percent when using the fully restricted yields-only model.

Table 4.2.10: US full sample: Level RMSFE

\begin{tabular}{llllllll}
\hline Forecast & Yields BM & LSB Partial & LSB Full & $\mathrm{MF} \mathrm{Un}^{\dagger}$ & MF Partial & MF Full & $\mathrm{AR}^{\dagger}$ \\
\hline 1 & 0.65 & $\mathbf{0 . 9 8}$ & $\mathbf{0 . 9 8}$ & 1.00 & $\mathbf{0 . 9 8}$ & 1.00 & $\mathbf{0 . 9 9}$ \\
2 & 0.89 & $\mathbf{0 . 9 8}$ & $\mathbf{0 . 9 7}$ & 1.00 & $\mathbf{0 . 9 7}$ & 1.00 & $\mathbf{0 . 9 9}$ \\
3 & 1.04 & $\mathbf{0 . 9 8}$ & $\mathbf{0 . 9 7}$ & 1.00 & $\mathbf{0 . 9 7}$ & 1.01 & 1.00 \\
4 & 1.19 & $\mathbf{0 . 9 9}$ & $\mathbf{0 . 9 7}$ & $\mathbf{0 . 9 9}$ & $\mathbf{0 . 9 8}$ & 1.02 & 1.01 \\
8 & 1.28 & 1.09 & $\mathbf{0 . 9 4}$ & $\mathbf{0 . 9 6}^{* *}$ & 1.03 & 1.07 & 1.07 \\
12 & 1.35 & 1.12 & $\mathbf{0 . 8 4} 4^{* * *}$ & $\mathbf{0 . 9 0}^{* *}$ & $\mathbf{0 . 9 9}$ & 1.06 & 1.07 \\
16 & 1.55 & 1.10 & $\mathbf{0 . 7 5} 5^{* * *}$ & $\mathbf{0 . 9 0}^{* * *}$ & $\mathbf{0 . 9 3}^{*}$ & $\mathbf{0 . 8 1} 1^{* * *}$ & 1.04 \\
\hline \hline
\end{tabular}

See Table 4.2.1 for table details.

The Slope and Bow forecast performance tests are in tables 4.2.11 and 4.2.12. These factors, which explain less of the variation in the yield curve, also show statistically and economically significant improvement in forecast performance from using alternative models. The Slope component results are consistent with the Level component, where the greatest forecast improvement comes from using restricted yields-only models. However, for the Bow component the macro-finance models provide the best forecast performance.

Table 4.2.11: US full sample: Slope RMSFE

\begin{tabular}{|c|c|c|c|c|c|c|c|}
\hline Forecast & Yields BM & LSB Partial & LSB Full & $\mathrm{MF} \mathrm{Un}^{\dagger}$ & MF Partial & MF Full & $\mathrm{AR}^{\dagger}$ \\
\hline 1 & 0.79 & 1.00 & 1.01 & $1.00 *$ & 1.02 & 1.00 & 1.02 \\
\hline 2 & 1.20 & 0.99 & 1.00 & 1.01 & 1.05 & 1.02 & 1.02 \\
\hline 3 & 1.57 & 0.98 & 0.99 & 1.04 & 1.08 & 1.06 & 1.00 \\
\hline 4 & 1.91 & 0.96 & 0.97 & 1.05 & 1.07 & 1.09 & 0.97 * \\
\hline 8 & 2.57 & $0.90^{* * *}$ & 0.94 & 1.08 & 1.06 & 1.17 & 0.92 * \\
\hline 12 & 3.00 & $0.81 * * *$ & $0.86^{* * *}$ & 1.01 & 0.98 & 1.13 & 0.93 \\
\hline 16 & 2.91 & $0.79 * * *$ & $0.85^{* * *}$ & $0.85^{* * *}$ & 0.78 * & 0.94 & 0.92 * \\
\hline
\end{tabular}

See Table 4.2.1 for table details. 
Table 4.2.12: US full sample: Bow RMSFE

\begin{tabular}{|c|c|c|c|c|c|c|c|}
\hline Forecast & Yields BM & LSB Partial & LSB Full & $\mathrm{MF} \mathrm{Un}^{\dagger}$ & MF Partial & MF Full & $\mathrm{AR}^{\dagger}$ \\
\hline 1 & 1.46 & 1.00 & 0.97 & 1.01 & 1.02 & 0.96 * & 1.00 \\
\hline 2 & 1.99 & 1.02 & 0.99 & 1.00 & 1.00 & 0.96 & 1.02 \\
\hline 3 & 2.27 & 1.05 & 0.99 & 0.97 & 0.97 & 0.93 * & 1.04 \\
\hline 4 & 2.47 & 1.08 & 1.00 & 0.96 & 0.96 & $0.90^{* *}$ & 1.07 \\
\hline 8 & 3.23 & 1.08 & 1.04 & 0.95 & 0.90 * & 0.91 & 1.08 \\
\hline 12 & 3.72 & 1.05 & 1.04 & $0.92 * *$ & $0.88^{* * *}$ & 0.89 * & 1.05 \\
\hline 16 & 4.07 & 1.02 & 1.04 & $0.91^{* *}$ & 0.89 ** & 0.89 * & 1.02 \\
\hline
\end{tabular}

See Table 4.2.1 for table details.

\subsection{Results summary}

To summarise the results I focus on economic significance and rank the models' forecasting performance for each variable. To further understand any practical benefit from using macro-finance models to forecast, I distinguish between two forecast horizons. The first is short-term forecasting, which I refer to as monitoring quarters. The monitoring quarters are defined as forecasts less than four quarters ahead, including the now-casts for inflation and activity, and reflect a period where policy changes are likely to have little effect. The second is the policy-relevant forecast horizon, which is the longer-term horizon that policy changes can effect. The policy-relevant forecast horizon is defined as from four to 16 quarters ahead.

For each variable that is forecast, the models are ranked from the lowest to highest RMSFE for each forecast period within the two forecast environment buckets (monitoring quarters and policy-relevant quarters). The model with the lowest RMSFE is given a 1, the second lowest is given a 2 and so fourth. The model with the lowest score in each of the forecasting environments is the best model in an economic sense and the model with the highest score is the lowest ranked. To gauge which model provides the best macro economic forecast, the rank for each macro forecast is summed and the model with the lowest overall score is the best macro economic model. The same exercise is 
done for the yield curve component forecasts to gauge which model provides the best yield curve forecast. In the tables below, the models are ranked from first (best) to seventh (worst). The final column ranks the overall score for the macroeconomic variables and yield curve components.

\subsubsection{Pre-GFC summary results}

Monitoring quarter forecasts

Monitoring quarter forecasts for inflation and the Fed funds rate are improved when using any of the macro-finance models considered (see Table 4.3.1). Indeed, for both cases, the macro-only benchmark model and the single equation AR(1) models rank last. However, information from the yield curve does not improve forecasts for activity relative to the benchmark macro-only model.

Taking into account how the models forecast macroeconomic variables overall shows the partially restricted three and two factor models provide the best forecasts. The AR(1) ranks last and the macro-only model is third to last.

Table 4.3.1: US pre-GFC: monitoring quarters, macro variables

\begin{tabular}{|c|c|c|c|c|}
\hline Rank & Inflation & Fed funds rate & Capacity Utilisation & Overall \\
\hline 1 & MF Partial & MF 2F Partial & Macro BM & MF Partial $=1$ \\
\hline 2 & MF 2F Partial & MF 2F & MF Partial & MF 2F Partial $=1$ \\
\hline 3 & MF Full & MF Un ${ }^{\dagger}$ & $\mathrm{MF}_{\mathrm{Un}}^{\dagger}$ & MF Full $=3$ \\
\hline 4 & MF 2F & MF Full & MF Full & $\mathrm{MF} \mathrm{Un}^{\dagger}=3$ \\
\hline 5 & MF Un ${ }^{\dagger}$ & MF Partial & MF 2F Partial $=5$ & Macro BM $=5$ \\
\hline 6 & Macro BM & Macro BM & $\mathrm{AR}^{\dagger}=5$ & $\mathrm{MF} 2 \mathrm{~F}=5$ \\
\hline 7 & $\mathrm{AR}^{\dagger}$ & $\mathrm{AR}^{\dagger}$ & MF 2F & $\mathrm{AR}^{\dagger}$ \\
\hline
\end{tabular}

For forecasting the yield curve components, the macro-finance models beat the yields-only model for the Level and Bow but the best models are the restricted yield curve models (see Table 4.3.2). Overall, the theoretically motivated yield curve restrictions (mean reversion parameters) improve the yield curve forecasts more so than the addition of macroeconomic variables in the model. 
The unrestricted macro-finance model is the worst performing model and the yields-only benchmark model is second to last.

Table 4.3.2: US pre-GFC: monitoring quarters, yield curve factors

\begin{tabular}{|c|c|c|c|c|}
\hline Rank & Level & Slope & Bow & Overall \\
\hline 1 & LSB Full & LSB Partial & LSB Full & LSB Full \\
\hline 2 & MF Partial & LSB Full = 2 & $\mathrm{AR}^{\dagger}$ & LSB Partial \\
\hline 3 & LSB Partial & Yields $\mathrm{BM}=2$ & LSB Partial & MF Partial \\
\hline 4 & MF Full & MF Full & MF Partial & $\mathrm{MF}$ Full $=4$ \\
\hline 5 & $\mathrm{AR}^{\dagger}$ & $\mathrm{MF} \mathrm{Un}^{\dagger}$ & MF Full & $\mathrm{AR}^{\dagger}=4$ \\
\hline 6 & $\mathrm{MF} \mathrm{Un}^{\dagger}$ & $\mathrm{AR}^{\dagger}$ & $\mathrm{MF} \mathrm{Un}^{\dagger}$ & Yields BM \\
\hline 7 & Yields BM & MF Partial & Yields BM & $\mathrm{MF} \mathrm{Un}^{\dagger}$ \\
\hline
\end{tabular}

\section{Policy relevant forecasts}

At the policy relevant forecast horizon, the partially restricted macro-finance model is the strongest performing model for inflation, the Fed funds rate, and activity (see Table 4.3.1). This suggests there is fundamental information in the yield curve that provides information at the policy relevant horizon for forecasting the ultimate outcomes of the macroeconomic variables considered. However, the weak performance of the unrestricted macro-finance model suggests fundamental information is best extracted using the theoretically motivated restrictions on the yield curve dynamics.

Table 4.3.3: US pre-GFC: policy relevant, macro variables

\begin{tabular}{llll|l}
\hline Rank & Inflation & Fed funds rate & Capacity Utilisation & Overall \\
\hline 1 & MF Partial & MF Partial & MF Partial & MF Partial \\
2 & MF 2F Partial & AR $^{\dagger}$ & Macro BM & MF 2F Partial $=2$ \\
3 & MF Full & MF 2F $=3$ & MF Full & Macro BM $=2$ \\
4 & MF 2F & Macro BM $=3$ & MF 2F Partial & MF Full $=4$ \\
5 & MF Un & MF 2F Partial & MF 2F & MF 2F $=4$ \\
6 & Macro BM $^{\dagger}$ & MF Full & MF Un $^{\dagger}$ & AR $^{\dagger}$ \\
7 & AR $^{\dagger}$ & MF Un $^{\dagger}$ & AR $^{\dagger}$ & MF Un $^{\dagger}$ \\
\hline \hline
\end{tabular}

The restrictions on the yield curve dynamics provide the best forecast for the yield curve factors, with the fully restricted yields-only model performing the 
best for the Level and the partially restricted yields-only model performing the best for the Slope and Bow (see Table 4.3.2). Relative to the unrestricted yields-only model, the macro-finance models generally outperform but not when compared to the restricted yield-only models.

Table 4.3.4: US pre-GFC: policy relevant, yield curve factors

\begin{tabular}{llll|l}
\hline Rank & Level & Slope & Bow & Overall \\
\hline 1 & LSB Full $^{\prime}$ & LSB Partial & LSB Partial & LSB Partial \\
2 & MF Un $^{\dagger}=2$ & AR $^{\dagger}$ & AR $^{\dagger}$ & LSB Full \\
3 & MF Partial $=2$ & LSB Full & MF Partial & MF Partial \\
4 & LSB Partial $=4$ & MF Partial & LSB Full & AR $^{\dagger}$ \\
5 & Yields BM $=4$ & Yields BM & MF Un & MF Un $^{\dagger}$ \\
6 & MF Full $_{7}$ & MF Un $^{\dagger}$ & Yields BM & Yields BM \\
7 & AR $^{\dagger}$ & MF Full & MF Full & MF Full \\
\hline \hline
\end{tabular}

\subsubsection{Full sample summary results}

\section{Monitoring quarter forecasts}

When extending to the full sample, including the zero lower bound period, the information from the yield curve is less important for forecasting inflation over the monitoring quarters (see Table 4.3.5). The benchmark macro-only model provides the strongest forecast performance for inflation and activity. However, the gain from incorporating yield curve information for the Fed funds rate continues to dominate. The macro-finance models all provide a better forecast performance for the Fed funds rate, with the partially restricted two-factor model providing the strongest forecast performance. 
Table 4.3.5: US full sample: monitoring quarters, macro variables

\begin{tabular}{llll|l}
\hline Rank & Inflation & Fed funds rate & Capacity Utilisation & Overall \\
\hline 1 & Macro BM $=1$ & MF 2F Partial $^{\dagger}$ & Macro BM & MF Un $^{\dagger}$ \\
2 & MF Partial $=1$ & MF Un $^{\dagger}$ & MF Partial & MF Partial $=2$ \\
3 & MF Un $^{\dagger}$ & MF Full & MF Un $^{\dagger}$ & Macro BM $=2$ \\
4 & MF 2F Partial & MF 2F $=4$ & MF Full & MF 2F Partial \\
5 & MF 2F & $\mathrm{AR}^{\dagger}=4$ & MF 2F Partial & MF Full \\
6 & MF Full & MF Partial & MF 2F & MF 2F \\
7 & AR $^{\dagger}$ & Macro BM & AR $^{\dagger}$ & AR $^{\dagger}$ \\
\hline \hline
\end{tabular}

Restrictions on the yields-only models continue to outperform for yield curve component forecasts, although in the case of the Level component the partially restricted macro-finance model is the strongest performing model (see Table 4.3.6). Overall, the restricted yields-only models provide the strongest forecast performance, followed by the restricted macro-finance models.

Table 4.3.6: US full sample: monitoring quarters, yield curve factors

\begin{tabular}{llll|l}
\hline Rank & Level & Slope & Bow & Overall \\
\hline 1 & MF Partial & LSB Partial & MF Full & LSB Full \\
2 & LSB Partial $=2$ & LSB Full & LSB Full & LSB Partial \\
3 & LSB Full $=2$ & Yields BM & Yields BM & MF Partial $=3$ \\
4 & AR $^{\dagger}$ & MF Un $^{\dagger}$ & MF Un \\
5 & MF Un $^{\dagger}$ & MF Full & MF Partial $=4$ & MF Full $=3$ \\
6 & MF Full $=6$ & AR $^{\dagger}$ & AR $^{\dagger}$ & MF Un $^{\dagger}=3$ \\
7 & Yields BM $=6$ & MF Partial & LSB Partial $^{\prime}$ & AR $^{\dagger}$ \\
\hline \hline
\end{tabular}

Policy relevant forecasts

Over the policy relevant horizon (see Table 4.3.7), the partially restricted macro-finance model is the best performing model for inflation and activity, while the fully restricted version is the best for the Fed funds rate. More generally, the macro-finance models outperform the macro-only model in every case for the macroeconomic variables. Economically, this is a stronger result compared to the pre-GFC period, where the macro-only model ranked second for activity forecasts (see Table 4.3 .3 for pre-GFC results). The restrictions on 
the yield curve component of the macro-finance model also continues to be an element in the best performing models.

Table 4.3.7: US full sample: policy relevant, macro variables

\begin{tabular}{llll|l}
\hline Rank & Inflation & Fed funds rate & Capacity Utilisation & Overall \\
\hline 1 & MF Partial & MF Full & MF Partial & MF Partial \\
2 & MF 2F Partial & AR $^{\dagger}$ & MF Un $^{\dagger}$ & MF Full $=2$ \\
3 & MF Full & MF 2F Partial $^{\prime}$ & MF 2F & MF 2F Partial =2 \\
4 & MF 2F & MF Partial & MF 2F Partial & MF 2F \\
5 & MF Un & MF 2F & MF Full & MF Un $^{\dagger}$ \\
6 & Macro BM $=6^{\dagger}$ & MF Un & Macro BM & AR $^{\dagger}$ \\
7 & AR $^{\dagger}=6$ & Macro BM & AR $^{\dagger}$ & Macro BM $^{\prime}$ \\
\hline \hline
\end{tabular}

Consistent with previous results, the restrictions on the yield curve elements in the models provide the best forecasting model for the yield curve components (see Table 4.3.8). For the Level, the fully restricted yields-only model is the best, for the Slope the partially restricted version is the best, and for the Bow the partially restricted macro-finance model is the best.

Table 4.3.8: US full sample: policy relevant, yield curve factors

\begin{tabular}{|c|c|c|c|c|}
\hline Rank & Level & Slope & Bow & Overall \\
\hline 1 & LSB Full & LSB Partial & MF Partial & LSB Full = 1 \\
\hline 2 & MF Un ${ }^{\dagger}$ & LSB Full & MF Full & MF Partial = 1 \\
\hline 3 & MF Partial & $\mathrm{AR}^{\dagger}$ & $\mathrm{MF} \mathrm{Un}^{\dagger}$ & MF Un ${ }^{\dagger}$ \\
\hline 4 & Yields BM & MF Partial & Yields BM & Yields BM \\
\hline 5 & MF Full & Yields BM & LSB Full & MF Full \\
\hline 6 & $\mathrm{AR}^{\dagger}$ & MF Un ${ }^{\dagger}$ & $\mathrm{AR}^{\dagger}$ & $\mathrm{AR}^{\dagger}=6$ \\
\hline 7 & LSB Partial & MF Full & LSB Partial & LSB Partial $=6$ \\
\hline
\end{tabular}

\subsection{Comparison with quasi real-time results}

In this section I present the key quasi-real-time results, comparing the results with the full real-time exercise ${ }^{4}$ and the results in the literature. For brevity,

\footnotetext{
${ }^{4}$ Full statistical results are available in Appendix B.
} 
only the full-sample results are presented but the pre-GFC sample period shows consistent themes and these results are available on request.

\section{Inflation forecasts}

In quasi real-time, the macro-finance models all significantly improve the forecast performance for inflation from eight quarters ahead (see Table 4.4.1). The forecast performances of the macro-finance models are comparable to the macro-only model at other horizons, although economically the unrestricted macro-finance model outperforms the macro-only model from two quarters ahead. This result it consistent with the full real-time forecast environment, with the partially restricted macro-finance providing the largest forecast gain overall (see Table 4.2.7 for the real-time forecast performance results).

Table 4.4.1: US full sample: inflation RMSFE

\begin{tabular}{|c|c|c|c|c|c|c|c|}
\hline Forecast & Macro BM & MF Un ${ }^{\dagger}$ & MF Partial & MF full & MF 2F & MF 2F Partial & $\mathrm{AR}^{\dagger}$ \\
\hline 1 & 0.74 & 1.03 & 1.01 & 1.04 & 1.02 & 1.02 & 1.07 \\
\hline 2 & 0.79 & $0.99 * *$ & 0.95 & 1.03 & 1.01 & 1.00 & 1.13 \\
\hline 3 & 0.82 & 1.02 & 0.97 & 1.10 & 1.05 & 1.04 & 1.20 \\
\hline 4 & 0.86 & 1.02 & 0.95 & 1.10 & 1.06 & 1.05 & 1.27 \\
\hline 8 & 1.21 & $0.86^{* * *}$ & $0.79 * * *$ & 0.83 * & $0.85^{* *}$ & $0.84^{* *}$ & 1.03 \\
\hline 12 & 1.47 & $0.80^{* * *}$ & $0.73^{* * *}$ & $0.76^{* *}$ & $0.76^{* * *}$ & $0.77^{* * *}$ & $0.87 *$ \\
\hline 16 & 1.52 & $0.74^{* * *}$ & $0.65^{* * *}$ & $0.71^{* * *}$ & $0.72^{* * *}$ & $0.73^{* * *}$ & 0.89 \\
\hline
\end{tabular}

See table 4.2.1 for table details.

\section{Capacity utilisation forecasts}

For capacity utilisation, Table 4.4.2 shows the macro-finance models outperform the macro-only model at all forecast horizons, consistent with the results found in the literature. However, this is a stronger result compared to the full real-time forecast environment. In particular, the forecast performance gain from using macro-finance models in full real-time disappears at the 0-4 quarter head forecast horizon (see Table 4.2.8 for the real-time forecast performance results). 
Table 4.4.2: US full sample: capacity utilisation RMSFE

\begin{tabular}{|c|c|c|c|c|c|c|c|}
\hline Forecast & Macro BM & MF Un ${ }^{\dagger}$ & MF Partial & MF full & MF 2F & MF 2F Partial & $\mathrm{AR}^{\dagger}$ \\
\hline 1 & 1.24 & $0.97^{* * *}$ & 0.95 * & 0.97 & $0.95^{* *}$ & $0.94^{* *}$ & 0.99 * \\
\hline 2 & 2.23 & $0.97^{* * *}$ & 0.96 & 0.97 & $0.94 *$ & 0.94 * & 0.98 * \\
\hline 3 & 3.14 & $0.96^{* * *}$ & 0.95 & 0.96 & 0.94 * & $0.94 *$ & 0.98 * \\
\hline 4 & 3.91 & $0.96^{* * *}$ & 0.95 & 0.96 & $0.94 *$ & 0.93 * & 0.99 * \\
\hline 8 & 5.58 & $0.92 * *$ & $0.90 * *$ & $0.90 *$ & $0.89^{* *}$ & $0.89^{* *}$ & 1.01 \\
\hline 12 & 6.61 & $0.84^{* *}$ & $0.83 * *$ & $0.78^{* * *}$ & $0.80^{* * *}$ & $0.81^{* * *}$ & 1.04 \\
\hline 16 & 7.66 & 0.80 * & 0.81 * & $0.73^{* *}$ & $0.75^{* * *}$ & $0.76^{* * *}$ & 1.03 \\
\hline
\end{tabular}

See table 4.2.1 for table details.

The forecast performance results between the two forecasting environments are similar for the Fed funds rate, Level component, and Bow component (see Appendix B for quasi real-time forecast performance results). The macro-finance models had a relatively stronger performance for the Slope component in the quasi real-time forecast environment compared to the full real-time exercise. This result is consistent with the forecast for capacity utilisation, which the Slope is conceptually related to.

Overall, the macro-finance models improve the forecast performance of the yield curve factors relative to the unrestricted yields-only model, which is a result consistent with the literature, however, placing restrictions on the yields-only models can further improve forecast performance. This result holds in both forecasting environments. 


\section{Chapter 5}

\section{NZ Model}

In New Zealand the trough of the policy rate was 2.5 percent. Since the lower bound for policy was never in effect I do not split the sample for the GFC. The sample period is 1994Q1 - 2014Q1 ${ }^{1}$.

\subsection{In-sample model fit}

Table 6.1.1 reports the in-sample fit results for the New Zealand models. The macro-finance models all give lower AIC results relative to the macro-only model, consistent with the US results, suggesting the macro-finance models provide a better fit to the economic model $^{2}$ (see Table 6.1.1). The yields-only models show a gain from restricting the yield curve dynamics but the gain is economically small.

\footnotetext{
${ }^{1}$ The pre-GFC models were also tested and the results are similar.

${ }^{2}$ The GDP growth version of the model showed the same results.
} 
Table 5.1.1: NZ full sample model fit: AIC

\begin{tabular}{lcc|lcc}
\hline \multicolumn{2}{c|}{ Yields-only } & \multicolumn{3}{c}{ Macro-finance } \\
\hline & & & & & Output gap \\
Yields-only & -1.08 & -0.72 & Macro-only & -4.24 & BIC \\
Partial & -1.09 & -0.88 & MF unrestricted & -7.70 & -3.64 \\
Full & $\mathbf{- 1 . 1 0}$ & -1.04 & MF Partial & -6.87 & -6.02 \\
& & & MF full & -6.71 & -5.64 \\
& & MF two factor & -6.79 & -5.63 \\
& & MF two factor Partial & -6.65 & -5.68 \\
& & &
\end{tabular}

See Table 3.2.1 for model name references. The bolded numbers indicate the top models.

\subsection{Real-time forecast performance}

The results below are presented in the same format as the US results, with the tables showing the relative forecast performance against the benchmark models. The benchmark model for the yield curve dynamics is the yields-only model and for the macro variables it is the macro-only model. CPI inflation forecast performance is measured in quarterly annual percent change, the output gap is in percentage deviation from potential, the exchange rate is in percent change, and the 90-day interest rate and yield curve components are in percentage levels.

Inflation forecasts

The unrestricted macro-finance model significantly improves the forecasts for inflation at all forecast horizons (see Table 5.2.1). The now-cast of inflation is significantly improved when using any of the macro-finance models (except for the two-factor partial restrictions). The AR(1) model provides the worst performance, underperforming the benchmark macro-only model and the macro-finance models. These results are similar to the US results, although stronger for the short-term forecasts (see Table 4.2.7 for US inflation forecast performance results). 
Table 5.2.1: NZ: inflation RMSFE

\begin{tabular}{llllllll}
\hline Forecast & Macro BM & MF Un & MF Partial & MF Full & MF 2F & MF 2F Partial & $\mathrm{AR}^{\dagger}$ \\
\hline 0 & 0.28 & $\mathbf{0 . 9 4} 4^{* * *}$ & $\mathbf{0 . 9 5} * * *$ & $\mathbf{0 . 9 6}$ * $^{* *}$ & 1.01 & 1.01 & 1.00 \\
1 & 0.36 & $\mathbf{0 . 9 2} * * *$ & $\mathbf{0 . 9 7}$ & $\mathbf{0 . 9 7}$ & 1.01 & 1.01 & 1.01 \\
2 & 0.45 & $\mathbf{0 . 9 0} * * *$ & $\mathbf{0 . 9 7}$ & $\mathbf{0 . 9 7}$ & $\mathbf{0 . 9 9}$ & $\mathbf{0 . 9 9}$ & 1.01 \\
3 & 0.54 & $\mathbf{0 . 9 0} * *$ & $\mathbf{0 . 9 5}$ & $\mathbf{0 . 9 7}$ & $\mathbf{0 . 9 7}$ & $\mathbf{0 . 9 7}$ & 1.01 \\
4 & 0.62 & $\mathbf{0 . 8 9}^{* *}$ & $\mathbf{0 . 9 4}$ & $\mathbf{0 . 9 6}$ & $\mathbf{0 . 9 4}$ & $\mathbf{0 . 9 4}$ & 1.01 \\
8 & 0.94 & $\mathbf{0 . 9 2} * *$ & $\mathbf{0 . 9 4}$ & $\mathbf{0 . 9 6}$ & $\mathbf{0 . 9 2}$ & $\mathbf{0 . 9 1}$ & 1.06 \\
12 & 1.17 & $\mathbf{0 . 9 4} * *$ & $\mathbf{0 . 9 9}$ & $\mathbf{0 . 9 7}$ & $\mathbf{0 . 9 4}$ & $\mathbf{0 . 9 3}$ & 1.18 \\
16 & 1.40 & $\mathbf{0 . 9 3} * *$ & 1.05 & 1.01 & $\mathbf{0 . 9 9}$ & $\mathbf{0 . 9 6}$ & 1.48 \\
\hline \hline
\end{tabular}

See Table 4.2.1 for table details.

Output gap forecasts

For the output gap, the macro-finance models outperform the macro-only model at only long-term horizons, from eight quarters out (see Table 5.2.2). The improvement is not statistically significant but economically the gain reaches 25 percent when using the unrestricted macro-finance model. However, the AR(1) provides the best real-time forecast performance.

Table 5.2.2: NZ: output gap RMSFE

\begin{tabular}{llllllll}
\hline Forecast & Macro BM & MF Un $^{\dagger}$ & MF Partial & MF Full & MF 2F & MF 2F Partial & AR $^{\dagger}$ \\
\hline 0 & 1.39 & 1.10 & 1.06 & 1.06 & 1.11 & 1.11 & $\mathbf{0 . 9 7}^{* *}$ \\
1 & 1.44 & 1.15 & 1.11 & 1.12 & 1.17 & 1.17 & $\mathbf{0 . 9 7}^{* *}$ \\
2 & 1.43 & 1.20 & 1.17 & 1.22 & 1.21 & 1.21 & 1.01 \\
3 & 1.51 & 1.21 & 1.20 & 1.29 & 1.21 & 1.22 & 1.00 \\
4 & 1.65 & 1.19 & 1.21 & 1.33 & 1.17 & 1.19 & $\mathbf{0 . 9 3}$ ** \\
8 & 2.20 & $\mathbf{0 . 9 9}$ & 1.08 & 1.29 & $\mathbf{0 . 9 5}$ & $\mathbf{0 . 9 8}$ & $\mathbf{0 . 7 6}$ * $^{*}$ \\
12 & 2.67 & $\mathbf{0 . 8 7}$ & 1.09 & 1.26 & $\mathbf{0 . 8 8}$ & $\mathbf{0 . 8 8}$ & $\mathbf{0 . 6 8}$ \\
16 & 3.46 & $\mathbf{0 . 7 6}$ & 1.22 & 1.32 & $\mathbf{0 . 8 3}$ & $\mathbf{0 . 8 4}$ & $\mathbf{0 . 5 7}$ \\
\hline \hline
\end{tabular}

See Table 4.2.1 for table details.

90-day rate forecasts

Macro-finance models improve the forecast performance for the 90-day rate at most horizons (see Table 5.2.3). These models also generally outperform the AR(1) model forecasts. These results are consistent with the US results, 
highlighting the usefulness of using the yield curve in conjunction with traditional macroeconomic models to forecast policy rates.

Table 5.2.3: NZ: 90-day interest rate RMSFE

\begin{tabular}{|c|c|c|c|c|c|c|c|}
\hline Forecast & Macro BM & $\mathrm{MF} \mathrm{Un}^{\dagger}$ & MF Partial & MF Full & MF 2F & MF 2F Partial & $\mathrm{AR}^{\dagger}$ \\
\hline 1 & 0.56 & $0.71^{* * *}$ & $0.89 * *$ & $0.85^{* *}$ & $0.77^{* *}$ & $0.74^{* *}$ & 1.03 \\
\hline 2 & 1.03 & $0.81^{* * *}$ & $0.90^{* *}$ & $0.80^{* * *}$ & $0.83^{* *}$ & $0.81^{* *}$ & $0.99 * * *$ \\
\hline 3 & 1.41 & $0.88^{* * *}$ & 0.91 * & $0.83^{* * *}$ & $0.88^{*}$ & $0.87^{* *}$ & $0.97^{* *}$ \\
\hline 4 & 1.73 & $0.95^{* *}$ & 0.95 & $0.88^{*}$ & 0.93 & 0.92 & $0.95^{* *}$ \\
\hline 8 & 2.36 & 1.13 & 1.10 & 1.22 & 1.01 & 1.03 & $0.99 *$ \\
\hline 12 & 2.98 & 1.00 & 1.00 & 1.20 & 0.90 & 0.92 & 0.94 \\
\hline 16 & 3.38 & $0.84 *$ & 0.94 & 1.12 & $0.83^{* *}$ & $0.83^{* *}$ & 0.93 \\
\hline
\end{tabular}

See Table 4.2.1 for table details.

Exchange rate forecasts

Table 5.2.4 shows the macro-finance models can improve the forecast performance for the exchange rate, particularly at longer horizons, but the gain is not statistically significant. The AR(1) model provides the most significant gain, consistent with the exchange rate forecasting literature that shows it is difficult to beat a simple single equation model.

Table 5.2.4: NZ: TWI exchange rate RMSFE

\begin{tabular}{llllllll}
\hline Forecast & Macro BM & MF Un $^{\dagger}$ & MF Partial & MF Full & MF 2F & MF 2F Partial & AR $^{\dagger}$ \\
\hline 1 & 4.38 & $\mathbf{0 . 9 9}$ & 1.03 & 1.02 & 1.02 & 1.03 & $\mathbf{0 . 9 7}^{\text {** }}$ \\
2 & 4.71 & 1.00 & 1.02 & 1.01 & 1.01 & 1.02 & $\mathbf{0 . 9 4}^{* * *}$ \\
3 & 4.74 & $\mathbf{0 . 9 9}$ & 1.03 & 1.03 & 1.01 & 1.02 & $\mathbf{0 . 9 1}^{* *}$ \\
4 & 4.61 & 1.00 & 1.02 & 1.04 & 1.00 & 1.01 & $\mathbf{0 . 9 3}^{* *}$ \\
8 & 4.81 & $\mathbf{0 . 9 7}$ & 1.06 & 1.08 & $\mathbf{0 . 9 5}$ & $\mathbf{0 . 9 5}$ & $\mathbf{0 . 9 0}$ \\
12 & 6.54 & $\mathbf{0 . 9 1}$ & 1.16 & 1.15 & $\mathbf{0 . 9 1}$ & $\mathbf{0 . 9 1}$ & $\mathbf{0 . 6 7}$ \\
16 & 8.36 & $\mathbf{0 . 8 3}$ & 1.31 & 1.20 & $\mathbf{0 . 8 8}$ & $\mathbf{0 . 8 9}$ & $\mathbf{0 . 5 2}$ \\
\hline \hline
\end{tabular}

See Table 4.2.1 for table details. 


\section{Yield curve component forecasts}

For the Level component, the macro-finance models do not improve the forecast performance (see Table 5.2.5). Indeed, the forecasts are materially worse than the unrestricted yields-only model. This result is in contrast to the US results (see Table 4.2.10) and the improvement in inflation forecasts from using the macro-finance models. However, the restricted yields-only models improve the forecast performance, with the partially restricted yields-only model significantly improving forecast performance and being the strongest performing model. This latter result is consistent with the US results.

Table 5.2.5: NZ: Level RMSFE

\begin{tabular}{|c|c|c|c|c|c|c|c|}
\hline Forecast & Yields BM & LSB Partial & LSB Full & $\mathrm{MF} \mathrm{Un}^{\dagger}$ & MF Partial & MF Full & $\mathrm{AR}^{\dagger}$ \\
\hline 1 & 0.57 & $0.97^{*}$ & 0.99 & 1.20 & 1.12 & 1.06 & 1.00 \\
\hline 2 & 0.78 & $0.94^{* *}$ & 0.98 & 1.22 & 1.14 & 1.12 & 0.99 \\
\hline 3 & 0.89 & $0.90^{* * *}$ & 0.94 & 1.17 & 1.09 & 1.06 & 0.98 \\
\hline 4 & 1.00 & $0.89^{* * *}$ & 0.92 & 1.18 & 1.10 & 1.10 & 0.97 \\
\hline 8 & 1.27 & $0.87^{* * *}$ & 0.87 * & 1.14 & 1.16 & 1.15 & $0.93^{* *}$ \\
\hline 12 & 1.36 & $0.92^{* * *}$ & 0.92 & 1.11 & 1.30 & 1.36 & 0.95 * \\
\hline 16 & 1.36 & $0.95^{* * *}$ & 0.94 & 1.17 & 1.65 & 1.85 & $0.99 * *$ \\
\hline
\end{tabular}

See Table 4.2.1 for table details.

Slope forecasts show some improvement from using macro-finance models at shorter-term forecast horizons but the improvement is not statistically significant (see Table 5.2.6). Consistent with the Level component and US results, the Slope and Bow component forecasts are improved when using restricted yields-only models (see Table 5.2.7 for Bow component forecast results). Indeed, for the majority of the Slope component forecasts and all the Bow component forecasts the macro-finance models materially deteriorate forecast performance. 
Table 5.2.6: NZ: Slope RMSFE

\begin{tabular}{|c|c|c|c|c|c|c|c|}
\hline Forecast & Yields BM & LSB Partial & LSB Full & $\mathrm{MF} \mathrm{Un}^{\dagger}$ & MF Partial & MF Full & $\mathrm{AR}^{\dagger}$ \\
\hline 1 & 0.84 & 0.90 ** & $0.88^{* *}$ & 1.03 & 0.99 & 0.93 & $0.97^{* * *}$ \\
\hline 2 & 1.33 & $0.90 *$ & $0.87^{*}$ & 1.04 & 1.02 & 0.99 & $0.98^{* *}$ \\
\hline 3 & 1.66 & 0.89 & 0.87 * & 1.01 & 0.98 & 0.98 & $0.98^{*}$ \\
\hline 4 & 1.93 & 0.91 & 0.89 & 1.04 & 0.99 & 1.05 & $0.96 *$ \\
\hline 8 & 2.32 & 0.95 & 0.98 & 1.09 & 1.09 & 1.32 & $0.96^{* *}$ \\
\hline 12 & 2.41 & 1.05 & 1.08 & 1.16 & 1.17 & 1.50 & 1.04 \\
\hline 16 & 2.54 & 1.03 & 1.05 & 1.13 & 1.19 & 1.54 & 1.02 \\
\hline
\end{tabular}

See Table 4.2.1 for table details.

Table 5.2.7: NZ: Bow RMSFE

\begin{tabular}{llllllll}
\hline Forecast & Yields BM & LSB Partial & LSB Full & $\mathrm{MF} \mathrm{Un}^{\dagger}$ & $\mathrm{MF}$ Partial & $\mathrm{MF} \mathrm{Full} \mathrm{AR}^{\dagger}$ \\
\hline 1 & 1.37 & $\mathbf{0 . 9 7}$ & $\mathbf{0 . 9 4}$ & 1.13 & 1.06 & 1.04 & $\mathbf{0 . 9 8}$ \\
2 & 1.70 & $\mathbf{0 . 9 7}$ & $\mathbf{0 . 9 2}$ & 1.06 & 1.03 & 1.06 & $\mathbf{0 . 9 8}$ \\
3 & 1.86 & $\mathbf{0 . 9 6}$ & $\mathbf{0 . 9 1}$ & 1.04 & 1.03 & 1.10 & $\mathbf{0 . 9 8}$ \\
4 & 1.99 & $\mathbf{0 . 9 7}$ & $\mathbf{0 . 9 6}$ & 1.04 & 1.07 & 1.29 & $\mathbf{0 . 9 7}$ \\
8 & 2.11 & $\mathbf{0 . 9 6}$ & $\mathbf{0 . 9 3}$ & 1.03 & 1.07 & 1.62 & $\mathbf{0 . 9 6}$ \\
12 & 2.20 & $\mathbf{0 . 9 8}$ & $\mathbf{0 . 9 8}$ & 1.09 & 1.24 & 2.25 & $\mathbf{0 . 9 8}$ \\
16 & 2.23 & 1.00 & 1.02 & 1.17 & 1.55 & 3.12 & 1.00 \\
\hline \hline
\end{tabular}

See Table 4.2.1 for table details.

\subsection{Results summary}

The tables below rank the forecast performance of the seven models for each variable, highlighting any economic gain from using macro-finance models for forecasting. Section 4.3 details how the rankings are calculated.

Monitoring quarter forecasts

At the monitoring quarter horizon, macro-finance models outperform the macro-only benchmark model and the AR(1) for inflation and the 90-day interest rate (see Table 5.3.1). The strongest performing model is the unrestricted macro-finance model. Although, adding in the restrictions on the yield curve dynamics still leads to the macro-finance models outperforming the macro-only 
and $\mathrm{AR}(1)$ models. For the exchange rate and the output gap, the AR model is the strongest performing model, suggesting the persistence in the variables own series is enough to generate the strongest forecasts.

Taking the forecast performance of all macroeconomic variables into account, overall, shows the macro-finance unrestricted and fully restricted models are the strongest performing models, with the $\mathrm{AR}(1)$ ranking third and the macro-only model ranking fourth.

Table 5.3.1: NZ: monitoring quarters, macro variables

\begin{tabular}{lllll|l}
\hline Rank & Inflation & 90-day rate & TWI & Output gap & Overall \\
\hline 1 & MF Un $^{\dagger}$ & MF Un $^{\dagger}=1$ & $\mathrm{AR}^{\dagger}$ & $\mathrm{AR}^{\dagger}$ & MF Un $^{\dagger}$ \\
2 & MF Partial & MF Full $=1$ & MF Un $^{\dagger}$ & Macro BM & MF Full \\
3 & MF Full & MF 2F Partial & Macro BM & MF Partial & AR $^{\dagger}$ \\
4 & MF 2F $=4$ & MF 2F & MF 2F & MF Un & Macro BM \\
5 & MF 2F Partial $=4$ & MF Partial & MF Full & MF Full & MF Partial \\
6 & Macro BM & AR $^{\dagger}$ & MF 2F Partial & MF 2F & MF 2F \\
7 & AR $^{\dagger}$ & Macro BM & MF Partial & MF 2F Partial & MF 2F Partial \\
\hline \hline
\end{tabular}

For the yield curve components, the restricted yields-only models provide the strongest forecasts (see Table 5.3.2). The partially restricted yields-only model is the strongest for the Level, and the fully restricted version is the best for the Slope and Bow. Although, the alternatively restricted yields-only models are the second best models in each case. Overall, the macro-finance models score below the yields-only models and the AR(1) models.

Table 5.3.2: NZ: monitoring quarters, yield curve factors

\begin{tabular}{llll|l}
\hline Rank & Level & Slope & Bow & Overall \\
\hline 1 & LSB Partial & LSB Full & LSB Full & LSB Full \\
2 & LSB Full & LSB Partial & LSB Partial & LSB Partial \\
3 & AR $^{\dagger}$ & AR $^{\dagger}$ & AR $^{\dagger}$ & AR $^{\dagger}$ \\
4 & Yields BM & MF Full & Yields BM & Yields BM \\
5 & MF Full & MF Partial & MF Partial & MF Full \\
6 & MF Partial & Yields BM & MF Full $=6$ & MF Partial \\
7 & MF Un $^{\dagger}$ & MF Un $^{\dagger}$ & MF Un $^{\dagger}=6$ & MF Un $^{\dagger}$ \\
\hline \hline
\end{tabular}




\section{Policy relevant horizon}

At the policy relevant forecast horizon, the partially restricted two factor macro-finance model provides the best forecast performance for inflation and the unrestricted two factor model provides the best forecast performance for the 90-day interest rate (see Table 5.3.3). For inflation, the macro-finance models all outperform the macro-only and AR(1) models. Meanwhile, for the 90-day rate the macro-only and $\mathrm{AR}(1)$ models outperform the three factor macro-finance models.

As in to the monitoring quarter case, the AR models give the best forecast performance for the exchange rate and the output gap. However, the macro-finance models generally provide a stronger performance compared to the macro-only model, suggesting there is valuable information in bond yields.

Table 5.3.3: NZ: policy relevant, macro variables

\begin{tabular}{lllll|l}
\hline Rank & Inflation & 90-day rate & TWI & Output gap & Overall \\
\hline 1 & MF 2F Partial & MF 2F & AR $^{\dagger}$ & AR $^{\dagger}$ & MF 2F $=1$ \\
2 & MF Un $^{\dagger}$ & MF 2F Partial & MF 2F Partial & MF 2F & MF 2F Partial =1 \\
3 & MF 2F & AR $^{\dagger}$ & MF 2F & MF Un $^{\dagger}$ & AR $^{\dagger}$ \\
4 & MF Full & Macro BM & MF Un & MF 2F Partial & MF Un $^{\dagger}$ \\
5 & MF Partial & MF Partial & Macro BM & Macro BM & Macro BM \\
6 & Macro BM & MF Un & MF Partial & MF Partial & MF Partial \\
7 & AR $^{\dagger}$ & MF Full & MF Full & MF Full & MF Full \\
\hline \hline
\end{tabular}

For the Level and Bow components, the partially restricted yields-only model is the highest ranking model (see Table 5.3.4). This model also ranks as the best model overall for forecasting bond yields. For the Slope component, the AR(1) is the best, followed by the partially restricted yields-only model.

Overall, the macro-finance models rank below the yield-only modles. This result is consistent with the NZ monitoring quarters shown in the previous section. The inability of the macro-finance models to beat the unrestricted yields-only model is in contrast to the US results and the international literature on yield curve forecasting ${ }^{3}$.

\footnotetext{
${ }^{3}$ An area for future work could involve analysing the liquidity in New Zealand government
} 
Table 5.3.4: NZ: policy relevant, yield curve factors

\begin{tabular}{llll|l}
\hline Rank & Level & Slope & Bow & Overall \\
\hline 1 & LSB Partial & AR $^{\dagger}$ & LSB Partial & LSB Partial \\
2 & LSB Full & LSB Partial & LSB Full $=2^{\dagger}$ & AR $^{\dagger}$ \\
3 & AR $^{\dagger}$ & Yields BM & AR $^{\dagger}=2$ & LSB Full $^{\prime}$ \\
4 & Yields BM & LSB Full & Yields BM $^{\dagger}$ & Yields BM \\
5 & MF Un $^{\dagger}$ & MF Un $^{\dagger}$ & MF Un $^{\dagger}$ & MF Un \\
6 & MF Partial & MF Partial & MF Partial & MF Partial \\
7 & MF Full & MF Full & MF Full & MF Full \\
\hline \hline
\end{tabular}

\subsection{Comparison with quasi real-time results}

This section compares the quasi real-time and full real-time forecast environments, focusing on the key results.

Inflation forecasts

The macro-finance models' forecast performance for inflation is slightly stronger in the quasi real-time environment (see Table 5.4.1) compared to the full real-time forecast environment (see Table 5.2.1). In the full real-time forecast environment the forecast gain from using macro-finance models peaks at 11 percent when using the unrestricted macro-finance model. However, the benefit peaks at 31 in the quasi real-time environment when using the partially restricted two-factor macro-finance model. These results suggest that the forecast gain from using macro-finance models to forecast inflation is a robust finding but using a quasi real-time environment to assess the benefit could result in using a two-factor macro-finance model, which does not perform as strongly as the unrestricted three-factor model across most forecast horizons in real-time. In addition, the AR(1) model provides the strongest forecast performance in quasi real-time but is systematically outperformed by macro-finance and macro-only models in the full real-time environment.

bond yields. 
Table 5.4.1: NZ: inflation RMSFE

\begin{tabular}{llllllll}
\hline Forecast & Macro BM & MF Un & MF Partial & MF full & MF 2F & MF 2F Partial & $\mathrm{AR}^{\dagger}$ \\
\hline 1 & 0.11 & $\mathbf{0 . 9 4} 4^{* * *}$ & 1.02 & 1.01 & 1.03 & 1.03 & $\mathbf{0 . 9 4}$ \\
2 & 0.21 & $\mathbf{0 . 9 4} 4^{* *}$ & 1.01 & 1.03 & $\mathbf{0 . 9 9}$ & $\mathbf{0 . 9 9}$ & $\mathbf{0 . 9 6}$ * $^{*}$ \\
3 & 0.31 & $\mathbf{0 . 9 5 * *}$ & 1.01 & 1.05 & $\mathbf{0 . 9 6}$ & $\mathbf{0 . 9 6}$ & $\mathbf{0 . 9 5}^{*}$ \\
4 & 0.41 & $\mathbf{0 . 9 6}^{*}$ & $\mathbf{0 . 9 9}$ & 1.05 & $\mathbf{0 . 9 3}$ & $\mathbf{0 . 9 4}$ & $\mathbf{0 . 9 3}^{*}$ \\
8 & 0.81 & $\mathbf{0 . 9 8}$ & $\mathbf{0 . 9 3}$ & 1.05 & $\mathbf{0 . 8 4}{ }^{*}$ & $\mathbf{0 . 8 5}$ & $\mathbf{0 . 8 3}$ \\
12 & 1.21 & $\mathbf{0 . 9 4}$ & $\mathbf{0 . 8 6}$ * $^{*}$ & 1.03 & $\mathbf{0 . 7 9}$ & $\mathbf{0 . 7 9}$ & $\mathbf{0 . 7 8}$ \\
16 & 1.85 & $\mathbf{0 . 8 7}$ & $\mathbf{0 . 7 7}$ & 1.06 & $\mathbf{0 . 7 0}$ & $\mathbf{0 . 6 9}$ & $\mathbf{0 . 6 7}$ \\
\hline \hline
\end{tabular}

See table 4.2.1 for table details.

\section{Output gap forecasts}

Consistent with the full real-time environment, the macro-finance models improve the forecast performance for the output gap at long horizons but not at other forecast horizons (see Table 5.4.2 for the quasi real-time results and Table 5.2.2 for full real-time results). In both forecast environments the two factor macro-finance models provide the best forecasts out of the macro-finance models, with the gain peaking at 12 percent. However, the $\operatorname{AR}(1)$ provides the best forecast performance over the majority of the forecast horizons, which is consistent with the full real-time forecast environment.

Table 5.4.2: NZ: output gap RMSFE

\begin{tabular}{|c|c|c|c|c|c|c|c|}
\hline Forecast & Macro BM & $\mathrm{MF} \mathrm{Un}^{\dagger}$ & MF Partial & MF full & MF 2F & MF 2F Partial & $\mathrm{AR}^{\dagger}$ \\
\hline 1 & 0.63 & 1.06 & 1.11 & 1.14 & 1.07 & 1.09 & 1.00 \\
\hline 2 & 1.02 & 1.06 & 1.12 & 1.19 & 1.07 & 1.10 & $0.99^{* *}$ \\
\hline 3 & 1.35 & 1.08 & 1.14 & 1.25 & 1.07 & 1.11 & $0.94^{* *}$ \\
\hline 4 & 1.72 & 1.10 & 1.13 & 1.25 & 1.06 & 1.10 & $0.86^{* * *}$ \\
\hline 8 & 2.51 & 1.05 & 1.03 & 1.18 & 0.96 & 0.98 & $0.78^{* * *}$ \\
\hline 12 & 2.85 & 1.00 & 0.97 & 1.07 & 0.96 & 0.96 & $0.77^{* * *}$ \\
\hline 16 & 3.62 & $0.94 *$ & $0.90^{* * *}$ & 1.20 & 0.90 & $0.88^{* *}$ & $0.64^{* * *}$ \\
\hline
\end{tabular}

See table 4.2.1 for table details.

\section{TWI exchange rate forecasts}

Table 5.4.3 shows macro-finance models significantly improve the forecast performance of the TWI exchange rate from four quarters ahead relative 
to the benchmark macro-only model, with the gain peaking at 29 percent, however the AR(1) outperforms all models. The macro-finance models have a stronger performance in the quasi real-time forecast environment, with the full real-time environment showing economically better forecast performance at longer horizons for some model specifications but the improvement is not statistically significant (see Table 5.2.4 for the real-time forecast performance results).

Table 5.4.3: NZ: TWI exchange rate RMSFE

\begin{tabular}{|c|c|c|c|c|c|c|c|}
\hline Item & Macro BM & $\mathrm{MF} \mathrm{Un}^{\dagger}$ & MF Partial & MF Full & MF 2F & MF 2F Partial & $\mathrm{AR}^{\dagger}$ \\
\hline 1 & 4.53 & 0.99 & 1.01 & 1.01 & 1.02 & 1.02 & $0.94^{* *}$ \\
\hline 2 & 4.88 & 1.01 & 1.01 & 1.00 & 1.02 & 1.02 & $0.91^{* *}$ \\
\hline 3 & 4.89 & 1.01 & 1.00 & 1.01 & 1.00 & 1.00 & $0.88^{* *}$ \\
\hline 4 & 4.70 & $0.98^{* *}$ & 0.98 & 0.99 & 0.98 & 0.98 & $0.91^{* * *}$ \\
\hline 8 & 5.08 & $0.99^{* *}$ & $0.93^{* * *}$ & 0.96 & $0.93^{* *}$ & $0.91^{* *}$ & $0.85^{* * *}$ \\
\hline 12 & 6.32 & $0.97^{*}$ & 0.89 * & 1.09 & 0.81 & 0.79 * & $0.69 * *$ \\
\hline 16 & 8.38 & 0.90 * & $0.81 *$ & 1.22 & $0.71 *$ & 0.68 * & $0.52 *$ \\
\hline
\end{tabular}

See table 4.2.1 for table details.

The forecast performance results are broadly similar between the two forecast environments for the other variables considered. Forecasts for the policy rate can be improved using macro-finance models, which embody the entire yield curve. In some cases the macro-finance models can improve the forecasts for the yield curve components compared to the unrestricted yields-only model, which is a stronger result than in the full real-time environment. However, the restricted yield-only models consistently provide the best forecast performance, consistent with the full real-time environment. 


\section{Chapter 6}

\section{Open Economy Model}

In this section, the New Zealand model is extended to include US yield curve components, thus modelling New Zealand as a small open economy with financial links to the United States. This is an initial step at a macro-finance model for a small open economy, using an extension of the set-up already used for the New Zealand economy in Chapter 5. Another approach would be to model global yield curves as in Diebold, Li, and Yue (2008) and then include macroeconomic variables to create a macro-finance model. Additionally, estimating a relative yield curve model could be beneficial for forecasting the exchange rate, making the model internally consistent with uncovered interest rate parity, as used in Yu-chin and Tsang (2013). However, the authors' model does not extend to the zero lower bound period or include macroeconomic variables. Modeling a relative yield curve using the latent factor approach where one country faces the zero lower bound is an area left for future research.

\subsection{In-sample model fit}

The in-sample fit of the models suggest that financial links macro-finance models add valuable information, with the AIC and BIC scores both lower for the financial links macro-finance models compared to the benchmark open 
macro-only model (see Table 6.1.1).

Table 6.1.1: Open economy full sample model fit: AIC

\begin{tabular}{llr}
\hline & \multicolumn{2}{c}{ Macro-finance } \\
\hline & AIC & Output gap \\
& BIC \\
Open macro-only & -3.69 & -3.09 \\
FL unrestricted & $\mathbf{- 1 0 . 7 7}$ & -8.61 \\
FL partial & $\mathbf{- 1 0 . 6 9}$ & -8.86 \\
FL full & $\mathbf{- 1 0 . 4 7}$ & -8.82 \\
FL two fac & -9.02 & -7.07 \\
FL two fac Partial & $-\mathbf{- 9 . 0 7}$ & -7.24 \\
\hline \hline
\end{tabular}

See Table 3.2.1 for model name references. The bolded numbers indicate the top models.

\subsection{Real-time forecast performance}

Inflation forecasts

The results in Table 6.2.1 show the financial links macro-finance models can improve inflation forecasts at most horizons. The unrestricted and partially restricted financial links models provide statistically significant improvement in longer-term forecasts. The forecast performance of the open and closed economy macro-only models are largely comparable at most horizons, although the closed economy version is statistically better at short-term horizons. The ability of the unrestricted and partially restricted financial links models to outperform the two macro-only models suggests there is value in incorporating international financial linkages. 
Table 6.2.1: Open econ: inflation RMSFE

\begin{tabular}{|c|c|c|c|c|c|c|c|c|}
\hline Forecast & Macro Open BM & FL Un & FL Partial & FL Full & FL 2F & FL 2F Partial & Closed $^{\dagger}$ & $\mathrm{AR}^{\dagger}$ \\
\hline 0 & 0.30 & 0.96 & $0.96 *$ & $0.95 *$ & 0.98 & 0.98 & 0.98 & 0.96 \\
\hline 1 & 0.38 & 0.97 & 0.97 & 0.97 & 1.02 & 1.02 & $0.98^{*}$ & $0.97^{* *}$ \\
\hline 2 & 0.46 & 0.99 & 0.98 & 0.99 & 1.08 & 1.09 & $0.99 *$ & $0.98^{*}$ \\
\hline 3 & 0.55 & 1.02 & 1.00 & 1.03 & 1.12 & 1.15 & 1.00 & $0.98 *$ \\
\hline 4 & 0.64 & 1.04 & 1.01 & 1.07 & 1.12 & 1.19 & 1.00 & 0.98 ** \\
\hline 8 & 0.96 & 0.96 & 0.93 & 1.23 & 0.97 & 1.34 & 1.02 & 1.02 \\
\hline 12 & 1.21 & $0.89^{* *}$ & $0.87 * *$ & 1.27 & 0.93 & 1.66 & 1.06 & 1.13 \\
\hline 16 & 1.28 & $0.89^{* * *}$ & $0.87^{* * *}$ & 1.42 & 1.04 & 2.15 & $1.35 *$ & 1.60 \\
\hline
\end{tabular}

See Table 4.2.1 for table details.

Output gap forecasts

Generally, the financial links macro-finance models do not improve the forecast performance for the output gap (see Table 6.2.2). There is small economic forecast improvement for longer-term forecasts when using the partially restricted financial links model. However, the AR(1) model provides the best forecast performance, with the gain peaking at 29 percent, followed by the closed economy model for one to four quarters head.

Table 6.2.2: Open econ: output gap RMSFE

\begin{tabular}{lllllllll}
\hline Forecast & Macro Open BM & FL Un & FL Partial & FL Full & FL 2F & FL 2F Partial & Closed $^{\dagger}$ & AR $^{\dagger}$ \\
\hline 0 & 1.37 & 1.15 & 1.13 & 1.13 & 1.20 & 1.19 & 1.00 & $\mathbf{0 . 9 7}$ \\
1 & 1.47 & 1.22 & 1.19 & 1.19 & 1.29 & 1.30 & $\mathbf{0 . 9 7}^{*}$ & $\mathbf{0 . 9 4}^{* * *}$ \\
2 & 1.61 & 1.23 & 1.18 & 1.21 & 1.36 & 1.40 & $\mathbf{0 . 9 1}^{* *}$ & $\mathbf{0 . 9 0}$ \\
3 & 1.84 & 1.21 & 1.12 & 1.19 & 1.44 & 1.51 & $\mathbf{0 . 8 8}^{* *}$ & $\mathbf{0 . 8 2}^{* *}$ \\
4 & 2.10 & 1.17 & 1.07 & 1.16 & 1.52 & 1.64 & $\mathbf{0 . 9 0}^{* * *}$ & $\mathbf{0 . 7 3}$ \\
8 & 2.36 & 1.03 & $\mathbf{0 . 9 9}$ & 1.11 & 1.94 & 2.04 & 1.21 & $\mathbf{0 . 7 1}$ \\
12 & 2.54 & 1.02 & $\mathbf{0 . 9 9}$ & 1.47 & 2.19 & 1.98 & 1.63 & $\mathbf{0 . 7 2}$ \\
16 & 2.70 & 1.00 & $\mathbf{0 . 9 7}$ & 1.65 & 2.35 & 6.82 & 2.46 & $\mathbf{0 . 7 2}$ \\
\hline \hline
\end{tabular}

See Table 4.2 .1 for table details.

\section{Policy rate forecasts}

Economically, the financial links macro-finance models improve the forecast performance for the 90-day interest rate (see Table 6.2.3). The improvement 
is statistically significant for longer-term forecasts when using the unrestricted and partially restricted financial links macro-finance models, with the improvement peaking at around 20 percent. However, the largest improvement from a statistical point of view comes from using an AR(1) model.

Table 6.2.3: Open econ: 90-day interest rate RMSFE

\begin{tabular}{|c|c|c|c|c|c|c|c|c|}
\hline Forecast & Macro Open BM & FL Un & FL Partial & FL Full & FL 2F & FL 2F Partial & Closed $^{\dagger}$ & $\mathrm{AR}^{\dagger}$ \\
\hline 1 & 0.49 & 1.05 & 1.04 & 0.97 & 0.89 & 0.89 & 1.08 & 1.16 \\
\hline 2 & 0.96 & 0.98 & 0.99 & 0.91 & 1.00 & 1.06 & 1.04 & 1.06 \\
\hline 3 & 1.44 & 0.91 & 0.89 & 0.92 & 1.02 & 1.21 & 0.98 & $0.95^{* * *}$ \\
\hline 4 & 1.91 & 0.91 & 0.88 & 0.94 & 1.05 & 1.33 & 0.92 & $0.86^{* * *}$ \\
\hline 8 & 3.20 & 1.00 & 0.90 & 1.12 & 1.37 & 2.09 & $0.79 * *$ & $0.73^{* * *}$ \\
\hline 12 & 3.47 & 0.86 & 0.82 & 0.98 & 1.72 & 2.46 & 0.99 & $0.81 *$ \\
\hline 16 & 3.45 & $0.78^{* * *}$ & $0.83^{* * *}$ & 1.04 & 2.16 & 3.00 & 1.30 & $0.91 *$ \\
\hline
\end{tabular}

See Table 4.2.1 for table details.

\section{Exchange rate forecasts}

Of the models considered, the financial links macro-finance models do not improve the forecast performance for the exchange rate (see Table 6.2.4). Indeed, the 'closed' economy version (where the US yield curve factors and economic variables are not used) slightly outperform the benchmark macro-only open economy model. The AR forecast of the exchange rate systematically outperforms all models.

Table 6.2.4: Open econ: NZD/USD exchange rate RMSFE

\begin{tabular}{lllllllll}
\hline Forecast & Macro Open BM & FL Un & FL Partial & FL Full & FL 2F & FL 2F Partial & Closed $^{\dagger}$ & AR $^{\dagger}$ \\
\hline 1 & 6.39 & 1.04 & 1.02 & 1.03 & 1.05 & 1.04 & $\mathbf{0 . 9 5}^{* *}$ & $\mathbf{0 . 9 1}$ \\
2 & 7.48 & 1.03 & 1.00 & 1.03 & 1.06 & 1.06 & $\mathbf{0 . 9 1}^{* *}$ & $\mathbf{0 . 8 6}^{* * *}$ \\
3 & 7.61 & 1.01 & $\mathbf{0 . 9 5}$ & 1.02 & 1.09 & 1.14 & $\mathbf{0 . 9 1}^{* *}$ & $\mathbf{0 . 8 2}^{* *}$ \\
4 & 7.16 & $\mathbf{0 . 9 8}$ & $\mathbf{0 . 9 5}$ & 1.02 & 1.13 & 1.23 & $\mathbf{0 . 9 4}^{* *}$ & $\mathbf{0 . 8 6}^{* * *}$ \\
8 & 6.16 & 1.09 & 1.07 & 1.32 & 1.34 & 1.19 & 1.06 & 1.03 \\
12 & 7.66 & $\mathbf{0 . 9 7}$ & $\mathbf{0 . 9 4} * *$ & 1.18 & 1.53 & 2.24 & 1.12 & $\mathbf{0 . 8 3}$ \\
16 & 6.87 & 1.04 & 1.00 & 1.33 & 1.70 & 6.52 & 1.81 & $\mathbf{0 . 9 1}$ \\
\hline \hline
\end{tabular}

See Table 4.2.1 for table details. 


\section{Yield curve component forecasts}

The unrestricted and partially restricted financial links models show some improvement in forecast performance for longer-term forecasts for the Level component relative to the benchmark model (see Table 6.2.5). The open-economy macro-finance models do not improve the forecast performance of the Slope component (see Table 6.2.6). However, consistent with the results for the United States and the New Zealand-only models, the best models for forecasting yield curve components are the restricted yield-only models.

Table 6.2.5: Open econ: Level RMSFE

\begin{tabular}{|c|c|c|c|c|c|c|c|}
\hline Forecast & Yields BM & LSB Partial & LSB Full & $\mathrm{FL} \mathrm{Un}^{\dagger}$ & FL Partial & FL Full & $\mathrm{AR}^{\dagger}$ \\
\hline 1 & 0.57 & $0.97 *$ & 0.99 & 1.32 & 1.19 & 1.17 & 1.00 \\
\hline 2 & 0.78 & $0.94^{* *}$ & 0.98 & 1.47 & 1.28 & 1.36 & 0.99 \\
\hline 3 & 0.89 & $0.90^{* * *}$ & 0.94 & 1.47 & 1.26 & 1.47 & 0.98 \\
\hline 4 & 1.00 & $0.89 * * *$ & 0.92 & 1.51 & 1.29 & 1.67 & 0.97 \\
\hline 8 & 1.27 & $0.87^{* * *}$ & $0.87 *$ & 1.13 & 1.13 & 1.46 & $0.93 *$ \\
\hline 12 & 1.36 & $0.92^{* * *}$ & 0.92 & $0.98^{* * *}$ & 1.02 & 1.20 & $0.95 *$ \\
\hline 16 & 1.36 & $0.95^{* * *}$ & 0.94 & $0.95^{* * *}$ & 0.96 * & 1.26 & $0.99^{* *}$ \\
\hline
\end{tabular}

See Table 4.2.1 for table details.

Table 6.2.6: Open econ: Slope RMSFE

\begin{tabular}{llllllll}
\hline Forecast & LSB BM & LSB Partial & LSB Full & FL Un $^{\dagger}$ & FL Partial & FL Full & AR $^{\dagger}$ \\
\hline 1 & 0.84 & $\mathbf{0 . 9 0 * *}$ & $\mathbf{0 . 9 0}$ & 1.17 & 1.09 & 1.02 & $\mathbf{0 . 9 7}^{* * *}$ \\
2 & 1.33 & $\mathbf{0 . 9 0}$ & $\mathbf{0 . 9 1}$ & 1.16 & 1.09 & 1.07 & $\mathbf{0 . 9 8}^{*}$ \\
3 & 1.66 & $\mathbf{0 . 8 9}$ & $\mathbf{0 . 9 4}$ & 1.10 & 1.07 & 1.15 & $\mathbf{0 . 9 8}^{*}$ \\
4 & 1.93 & $\mathbf{0 . 9 1}$ & $\mathbf{0 . 9 7}$ & 1.05 & 1.04 & 1.18 & $\mathbf{0 . 9 6}^{*}$ \\
8 & 2.32 & $\mathbf{0 . 9 5}$ & 1.10 & 1.23 & 1.14 & 1.29 & $\mathbf{0 . 9 6}{ }^{* *}$ \\
12 & 2.41 & 1.05 & 1.31 & 1.09 & 1.04 & 1.33 & 1.04 \\
16 & 2.54 & 1.03 & 1.30 & 1.08 & 1.10 & 1.36 & 1.02 \\
\hline \hline
\end{tabular}

See Table 4.2.1 for table details. 


\subsection{Results summary}

The tables below rank the forecast performance of the eight models for each variable, highlighting the economic significance of using macro-finance models for forecasting. Section 4.3 details how the rankings are calculated.

Monitoring quarter forecasts

At the monitoring quarter forecast horizon, the AR(1) models provide the best forecast performance for inflation, the exchange rate and the output gap (see Table 6.3.1). However, for inflation and the exchange rate, the three factor financial links models outperform the benchmark open economy model and the closed economy model in some specifications. For inflation, all three of the three factor financial links models outperform, while for the exchange rate the partially restricted financial links model outperforms. For the 90-day interest rate, all the financial links models, except the partially restricted two factor version, outperform the benchmark open macro-only model.

Taking into account the overall forecast performance for the macroeconomic variables, the partially restricted financial links model is the strongest performing model, followed by the AR(1) models. The benchmark open macro-only model ranks fifth, outperforming the two factor financial links models.

Table 6.3.1: Open econ: monitoring quarters, macro variables

\begin{tabular}{lllll|l}
\hline Rank & Inflation & 90-day rate & NZD/USD & Output gap & Overall \\
\hline 1 & AR $^{\dagger}$ & FL Full & $\mathrm{AR}^{\dagger}$ & $\mathrm{AR}^{\dagger}$ & FL Partial $^{\dagger}$ \\
2 & FL Partial & FL Partial & Closed $^{\dagger}$ & Closed $^{\dagger}$ & $\mathrm{AR}^{\dagger}$ \\
3 & FL Un & FL Un & FL Partial & Macro Open BM & FL Full $^{\dagger}$ \\
4 & FL Full $^{\dagger}$ & FL 2F & Macro Open BM & FL Partial & Closed $^{\dagger}$ \\
5 & Closed $^{\dagger}$ & Macro Open BM & FL Full & FL Full & FL Un $=5$ \\
6 & Macro Open BM & FL 2F Partial & FL Un & FL Un & Macro Open BM =5 \\
7 & FL 2F & Closed $^{\dagger}$ & FL 2F $=7$ & FL 2F & FL 2F \\
8 & FL 2F Partial & AR $^{\dagger}$ & FL 2F Partial $=7$ & FL 2F Partial & FL 2F Partial \\
\hline \hline
\end{tabular}

Consistent with previous results, the restricted yields-only models give 
the strongest forecast performance for yield curve factors (see Table 6.3.2). However, the benchmark yields-only model outperforms all the macro-finance models. Augmenting the models with US yield curve information and New Zealand macroeconomic variables does not improve the forecast performance. Similar results were found for the New Zealand model in Section 5.

Table 6.3.2: Open econ: monitoring quarters, yield curve factors

\begin{tabular}{lll|l}
\hline Rank & NZ Level & NZ Slope & Overall \\
\hline 1 & LSB Partial & LSB Partial & LSB Partial \\
2 & LSB Full & LSB Full $^{\dagger}$ & LSB Full $^{\dagger}$ \\
3 & AR $^{\dagger}$ & AR $^{\dagger}$ & AR $^{\dagger}$ \\
4 & Yields BM & Yields BM & Yields BM \\
5 & FL Partial & FL Partial $=5$ & FL Partial \\
6 & FL Full & FL Full $=5$ & FL Full \\
7 & FL Un $^{\dagger}$ & FL Un $^{\dagger}$ & FL Un $^{\dagger}$ \\
\hline \hline
\end{tabular}

Policy relevant forecasts

At the policy relevant forecast horizon, the partially restricted and unrestricted financial links models provide best forecasts for inflation (see Table 6.3.3). These models outperform the benchmark open macro-only model and the AR(1). For the 90-day rate, the $\mathrm{AR}(1)$ models provide the best forecasts although the partially restricted financial links model outperforms the benchmark open economy model. This partially restricted model provides the best economic forecasts overall, suggesting there is valuable information in the yield curves compared to traditional macro-only models. 
Table 6.3.3: Open econ: policy relevant quarters, macro variables

\begin{tabular}{|c|c|c|c|c|c|}
\hline Rank & Inflation & 90-day rate & NZD/USD & Output gap & Overall \\
\hline 1 & FL Partial & $\mathrm{AR}^{\dagger}$ & $\mathrm{AR}^{\dagger}$ & $\mathrm{AR}^{\dagger}$ & FL Partial \\
\hline 2 & FL Un & FL Partial & FL Partial & FL Partial & $\mathrm{AR}^{\dagger}$ \\
\hline 3 & Macro Open BM & FL Un & Macro Open BM & Macro Open BM & FL Un \\
\hline 4 & FL 2F & Closed $^{\dagger}$ & FL Un & FL Un & Macro Open BM \\
\hline 5 & Closed $^{\dagger}$ & Macro Open BM & Closed $^{\dagger}$ & FL Full & Closed $^{\dagger}$ \\
\hline 6 & $\mathrm{AR}^{\dagger}$ & FL Full & FL Full & Closed $^{\dagger}$ & FL Full \\
\hline 7 & FL Full & FL 2F & FL 2F & FL 2F & FL 2F \\
\hline 8 & FL 2F Partial & FL 2F Partial & FL 2F Partial & FL 2F Partial & FL 2F Partial \\
\hline
\end{tabular}

Table 6.3.4 shows the partially restricted yields-only model provides the best forecast overall for the yield curve factors, followed by the AR(1) models. The financial links models rank the lowest, consistent with the monitoring quarter horizon forecasts. While this result suggests there is little information advantage from using US yield curve factors to forecast New Zealand yield curve components, as previously discussed, this modelling strategy is an initial step and could benefit from further research.

Table 6.3.4: Open econ: policy relevant quarters, yield curve factors

\begin{tabular}{lll|l}
\hline Rank & NZ Level & NZ Slope & Overall \\
\hline 1 & LSB Partial & AR $^{\dagger}$ & LSB Partial \\
2 & LSB Full & Yields BM & AR $^{\dagger}$ \\
3 & AR $^{\dagger}$ & LSB Partial & LSB Full $^{\dagger}$ \\
4 & FL Un $^{\dagger}$ & LSB Full & Yields BM \\
5 & Yields BM & FL Un & FL Un \\
6 & FL Partial & FL Partial & FL Partial \\
7 & FL Full & FL Full & FL Full \\
\hline \hline
\end{tabular}

\subsection{Comparison with quasi real-time results}

This section compares the quasi real-time and full real-time forecast environments, focusing on the key results.

Inflation forecasts 
Economically, the majority of the financial links models significantly improve the forecast performance of inflation compared to the macro-only open economy model (see Table 6.4.1). Statistically, the closed economy macro-only model outperforms at all horizons. Assessing model forecasting performance using the quasi real-time environment would suggest there is little gain to augmenting a New Zealand model with financial links to the United States. However, this result does not hold in the full real-time forecasting environment, which shows the unrestricted and partially restricted financial links models generally outperform the open and closed economy macro-only models (see Table 6.2.1) ${ }^{1}$.

Table 6.4.1: Open econ: inflation RMSFE

\begin{tabular}{lllllllll}
\hline Item & Macro Open BM & FL Un & FL Partial & FL Full & FL 2F & FL 2F Partial & Closed $^{\dagger}$ & $\mathrm{AR}^{\dagger}$ \\
\hline 1 & 0.12 & $\mathbf{0 . 8 4}$ & $\mathbf{0 . 8 5}$ & $\mathbf{0 . 8 7}$ & $\mathbf{0 . 9 1}$ & $\mathbf{0 . 9 0}$ & $\mathbf{0 . 9 7}$ & $\mathbf{0 . 8 8}$ \\
2 & 0.23 & $\mathbf{0 . 9 0}$ & $\mathbf{0 . 9 1}$ & $\mathbf{0 . 9 6}$ & $\mathbf{0 . 9 9}$ & $\mathbf{0 . 9 7}$ & $\mathbf{0 . 9 9}$ & $\mathbf{0 . 9 0}$ \\
3 & 0.34 & $\mathbf{0 . 9 3}$ & $\mathbf{0 . 9 4}$ & 1.03 & 1.02 & 1.02 & $\mathbf{0 . 9 8}$ & $\mathbf{0 . 8 8}$ \\
4 & 0.45 & $\mathbf{0 . 9 2}$ & $\mathbf{0 . 9 3}$ & 1.06 & 1.00 & 1.05 & $\mathbf{0 . 9 6}$ & $\mathbf{0 . 8 5}$ \\
8 & 1.00 & $\mathbf{0 . 8 1}$ & $\mathbf{0 . 7 8}$ & 1.00 & $\mathbf{0 . 7 6}$ & $\mathbf{0 . 9 9}$ & $\mathbf{0 . 8 4}$ & $\mathbf{0 . 6 6}$ \\
12 & 1.73 & $\mathbf{0 . 7 0}$ & $\mathbf{0 . 6 6}$ & $\mathbf{0 . 8 7}$ & $\mathbf{0 . 6 2}$ & $\mathbf{0 . 9 0}$ & $\mathbf{0 . 7 7}$ & $\mathbf{0 . 5 4}$ \\
16 & 3.27 & $\mathbf{0 . 4 8}$ & $\mathbf{0 . 4 4}$ & $\mathbf{0 . 6 3}$ & $\mathbf{0 . 4 4}$ & $\mathbf{0 . 6 0}$ & $\mathbf{0 . 7 1}$ & $\mathbf{0 . 3 8}$ \\
\hline \hline
\end{tabular}

See table 4.2.1 for table details.

\section{Output gap forecasts}

The quasi real-time forecast environment shows the financial links models generally outperform the benchmark macro-only open economy model, particularly at the longer forecast horizons, albeit the improvement is economically significant rather than statistical (see Table 6.4.2). This result does not hold in the full real-time forecast environment, where the macro-finance models do not outperform the macro-only models (see Table 6.2.2). This stronger relationship between macro-finance models and activity in quasi real-time is consistent with the US results in Chapter 4.

\footnotetext{
${ }^{1}$ The outright forecast performance of the open economy macro-only model deteriorates in the quasi real-time forecast environment, which is a feature also found in some other forecasting exercises. Investigating this curious result is left for future analysis.
} 
Table 6.4.2: Open econ: output gap RMSFE

\begin{tabular}{lllllllll}
\hline Item & Macro Open BM & FL Un & FL Partial & FL Full & FL 2F & FL 2F Partial & Closed $^{\dagger}$ & $\mathrm{AR}^{\dagger}$ \\
\hline 1 & 0.65 & 1.03 & 1.06 & 1.01 & 1.03 & 1.05 & $\mathbf{0 . 9 3}^{*}$ & $\mathbf{0 . 9 6}$ (*** $^{* *}$ \\
2 & 1.10 & $\mathbf{0 . 9 4}$ & $\mathbf{0 . 9 8}$ & $\mathbf{0 . 9 7}$ & $\mathbf{0 . 9 8}$ & 1.08 & $\mathbf{0 . 8 9}$ & $\mathbf{0 . 9 1}$ \\
3 & 1.57 & $\mathbf{0 . 9 2}$ & $\mathbf{0 . 9 5}$ & $\mathbf{0 . 9 6}$ & $\mathbf{0 . 9 6}$ & 1.14 & $\mathbf{0 . 8 6}$ & $\mathbf{0 . 8 1}$ \\
4 & 2.16 & $\mathbf{0 . 8 9}$ & $\mathbf{0 . 8 9}$ & $\mathbf{0 . 9 1}$ & $\mathbf{0 . 9 0}$ & 1.11 & $\mathbf{0 . 8 2}$ & $\mathbf{0 . 6 8}^{*}$ \\
8 & 4.01 & $\mathbf{0 . 6 9}$ & $\mathbf{0 . 6 7}$ & $\mathbf{0 . 7 4}$ & $\mathbf{0 . 6 2}$ & $\mathbf{0 . 6 8}$ & $\mathbf{0 . 6 4}$ & $\mathbf{0 . 4 9}^{*}$ \\
12 & 4.78 & $\mathbf{0 . 6 8}$ & $\mathbf{0 . 6 4}$ & $\mathbf{0 . 8 3}$ & $\mathbf{0 . 6 0}$ & 1.18 & $\mathbf{0 . 5 9}$ & $\mathbf{0 . 4 6}^{*}$ \\
16 & 7.20 & $\mathbf{0 . 5 3}$ & $\mathbf{0 . 5 0}$ & $\mathbf{0 . 6 6}$ & $\mathbf{0 . 5 1}$ & 1.14 & $\mathbf{0 . 4 7}$ & $\mathbf{0 . 3 2}$ \\
\hline \hline
\end{tabular}

See table 4.2.1 for table details.

\section{NZD/USD exchange rate forecasts}

Economically, financial links macro-finance and the closed macro-only models all improve the forecast performance for the exchange rate at all horizons compared to the open macro-only model (see Table 6.4.3). However, the result is only statistically significant for the near-term forecasts from the closed macro-only model (and the AR(1)) ${ }^{2}$. This result is in contrast to the full real-time forecast environment for the financial links models but is largely consistent for the closed macro-only and AR(1) models.

Table 6.4.3: Open econ: NZD/USD exchange rate RMSFE

\begin{tabular}{lllllllll}
\hline Item & Macro Open BM & FL Un & FL Partial & FL Full & FL 2F & FL 2F Partial & Closed $^{\dagger}$ & AR $^{\dagger}$ \\
\hline 1 & 6.86 & $\mathbf{0 . 9 8}$ & $\mathbf{0 . 9 7}$ & $\mathbf{0 . 9 7}$ & $\mathbf{0 . 9 7}$ & $\mathbf{0 . 9 6}$ & $\mathbf{0 . 9 3}$ & $\mathbf{0 . 8 5}$ \\
2 & 8.09 & $\mathbf{0 . 9 7}$ & $\mathbf{0 . 9 4}$ & $\mathbf{0 . 9 7}$ & $\mathbf{0 . 9 3}$ & $\mathbf{0 . 9 5}$ & $\mathbf{0 . 8 9}^{* *}$ & $\mathbf{0 . 8 0}$ \\
3 & 8.80 & $\mathbf{0 . 8 7}$ & $\mathbf{0 . 8 4}$ & $\mathbf{0 . 8 7}$ & $\mathbf{0 . 8 2}$ & $\mathbf{0 . 8 6}$ & $\mathbf{0 . 8 2}$ & $\mathbf{0 . 7 1}^{*}$ \\
4 & 9.19 & $\mathbf{0 . 7 8}$ & $\mathbf{0 . 7 6}$ & $\mathbf{0 . 7 9}$ & $\mathbf{0 . 7 3}$ & $\mathbf{0 . 7 6}$ & $\mathbf{0 . 7 7}$ & $\mathbf{0 . 6 7}$ \\
8 & 11.00 & $\mathbf{0 . 6 8}$ & $\mathbf{0 . 6 6}$ & $\mathbf{0 . 8 3}$ & $\mathbf{0 . 6 2}$ & $\mathbf{0 . 9 0}$ & $\mathbf{0 . 7 1}$ & $\mathbf{0 . 5 7}$ \\
12 & 14.49 & $\mathbf{0 . 4 9}$ & $\mathbf{0 . 4 6}$ & $\mathbf{0 . 5 5}$ & $\mathbf{0 . 4 7}$ & $\mathbf{0 . 7 3}$ & $\mathbf{0 . 7 5}$ & $\mathbf{0 . 4 4}$ \\
16 & 26.33 & $\mathbf{0 . 3 2}$ & $\mathbf{0 . 2 9}$ & $\mathbf{0 . 4 3}$ & $\mathbf{0 . 3 0}$ & $\mathbf{0 . 4 1}$ & $\mathbf{0 . 7 1}$ & $\mathbf{0 . 2 4}$ \\
\hline \hline
\end{tabular}

See table 4.2.1 for table details.

The quasi real-time results for the 90-day rate, Level, and Slope are in Appendix B. These results are consistent with the other forecast variables, where the

\footnotetext{
${ }^{2}$ This reflects the large forecast errors across all models, which is captured by the Diebold-Mariano test.
} 
financial links models show stronger forecast performance in quasi real-time compare to the full real-time forecast environment. 


\section{Chapter 7}

\section{Conclusion}

This thesis uses macro-finance modelling techniques to analyse the dynamic inter-relationships between the macroeconomy and the yield curve in a forecasting environment. In addition, I use theoretically motivated restrictions on the yield curve dynamics and test whether these restrictions improve forecast performance. The importance of the Bow yield curve factor is also tested, given the uncertainty in the literature about the Bow's role in macro-finance models.

The in-sample results show the macro-finance models provide a superior fit to the data compared to either macro-only models or yield-only models. The quasi real-time forecasting environment also shows macro-finance models generally outperform macro-only models when forecasting macroeconomic variables. The macro-finance models also generally outperform yields-only models for yield curve component forecasts. However, the restricted yields-only models provide further gain still.

Although there is valuable information in macroeconomic variables for forecasting yield curve components, the theoretically motivated restrictions on the yield curve dynamics provide the strongest forecast performance for yield curve components (as well as macroeconomic variables in many cases). The dominance between the fully or partially restricted version is less clear, with 
each model outperforming in some circumstances. Nevertheless, this suggests that although the time-varying term premia in bond yields is important for yield curve estimation it appears to be less important for macro-finance forecasting. The improved forecast performance from using restricted yields-only models also holds in the real-time environment.

The results are more mixed for macroeconomic variables in the real-time forecasting environment, with less of a gain from using macro-finance models. Macro-finance models do not improve monitoring quarter forecasts for activity in either application for the United States and New Zealand. This is in contrast to much of the recent macro-finance literature. However, at the policy relevant forecast horizon yield curve information can improve activity forecasts. The improvement from using macro-finance models to forecast inflation and the policy rate is more robust.

For New Zealand, a simple AR(1) model is the best model for forecasting the exchange rate but macro-finance models do outperform the macro-only model. This suggests there is valuable information in the yield curve components relative to traditional macroeconomic models.

Finally, the results also show it is beneficial to include all three yield curve factors in yield curve estimation and in the macro-finance models, despite the little variance of the yield curve explained by the Bow. In terms of model fit for the ANSMs and KANSMs, the three factor models had high log likelihoods and lower standard errors around the parameters. In the real-time forecasting exercise, the three factor macro-finance models were generally stronger performers compared to the two factor versions, which tended to have stronger results in the quasi real-time forecasting environment.

There are two key results from comparing the quasi real-time and full real-time forecast environments. Firstly, overall, the restricted yield-only models provide the best forecast performance for yield curve factors. The macro-finance models are generally able to outperform the unrestricted yields-only model, which is consistent with results in the literature, but do not outperform the restricted yields-only models, which has not been previously tested in the 
literature. Secondly, using restrictions on the yield curve dynamics generally improves the forecast performance of macro-finance models for macroeconomic variables. However, using a quasi real-time environment to assess the forecast performance can overstate the usefulness of macro-finance models and understate the usefulness of placing restrictions on the yield curve dynamics, which results in a more parsimonious model and better forecast performance in practice.

Overall, this analysis suggests there is benefit for practitioners to use macro-finance models in real-time for forecasting macroeconomic variables. The forecasting gain relative to traditional macroeconomic models is more significant at longer horizons, suggesting the yield curve factors contain fundamental information about the likely evolution of the economy.

There are several possible avenues for future research. One avenue is modelling data revisions, as in Jacobs and van Norden (2011) who use state space modelling techniques to give rich dynamics in the measurement error that allow for data revision properties. The analysis in this thesis demonstrates that yield curve factors can improve forecasts for macroeconomic variables in a quasi real-time setting but the result is weaker in the full real-time forecasting exercise. Thus, reducing the influence of data revisions and missing data could lead to further gain in forecast performance.

There is evidence of improving forecast performance for open economies by including international financial links in a macro-finance model, however more sophisticated modelling techniques may be required to fully model the dynamics. Jointly estimating cross-country bond yields, similar to Diebold, Li, and Yue (2008) and Yu-chin and Tsang (2013), could improve the performance and soundness of the open economy version of the macro-finance model presented. The model would need to allow for the zero lower bound in some countries, which is a direction of research yet to be undertaken in the literature. This would create internally consistent estimation of global bond yields, which could be particularly important for modelling small open economies.

From a practical point of view, it would be more efficient to estimate the 
macro-finance models in one step. This would likely use the state-space representation of the macro-finance model with the Kalman filter. The ideal framework would also use the Kalman filter to estimate values of missing data in real-time. 


\section{Bibliography}

Ang, A. and Piazzesi, M. 2003. A no-arbitrage vector autoregression of term structure dynamics with macroeconomic and latent variables. Journal of Monetary Economics, 50, 745-787.

Ang, A., Piazzesi, M., and Wei, M. 2006. What does the yield curve tell us about GDP growth?, Journal of Econometrics. 131, 359-403.

Ang, A., Bekaert, G., and Wei, M. 2007. Do macro variables, asset markets, or surveys forecast inflation better? Journal of Monetary Economics, 54, 1163-1212.

Backus, D., Foresi, S., Mozumdar, A., and Wu, L. 2001. Predictable changes in yields and forward rates. Journal of Financial Economics, 59, 281-311.

Bank for International Settlements. 2005. Zero-coupon yield curves: technical documentation. Bank for International Settlements, Switzerland

Balfoussia, H., and Wickens, M. 2007. Macroeconomic sources of risk in the term structure. Journal of Money, Credit and Banking, 39, 205-236.

Benati, L., and Goodhart, C. 2008. Investigating time-variation in the marginal predictive power of the yield spread. Journal of Economic Dynamics and Control, 32, 1236-1272.

Bernanke, B., Reinhart, V., and Sack, B. 2004. Monetary policy alternatives at the zero bound: an empirical assessment. Brookings 
Papers on Economic Activity, Economic Studies Program, The Brookings Institution, 35, 1-100.

Bernard, H., and Gerlach, S. 1998. Does the term structure predict recessions? The international evidence. International Journal of Finance and Economics, 3, 195-215.

Black, F. 1995. Interest rates as options. Journal of Finance 50, 1371-1376.

Bikbov, R., and Chernov, M. 2010. No-arbitrage macroeconomic determinants of the yield curve. Journal of Econometrics, 159, 166-182.

Campbell, J. and Shiller, R. 1991. Yield spreads and interest rate movements: a bird's eye view. Review of Economic Studies 58, 495-514.

Chauvet, M., and Senyuz, Z. 2012. A dynamic factor model of the yield curve as a predictor of the economy. Finance and Economics Discussion Series 2012-32, Board of Governors of the Federal Reserve System (U.S.).

Christensen, J., Diebold, F., and Rudebusch, G. 2011. The affine arbitrage-free class of Nelson-Siegel term structure models. Journal of Econometrics, 164, 4-20.

Christensen, J. ,and Rudebusch, G. 2013. Estimating shadow-rate term structure models with near-zero yields. Working Paper Series 2013-07, Federal Reserve Bank of San Francisco.

Christoffersen, P., Ghysels, E., Swanson, N. 2002. Let's get 'real' about using economic data. Journal of Empirical Finance, 9, 343-360.

Clark, T., and West, K. 2007. Approximately normal tests for equal predictive accuracy in nested models. Journal of Econometrics, 138, 291311.

Cochrane, J., and Piazzesi, M. 2005. Bond risk premia. American Economic Review, 95, 138-160.

Croushore, D., 2006. Forecasting with Real-Time Macroeconomic Data. Handbook of Economic Forecasting, Chapter 17. 
Cox, J.C., Ingersoll, J.E., and Ross, S.A. 1985. A theory of the term structure of interest rates. Econometrica, 53, 385407.

Croushore D, and Evans, C. 2006. Data revisions and the identification of monetary policy shocks. Journal of Monetary Economics, 53, 1135-1160.

DAgostino, A., Giannone, D., and Surico, P. 2006. (Un)Predictability and macroeconomic stability. Working Paper Series 0605, European Central Bank.

Dai, Q., and Singleton, K. 2000. Specification analysis of affine term structure models. Journal of Finance, 55, 1943-1978.

Dai, Q., and Singleton, K. 2002. Expectation puzzles, time-varying risk premia, and affine models of the term structure. Journal of Financial Economics, 63, 415-441.

Dewachter, H., and Lyrio, M. 2006. A structural macro model of the yield curve. Computing in Economics and Finance 236

Dewachter, H., and Lyrio, M. 2006. Macro factors and the term structure of interest rates. Journal of Money, Credit and Banking, 38, 119-140.

Dewachter, H., and Lyrio, M. 2008. Learning, macroeconomic dynamics and the term structure of interest rates. NBER Chapters, in: Asset Prices and Monetary Policy, 191-245. National Bureau of Economic Research, Inc.

Diebold, F., and Mariano, R. 1995. Comparing predictive accuracy. Journal of Business and Economic Statistics, 13, 253-63.

Diebold, F., Rudebusch, G., and Aruoba, B. 2006. The macroeconomy and the yield curve: a dynamic latent factor approach. Journal of Econometrics, 131, 309-338.

Diebold, F., and Li, C. 2006. Forecasting the term structure of government bond yields. Journal of Econometrics, 130, 337-364. 
Diebold, F., Li, C. and Yue, V. 2008. Global yield curve dynamics and interactions: a dynamic Nelson-Siegel approach. Journal of Econometrics, 146, 351-363.

Diebold, F., and Rudebusch, G. 2012. Yield curve modeling and forecasting: the dynamic Nelson-Siegel approach. Economics Books, Princeton University Press.

Duffie, D. 2001. Dynamic Asset Pricing Theory, Third ed. Princeton: Princeton University Press.

Duffee, G. 2002. Term premia and interest rate forecasts in affine models. Journal of Finance, 57, 405-443.

Estrella, A., and Hardouvelis, G., 1991. The term structure as a predictor of real economic activity. Journal of Finance, American Finance Association, $46,555-76$.

Fama, E. and Bliss, R. 1987. The information in long-maturity forward rates. American Economic Review, 77, 680-692.

Filipovic, D. 1999. A note on the Nelson-Siegel family. Mathematical Finance, 9, 349-359.

Filipovic, D. 2000. Exponential-polynomial families and the term structure of interest rates. Bernoulli, 6, 1-27.

Ghysels, E., Horan, C., and Moench, E. 2012. Forecasting through the rear-view mirror: data revisions and bond return predictability. Staff Reports 581, Federal Reserve Bank of New York.

Gurkaynak, R., Sack, B., and Swanson, E. 2005. Do actions speak louder than words? The response of asset prices to monetary policy actions and statements. International Journal of Central Banking, 1, 55-93.

Gurkaynak, R., Sack, B., and Wright, J. 2007. The U.S. Treasury yield curve: 1961 to the present. Journal of Monetary Economics, 54, 2291-2304. 
Gurkaynak, R., and Wright, J. 2012. Macroeconomics and the term structure. Journal of Economic Literature, 50, 331-67

Hamilton, J. 1994. Time Series Analysis. Princeton University Press.

Hamilton, J., and Wu, J. 2012. Identification and estimation of Gaussian affine term structure models. Journal of Econometrics, 168, 315-331.

Hordahl, P., Tristani, O., and Vestin, D. 2008. The yield curve and macroeconomic dynamics. Economic Journal, 118, 1937-1970.

Jacobs, J., and van Norden, S. 2011. Modelling data revisions: measurement error and dynamics of 'true' values. Journal of Econometrics, $161,101-109$.

Joslin, S., Priebsch M., and Singleton, K. 2009. Risk premium accounting in macro-dynamic term structure models. Manuscript, MIT and Stanford University.

Joslin, S., Singleton, K., and Zhu, H. 2011. A new perspective on Gaussian dynamic term structure models. Review of Financial Studies, 24, 926-970.

Joslin, S., Priebsch M., and Singleton, K. 2014. Risk premiums in dynamic term structure models with unspanned macro risks The Journal of Finance, $69,11971233$.

Kim, D., and Singleton, K. 2012. Term structure models and the zero bound: an empirical investigation of Japanese yields. Journal of Econometrics, 170, 32-49.

Koenig E., Dolmas, S., and Piger, J. 2003. The use and abuse of real-time data in economic forecasting. The Review of Economics and Statistics, 85, 618-628.

Kozicki, S., and Tinsley, P.A. 2005. What do you expect? Imperfect policy credibility and tests of the expectations hypothesis. Journal of Monetary Economics, 52, 421-447. 
Krippner, L. 2006. A theoretically-consistent version of the Nelson and Siegel class of yield curve models. Applied Mathematical Finance, 13, 39-59.

Krippner, L. 2008. A macroeconomic foundation for the Nelson and Siegel class of yield curve models. Research Paper Series 226, Quantitative Finance Research Centre, University of Technology, Sydney.

Krippner, L., and Thorsrud, L. 2009. Forecasting New Zealands economic growth using yield curve information. Discussion Paper, Reserve Bank of New Zealand, 2009/18

Krippner, L. 2011. Modifying Gaussian term structure models when interest rates are near the zero lower bound. Discussion paper, Centre for Applied Macroeconomic Analysis 36/2011.

Krippner, L. 2013. A tractable framework for zero lower bound Gaussian term structure models. Discussion Paper, Reserve Bank of New Zealand, 2013/02.

Krippner, L. 2015. Term Structure Modeling at the Zero Lower Bound: A Practitioners Guide. Palgrave-Macmillan.

Le, A., Singleton, K., and Dai, J. 2010. Discrete-time affine term structure models with generalized market prices of risk. Review of Financial Studies, 23,21842227

Litterman, R., and Scheinkman , J. 1991. Common factors affecting bond returns. Journal of Fixed Income, 1, 49-53.

Ludvigson, S., and $\mathrm{Ng}$, S. 2009. A factor analysis of bond risk premia. NBER Working Papers 15188, National Bureau of Economic Research, Inc.

Lutkepohl, H. 2005. New Introduction to Multiple Time Series Analysis. Springer-Verlag, Berlin, Germany. 
Moench, E. 2008. Forecasting the yield curve in a data-rich environment: a no-arbitrage factor-augmented VAR approach. Journal of Econometrics, $146,26-43$.

Moench, E. 2012. Term structure surprises: the predictive content of curvature, level, and slope. Journal of Applied Econometrics, 27, 574-602.

Nelson, C. and Siegel, A. 1987. Parsimonious modelling of yield curves. Journal of Business, 473-489.

Nyholm, K. 2007. A new approach to predicting recessions. Economic Notes, 36, 2742.

Orphanides, A. 2001. Monetary policy rules based on real-time Data. American Economic Review, American Economic Association, 91, 964-985.

Orphanides, A., and van Norden, S. 2002. The unreliability of output-gap estimates in real time. The Review of Economics and Statistics, $84,569-583$.

Pancost, A. 2013. Zero-coupon yields and the cross-section of bond prices. Available at SSRN: http: / / ssrn. com/abstract $=2157271$.

Singleton, K. 2006. Empirical Dynamic Asset Pricing. Princeton University Press.

Smith, J., and Taylor, J. 2009. The term structure of policy rules. Journal of Monetary Economics, 56, 907-917.

Stark, T., and Croushore, D. 2002. Forecasting with a real-time data set for macroeconomists. Journal of Macroeconomics, 24, 507-531.

Stock, J., and Watson, W. 2003. Forecasting output and inflation: the role of asset prices. Journal of Economic Literature, 41, 788-829.

Svensson, L. 1995. Estimating forward interest rates with the extended Nelson-Siegel method. Sveriges Riksbank Quarterly Review, 3, 13-26.

Piazzesi, M. 2005. Bond yields and the Federal Reserve. Journal of Political Economy, 113, 311-344. 
Piazzesi, M. 2010. Affine term structure models. In Handbook of Financial Econometrics (Y. Ait-Sahalia and L. P. Hansen, eds.). North-Holland.

Rudebusch, G., and $\mathrm{Wu}, \mathrm{T} .2008$ A macro-finance model of the term structure, monetary policy and the economy. Economic Journal, 118, 906-926.

Rudebusch, G., and Williams, J. 2009. Forecasting recessions: the puzzle of the enduring power of the yield curve. Journal of Business and Economic Statistics, 27, 492-503.

Rudebusch, G. 2010. Macro-finance models of interest rates and the economy. Manchester School, University of Manchester, 78, 25-52.

Wheelock, D. and Wohar M. 2009. Can the term spread predict output growth and recessions? a survey of the literature. Review, Federal Reserve Bank of St. Louis, issue Sep, 419-440.

Wright, J. 2011. Term premia and inflation uncertainty: empirical evidence from an international panel dataset. American Economic Review, 101, 1514-1534.

Yu-chin, C. and Tsang, K. 2013. What does the yield curve tell us about exchange rate predictability?'. The Review of Economics and Statistics, 95, 185-205. 


\section{Appendix A}

\section{Arbitrage Free Nelson-Siegel Model Results}

\section{A.1 In sample (K)ANSM model fit}

Tables in this appendix detail the parameter estimates and diagnostics for the ANS models, for the US and New Zealand.

Table A.1.1: US ANSM(3) parameters

\begin{tabular}{rrrrrr}
\hline Parameters & Estimate & Std error & Parameters & Estimate & Std error \\
\hline$\phi$ & 0.5275 & 0.0110 & $\theta_{1}$ & 7.3651 & 1.9988 \\
$\kappa_{11}$ & 0.1170 & 0.0772 & $\theta_{2}$ & -1.9330 & 1.4046 \\
$\kappa_{12}$ & -0.0005 & 0.0907 & $\theta_{3}$ & -0.0956 & 1.4561 \\
$\kappa_{13}$ & -0.1699 & 0.0810 & $\sigma_{1}$ & 0.0051 & 0.0003 \\
$\kappa_{21}$ & 0.4699 & 0.1446 & $\sigma_{2}$ & 0.0096 & 0.0004 \\
$\kappa_{22}$ & 0.5271 & 0.1490 & $\sigma_{3}$ & 0.0307 & 0.0019 \\
$\kappa_{23}$ & -0.5833 & 0.1498 & $\rho_{12}$ & -0.5408 & 0.0474 \\
$\kappa_{31}$ & -0.5173 & 0.4522 & $\rho_{13}$ & -0.1926 & 0.0704 \\
$\kappa_{32}$ & -0.1001 & 0.6549 & $\rho_{23}$ & -0.0061 & 0.0763 \\
$\kappa_{33}$ & 1.0481 & 0.4436 & & & \\
\hline Log-likelihood: & -12452.0 & & & & \\
\hline \hline
\end{tabular}


Table A.1.2: US ANSM(3) model fit

\begin{tabular}{rrrrrrr}
\hline Maturity & $\sigma_{\nu}\left(\tau_{k}\right)$ & Std error & Mean residual & Std residual & RMSE & MAE \\
\hline 0.25 & 13.37 & 0.81 & -3.17 & 12.42 & 12.80 & 9.13 \\
0.5 & -3.44 & 0.88 & -0.61 & 1.38 & 1.51 & 1.19 \\
1 & 12.91 & 0.75 & 7.87 & 10.13 & 12.81 & 9.96 \\
2 & 6.26 & 0.47 & 3.92 & 4.88 & 6.25 & 4.98 \\
3 & -0.11 & 0.40 & 0.04 & 0.03 & 0.05 & 0.04 \\
5 & 4.33 & 0.54 & -2.88 & 2.95 & 4.12 & 3.40 \\
7 & 3.54 & 0.67 & -0.35 & 2.26 & 2.28 & 1.69 \\
10 & 11.38 & 0.79 & 7.64 & 7.13 & 10.44 & 8.67 \\
30 & 43.64 & 3.02 & 28.74 & 31.58 & 42.65 & 35.99 \\
\hline \hline
\end{tabular}

Table A.1.3: US ANSM(2) parameters

\begin{tabular}{rrrrrr}
\hline Parameters & Estimate & Std error & Parameters & Estimate & Std error \\
\hline$\phi$ & 0.2604 & 0.0050 & $\theta_{1}$ & -18.8815 & 52.2524 \\
$\kappa_{11}$ & 0.0001 & 0.0002 & $\theta_{2}$ & -3.2005 & 1.9579 \\
$\kappa_{12}$ & -0.0016 & 0.0027 & $\sigma_{1}$ & 0.0077 & 0.0002 \\
$\kappa_{21}$ & -0.0012 & 0.0009 & $\sigma_{2}$ & 0.0143 & 0.0009 \\
$\kappa_{22}$ & 0.1084 & 0.1060 & $\rho_{12}$ & -0.5053 & 0.0341 \\
\hline Log-likelihood: & -11635.6 & & & & \\
\hline \hline
\end{tabular}

Table A.1.4: US ANSM(2) model fit

\begin{tabular}{rrrrrrr}
\hline Maturity & $\sigma_{\nu}\left(\tau_{k}\right)$ & Std error & Mean residual & Std residual & RMSE & MAE \\
\hline 0.25 & 59.13 & 2.94 & -16.531 & 56.35 & 58.63 & 46.96 \\
0.5 & 44.05 & 2.33 & -12.223 & 42.15 & 43.81 & 35.60 \\
1 & 22.90 & 1.47 & -0.474 & 22.70 & 22.66 & 17.59 \\
2 & 6.61 & 0.51 & 0.797 & 6.21 & 6.25 & 4.99 \\
3 & 1.65 & 0.80 & 0.186 & 0.70 & 0.72 & 0.59 \\
5 & 3.12 & 0.66 & -0.908 & 2.93 & 3.06 & 2.41 \\
7 & 0.02 & 0.43 & -0.049 & 0.04 & 0.06 & 0.05 \\
10 & 8.59 & 0.56 & 3.814 & 7.70 & 8.58 & 6.88 \\
30 & 56.27 & 3.23 & 36.877 & 42.75 & 56.40 & 49.31 \\
\hline \hline
\end{tabular}


Table A.1.5: NZ ANSM(3) parameters

\begin{tabular}{rrrrrr}
\hline Parameters & Estimate & Std error & Parameters & Estimate & Std error \\
\hline$\phi$ & 0.7921 & 0.0000 & $\theta_{1}$ & 14.1085 & 4.3396 \\
$\kappa_{11}$ & 0.0594 & 0.0017 & $\theta_{2}$ & -7.6020 & 8.0631 \\
$\kappa_{12}$ & 0.0112 & 0.0010 & $\theta_{3}$ & -0.8180 & 1.6629 \\
$\kappa_{13}$ & -0.1274 & 0.0011 & $\sigma_{1}$ & 0.0075 & 0.0000 \\
$\kappa_{21}$ & 0.0970 & 0.0016 & $\sigma_{2}$ & 0.0275 & 0.0000 \\
$\kappa_{22}$ & 0.0209 & 0.0014 & $\sigma_{3}$ & 0.0355 & 0.0000 \\
$\kappa_{23}$ & -0.5299 & 0.0016 & $\rho_{12}$ & -0.6619 & 0.0002 \\
$\kappa_{31}$ & -0.5052 & 0.0016 & $\rho_{13}$ & -0.4840 & 0.0004 \\
$\kappa_{32}$ & -0.0126 & 0.0008 & $\rho_{23}$ & -0.0054 & 0.0005 \\
$\kappa_{33}$ & 1.2811 & 0.0011 & & & \\
\hline Log-likelihood: & -21485.00 & & & & \\
\hline \hline
\end{tabular}

Table A.1.6: NZ ANSM(3) model fit

\begin{tabular}{rrrrrrr}
\hline Maturity & $\sigma_{\nu}\left(\tau_{k}\right)$ & Std error & Mean residual & Std residual & RMSE & MAE \\
\hline 0.25 & 0.0004 & 0.0186 & 0.0000 & 0.000 & 0.000 & 0.000 \\
0.5 & -0.0001 & 0.0215 & 0.0000 & 0.000 & 0.000 & 0.000 \\
1 & -0.0005 & 0.0260 & 0.0002 & 0.000 & 0.000 & 0.000 \\
2 & -0.0016 & 0.0328 & -0.0001 & 0.000 & 0.000 & 0.000 \\
3 & 0.0244 & 0.0432 & 0.0187 & 0.000 & 0.019 & 0.019 \\
5 & 0.0000 & 0.0259 & 0.0009 & 0.000 & 0.001 & 0.001 \\
7 & 0.0000 & 0.0263 & 0.0011 & 0.000 & 0.001 & 0.001 \\
10 & -0.5738 & 0.2283 & 0.6395 & 0.000 & 0.640 & 0.640 \\
\hline \hline
\end{tabular}

Table A.1.7: NZ ANSM(2) parameters

\begin{tabular}{rrrrrr}
\hline Parameters & Estimate & Std error & Parameters & Estimate & Std error \\
\hline$\phi$ & 0.4133 & 0.0078 & $\theta_{1}$ & 18.8437 & 65.8522 \\
$\kappa_{11}$ & 0.0012 & 0.0056 & $\theta_{2}$ & -2.1822 & 0.9687 \\
$\kappa_{12}$ & 0.0113 & 0.0120 & $\sigma_{1}$ & 0.9370 & 0.0322 \\
$\kappa_{21}$ & -0.0002 & 0.0132 & $\sigma_{2}$ & 0.0203 & 0.0011 \\
$\kappa_{22}$ & 0.3502 & 0.1471 & $\rho_{12}$ & -0.6822 & 0.0256 \\
\hline
\end{tabular}

Log-likelihood: $\quad-10855.4$ 
Table A.1.8: NZ ANSM(2) model fit

\begin{tabular}{rrrrrrr}
\hline Maturity & $\sigma_{\nu}\left(\tau_{k}\right)$ & Std error & Mean residual & Std residual & RMSE & MAE \\
\hline 0.25 & 54.84 & 2.51 & 20.66 & 50.82 & 54.78 & 43.97 \\
0.5 & 40.09 & 1.88 & 14.85 & 37.21 & 40.00 & 32.15 \\
1 & 19.38 & 0.98 & 6.97 & 18.15 & 19.41 & 15.64 \\
2 & 0.00 & 0.46 & 0.00 & 0.00 & 0.00 & 0.00 \\
3 & 5.56 & 0.39 & -1.74 & 5.27 & 5.54 & 4.47 \\
5 & 4.23 & 0.35 & -1.28 & 4.04 & 4.23 & 3.39 \\
7 & 0.01 & 0.30 & 0.00 & 0.00 & 0.00 & 0.00 \\
10 & 5.75 & 0.50 & 2.94 & 4.98 & 5.78 & 4.61 \\
\hline \hline
\end{tabular}




\section{Appendix B}

\section{Quasi Real-Time Forecast Performance Results}

\section{B.1 US results}

For the US, I only present the full-sample results. The same themes are in the pre-GFC results and these results are available on request.

Table B.1.1: US full sample: effective Fed funds rate RMSFE

\begin{tabular}{|c|c|c|c|c|c|c|c|}
\hline Item & Macro BM & ${\mathrm{MF} U \mathrm{Un}^{\dagger}}^{\dagger}$ & MF Partial & MF Full & MF 2F & MF 2F Partial & $\mathrm{AR}^{\dagger}$ \\
\hline 1 & 0.49 & $0.83^{* * *}$ & $0.88^{* * *}$ & $0.90 * *$ & 0.92 & $0.89 *$ & $1.00^{* *}$ \\
\hline 2 & 0.90 & $0.87^{* * *}$ & $0.93 * *$ & $0.92 *$ & 0.91 & $0.89 *$ & 0.96 ** \\
\hline 3 & 1.29 & $0.88^{* * *}$ & 0.95 * & 0.94 & 0.90 * & $0.88^{* *}$ & $0.93^{* *}$ \\
\hline 4 & 1.65 & $0.89^{* * *}$ & 0.97 & 0.95 & 0.91 * & $0.90 * *$ & 0.92 ** \\
\hline 8 & 2.69 & $0.93 * *$ & 0.93 * & 0.95 & 0.94 & 0.93 & 0.91 * \\
\hline 12 & 3.53 & $0.85^{* * *}$ & $0.78^{* * *}$ & $0.78^{* *}$ & $0.84^{* * *}$ & $0.84^{* * *}$ & $0.86^{*}$ \\
\hline 16 & 4.35 & $0.78^{* * *}$ & $0.70^{* * *}$ & $0.61^{* * *}$ & $0.76^{* * *}$ & $0.77^{* * *}$ & $0.74^{* *}$ \\
\hline
\end{tabular}

See table 4.2.1 for table details. 
Table B.1.2: US full sample: Level RMSFE

\begin{tabular}{|c|c|c|c|c|c|c|c|}
\hline Item & Yields BM & LSB Partial & LSB Full & MF Un ${ }^{\dagger}$ & MF Partial & MF Full & $\mathrm{AR}^{\dagger}$ \\
\hline 1 & 0.65 & 0.98 & 0.99 & 1.03 & 1.00 & 1.01 & 0.99 \\
\hline 2 & 0.89 & 0.97 & 0.97 & 1.03 & 1.00 & 1.00 & 0.99 \\
\hline 3 & 1.04 & 0.98 & 0.97 & 1.02 & 0.99 & 1.01 & 1.00 \\
\hline 4 & 1.19 & 0.99 & 0.97 & 1.01 & 1.00 & 1.03 & 1.01 \\
\hline 8 & 1.28 & 1.08 & 0.93 & 0.99 & 1.07 & 1.11 & 1.06 \\
\hline 12 & 1.36 & 1.11 & $0.83^{* * *}$ & $0.94^{* * *}$ & 1.04 & 1.16 & 1.06 \\
\hline 16 & 1.55 & 1.09 & $0.74^{* * *}$ & $0.91^{* * *}$ & $0.95^{* *}$ & 0.97 & 1.03 \\
\hline
\end{tabular}

See table 4.2.1 for table details.

Table B.1.3: US full sample: Slope RMSFE

Table: Slope

\begin{tabular}{|c|c|c|c|c|c|c|c|}
\hline Item & Yields BM & LSB Partial & LSB Full & MF Un ${ }^{\dagger}$ & MF Partial & MF Full & $\mathrm{AR}^{\dagger}$ \\
\hline 1 & 0.79 & 1.00 & 1.01 & $1.00 * *$ & 1.01 & 1.00 & 1.01 * \\
\hline 2 & 1.20 & 0.99 & 0.99 & $0.98^{* *}$ & 1.03 & 1.00 & 1.02 \\
\hline 3 & 1.57 & 0.97 & 0.98 & $0.98^{* *}$ & 1.02 & 1.02 & 1.00 \\
\hline 4 & 1.91 & 0.96 & 0.97 & $0.97^{* *}$ & 1.02 & 1.05 & $0.96 *$ \\
\hline 8 & 2.58 & $0.89 * * *$ & $0.94 *$ & $0.96^{* * *}$ & 0.99 & 1.12 & $0.92 *$ \\
\hline 12 & 3.01 & $0.81^{* * *}$ & $0.86^{* * *}$ & $0.96^{* * *}$ & 0.99 & 1.12 & 0.92 \\
\hline 16 & 2.93 & $0.78^{* * *}$ & $0.85^{* * *}$ & $0.89 * * *$ & 0.92 & 1.09 & 0.91 * \\
\hline
\end{tabular}

See table 4.2.1 for table details.

Table B.1.4: US full sample: Bow RMSFE

\begin{tabular}{|c|c|c|c|c|c|c|c|}
\hline Item & Yields BM & LSB Partial & LSB Full & $\mathrm{MF} \mathrm{Un}^{\dagger}$ & MF Partial & MF Full & $\mathrm{AR}^{\dagger}$ \\
\hline 1 & 1.49 & 1.00 & $0.97 *$ & 1.01 & 1.02 & $0.95 *$ & 1.00 \\
\hline 2 & 2.02 & 1.02 & 0.98 & 0.99 * & 0.99 & 0.96 & 1.01 \\
\hline 3 & 2.31 & 1.05 & 0.99 & $0.95^{* *}$ & 0.96 & $0.92 *$ & 1.04 \\
\hline 4 & 2.52 & 1.08 & 1.00 & $0.92 * *$ & 0.92 & $0.89 * *$ & 1.07 \\
\hline 8 & 3.26 & 1.08 & 1.03 & $0.88^{* *}$ & $0.84^{* *}$ & 0.88 * & 1.08 \\
\hline 12 & 3.73 & 1.05 & 1.04 & $0.89 * *$ & $0.86^{* * *}$ & $0.87 *$ & 1.05 \\
\hline 16 & 4.07 & 1.02 & 1.04 & $0.88 *$ & 0.86 * & 0.88 & 1.02 \\
\hline
\end{tabular}

See table 4.2.1 for table details. 


\section{B.2 New Zealand results}

Table B.2.1: NZ: 90-day rate RMSFE

\begin{tabular}{|c|c|c|c|c|c|c|c|}
\hline Item & Macro BM & $\mathrm{MF} \mathrm{Un}^{\dagger}$ & MF Partial & MF Full & MF 2F & MF 2F Partial & $\mathrm{AR}^{\dagger}$ \\
\hline 1 & 0.51 & $0.60 * * *$ & $0.82^{* * *}$ & $0.78 * * *$ & $0.69^{* * *}$ & $0.70 * * *$ & 1.13 \\
\hline 2 & 0.96 & $0.69 * * *$ & $0.85^{* * *}$ & $0.67^{* * *}$ & $0.68^{* * *}$ & $0.69^{* * *}$ & 1.07 \\
\hline 3 & 1.42 & $0.78^{* * *}$ & $0.87^{* *}$ & $0.68^{* * *}$ & $0.74^{* * *}$ & $0.76^{* * *}$ & $0.96^{* *}$ \\
\hline 4 & 1.87 & $0.87^{* *}$ & $0.91 *$ & $0.74^{* *}$ & $0.81^{* *}$ & $0.83^{* *}$ & $0.88^{* *}$ \\
\hline 8 & 3.03 & 1.08 & 1.03 & 1.06 & 0.94 & 0.95 & $0.77^{* *}$ \\
\hline 12 & 3.51 & 1.02 & 0.98 & 1.13 & 0.89 & 0.90 & $0.80^{* *}$ \\
\hline 16 & 3.65 & $0.91^{* *}$ & $0.90 *$ & 1.27 & $0.84^{* *}$ & $0.85^{* *}$ & 0.86 \\
\hline
\end{tabular}

See table 4.2.1 for table details.

Table B.2.2: NZ: Level RMSFE

\begin{tabular}{|c|c|c|c|c|c|c|c|}
\hline Item & Yields BM & LSB Partial & LSB Full & $\mathrm{MF} \mathrm{Un}^{\dagger}$ & MF Partial & MF Full & $\mathrm{AR}^{\dagger}$ \\
\hline 1 & 0.57 & $0.97 *$ & 0.99 & 1.19 & 1.11 & 1.07 & 1.00 \\
\hline 2 & 0.78 & $0.94^{* *}$ & 0.98 & 1.21 & 1.13 & 1.14 & 0.99 \\
\hline 3 & 0.89 & $0.90^{* * *}$ & 0.94 & 1.17 & 1.07 & 1.09 & 0.98 \\
\hline 4 & 1.00 & $0.89^{* * *}$ & 0.92 & 1.20 & 1.08 & 1.12 & 0.97 \\
\hline 8 & 1.27 & $0.87^{* * *}$ & $0.87^{*}$ & 1.16 & 1.05 & 1.09 & $0.93^{* *}$ \\
\hline 12 & 1.35 & $0.91^{* * *}$ & 0.92 & 1.12 & 1.06 & 1.21 & $0.95 *$ \\
\hline 16 & 1.35 & $0.95^{* * *}$ & 0.94 & 1.19 & 1.09 & 1.40 & $0.99^{* *}$ \\
\hline
\end{tabular}

See table 4.2.1 for table details.

Table B.2.3: NZ: Slope RMSFE

\begin{tabular}{|c|c|c|c|c|c|c|c|}
\hline Item & Yields BM & LSB Partial & LSB Full & $\mathrm{MF}_{\mathrm{Un}}^{\dagger}$ & MF Partial & MF Full & $\mathrm{AR}^{\dagger}$ \\
\hline 1 & 0.84 & $0.90^{* *}$ & $0.88^{* *}$ & $0.81^{* * *}$ & $0.84^{* *}$ & $0.85 *$ & $0.98^{* * *}$ \\
\hline 2 & 1.33 & 0.90 & 0.88 * & $0.77^{* * *}$ & $0.81 *$ & $0.81 *$ & $0.98^{* *}$ \\
\hline 3 & 1.66 & 0.90 & 0.87 * & $0.81^{* * *}$ & 0.83 * & $0.79 *$ & 0.98 * \\
\hline 4 & 1.93 & 0.91 & 0.89 & $0.91^{* *}$ & 0.88 & 0.87 & 0.96 * \\
\hline 8 & 2.32 & 0.95 & 0.98 & 1.27 & 1.23 & 1.35 & $0.96^{* *}$ \\
\hline 12 & 2.41 & 1.05 & 1.07 & 1.36 & 1.32 & 1.68 & 1.04 \\
\hline 16 & 2.54 & 1.03 & 1.03 & 1.27 & 1.26 & 2.11 & 1.02 \\
\hline
\end{tabular}

See table 4.2.1 for table details. 
Table B.2.4: NZ: Bow RMSFE

\begin{tabular}{llllllll}
\hline Item & Yields BM & LSB Partial & LSB Full & MF Un $^{\dagger}$ & MF Partial & MF Full & AR $^{\dagger}$ \\
\hline 1 & 1.37 & $\mathbf{0 . 9 7}$ & $\mathbf{0 . 9 4}$ & 1.12 & 1.10 & 1.05 & $\mathbf{0 . 9 8}^{* *}$ \\
2 & 1.70 & $\mathbf{0 . 9 7}$ & $\mathbf{0 . 9 3}$ & 1.11 & 1.10 & 1.09 & $\mathbf{0 . 9 8}^{* *}$ \\
3 & 1.87 & $\mathbf{0 . 9 6}$ & $\mathbf{0 . 9 1}$ & 1.09 & 1.10 & 1.10 & $\mathbf{0 . 9 8}^{* *}$ \\
4 & 1.99 & $\mathbf{0 . 9 7}$ & $\mathbf{0 . 9 6}$ & 1.13 & 1.14 & 1.27 & $\mathbf{0 . 9 7}$ \\
8 & 2.11 & $\mathbf{0 . 9 6}$ & $\mathbf{0 . 9 3}$ & 1.14 & 1.12 & 1.63 & $\mathbf{0 . 9 6}$ \\
12 & 2.20 & $\mathbf{0 . 9 8}$ & $\mathbf{0 . 9 9}$ & 1.27 & 1.29 & 2.55 & $\mathbf{0 . 9 8}$ \\
16 & 2.23 & $\mathbf{1 . 0 0}$ & 1.02 & 1.30 & 1.40 & 3.91 & 1.00 \\
\hline \hline
\end{tabular}

See table 4.2.1 for table details.

\section{B.3 Open economy results}

Table B.3.1: Open econ: 90-day rate RMSFE

\begin{tabular}{|c|c|c|c|c|c|c|c|c|}
\hline Item & Macro Open BM & FL Un & FL Partial & FL Full & FL 2F & FL 2F Partial & Closed $^{\dagger}$ & $\mathrm{AR}^{\dagger}$ \\
\hline 1 & 0.73 & $0.48^{* *}$ & $0.48^{* *}$ & 0.52 ** & $0.52 * *$ & 0.50 ** & 0.70 & $0.78^{* *}$ \\
\hline 2 & 1.18 & $0.50 * *$ & $0.55^{* *}$ & $0.56^{* *}$ & $0.64 *$ & 0.63 * & 0.82 & $0.87^{* *}$ \\
\hline 3 & 1.58 & $0.61^{* * *}$ & $0.64^{* *}$ & $0.66^{* *}$ & $0.78^{*}$ & 0.85 & 0.92 & $0.87^{* *}$ \\
\hline 4 & 2.05 & $0.74^{* *}$ & $0.74^{* *}$ & $0.77^{*}$ & 0.88 & 1.04 & 0.94 & $0.81^{* * *}$ \\
\hline 8 & 4.68 & 0.72 & 0.66 & 0.76 & 0.76 & 1.00 & 0.69 & 0.50 * \\
\hline 12 & 8.14 & 0.43 & 0.40 & 0.45 & 0.41 & 0.53 & 0.47 & 0.34 \\
\hline 16 & 14.38 & 0.22 & 0.21 & 0.24 & 0.21 & 0.54 & 0.37 & 0.22 \\
\hline
\end{tabular}

See table 4.2.1 for table details.

Table B.3.2: Open econ: Level RMSFE

\begin{tabular}{|c|c|c|c|c|c|c|c|}
\hline Item & LSB BM & LSB Partial & LSB Full & $\mathrm{FL} \mathrm{Un}^{\dagger}$ & FL Partial & FL Full & $\mathrm{AR}^{\dagger}$ \\
\hline 1 & 0.57 & 0.97 * & 0.99 & 1.29 & 1.19 & 1.14 & 1.00 \\
\hline 2 & 0.78 & $0.94^{* *}$ & 0.98 & 1.41 & 1.27 & 1.29 & 0.99 \\
\hline 3 & 0.89 & $0.90^{* * *}$ & 0.94 & 1.42 & 1.21 & 1.29 & 0.98 \\
\hline 4 & 1.00 & $0.89^{* * *}$ & 0.92 & 1.48 & 1.24 & 1.38 & 0.97 \\
\hline 8 & 1.27 & $0.87^{* * *}$ & 0.87 * & 1.19 & 1.15 & 1.24 & $0.93 *$ \\
\hline 12 & 1.35 & $0.91^{* * *}$ & 0.92 & $1.10^{* * *}$ & 1.14 & 1.47 & 0.95 * \\
\hline 16 & 1.35 & $0.95^{* * *}$ & 0.94 & $1.02^{* * *}$ & 1.12 & 1.61 & 0.99 ** \\
\hline
\end{tabular}

See table 4.2.1 for table details. 
APPENDIX B. QUASI REAL-TIME FORECAST PERFORMANCE RESULTS119

Table B.3.3: Open econ: Slope RMSFE

\begin{tabular}{|c|c|c|c|c|c|c|c|}
\hline Item & LSB BM & LSB Partial & LSB Full & FL Un ${ }^{\dagger}$ & FL Partial & FL Full & $\mathrm{AR}^{\dagger}$ \\
\hline 1 & 0.84 & $0.90 * *$ & $0.90 * *$ & $0.83^{* * *}$ & $0.77^{* * *}$ & $0.78^{* * *}$ & $0.98^{* * *}$ \\
\hline 2 & 1.33 & 0.90 & 0.90 & $0.76^{* * *}$ & $0.72 * *$ & $0.70^{* *}$ & 0.98 * \\
\hline 3 & 1.66 & 0.90 & 0.89 & $0.78^{* * *}$ & $0.77^{* *}$ & $0.74^{* *}$ & $0.98 *$ \\
\hline 4 & 1.93 & 0.91 & 0.91 & $0.84^{* * *}$ & 0.84 * & $0.81^{* *}$ & 0.96 * \\
\hline 8 & 2.32 & 0.95 & 0.95 & 1.38 & 1.31 & 1.37 & $0.96^{* *}$ \\
\hline 12 & 2.41 & 1.05 & 1.03 & 1.43 & 1.37 & 1.48 & 1.04 \\
\hline 16 & 2.54 & 1.03 & 1.01 & 1.38 & 1.30 & 1.47 & 1.02 \\
\hline
\end{tabular}

See table 4.2.1 for table details. 


\section{Appendix C}

\section{Data}

\section{C.1 Macro-finance relationships}

Figure C.1: Macro-finance linkages

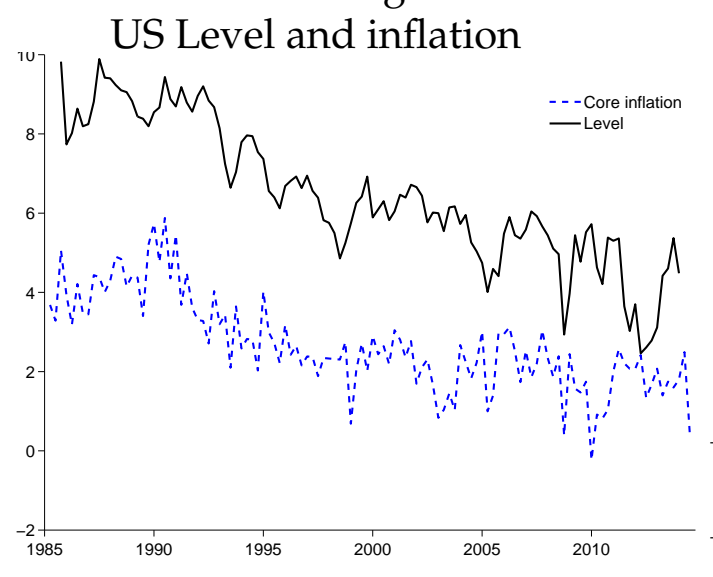

US Slope and real activity
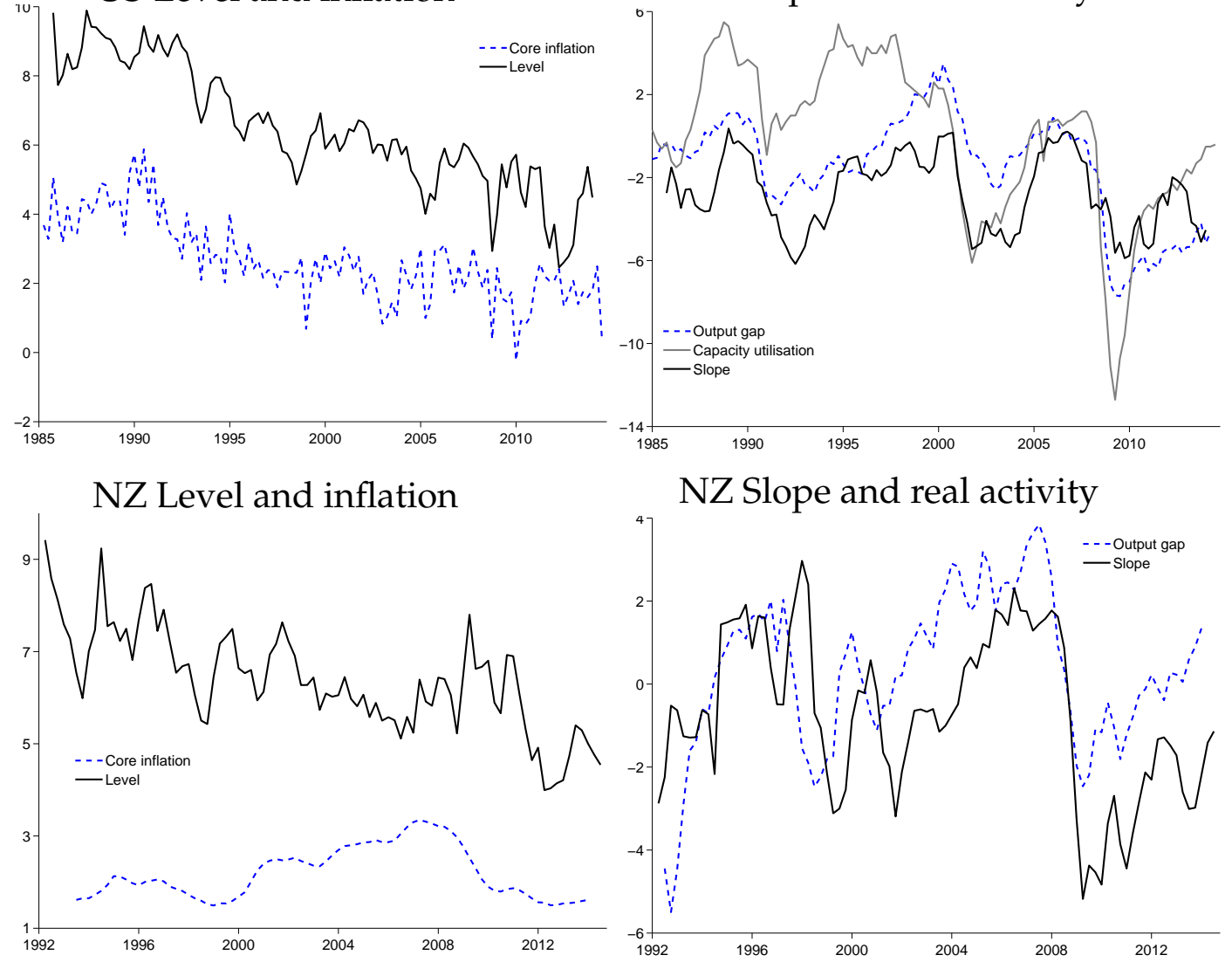


\section{C.2 Real-time data}
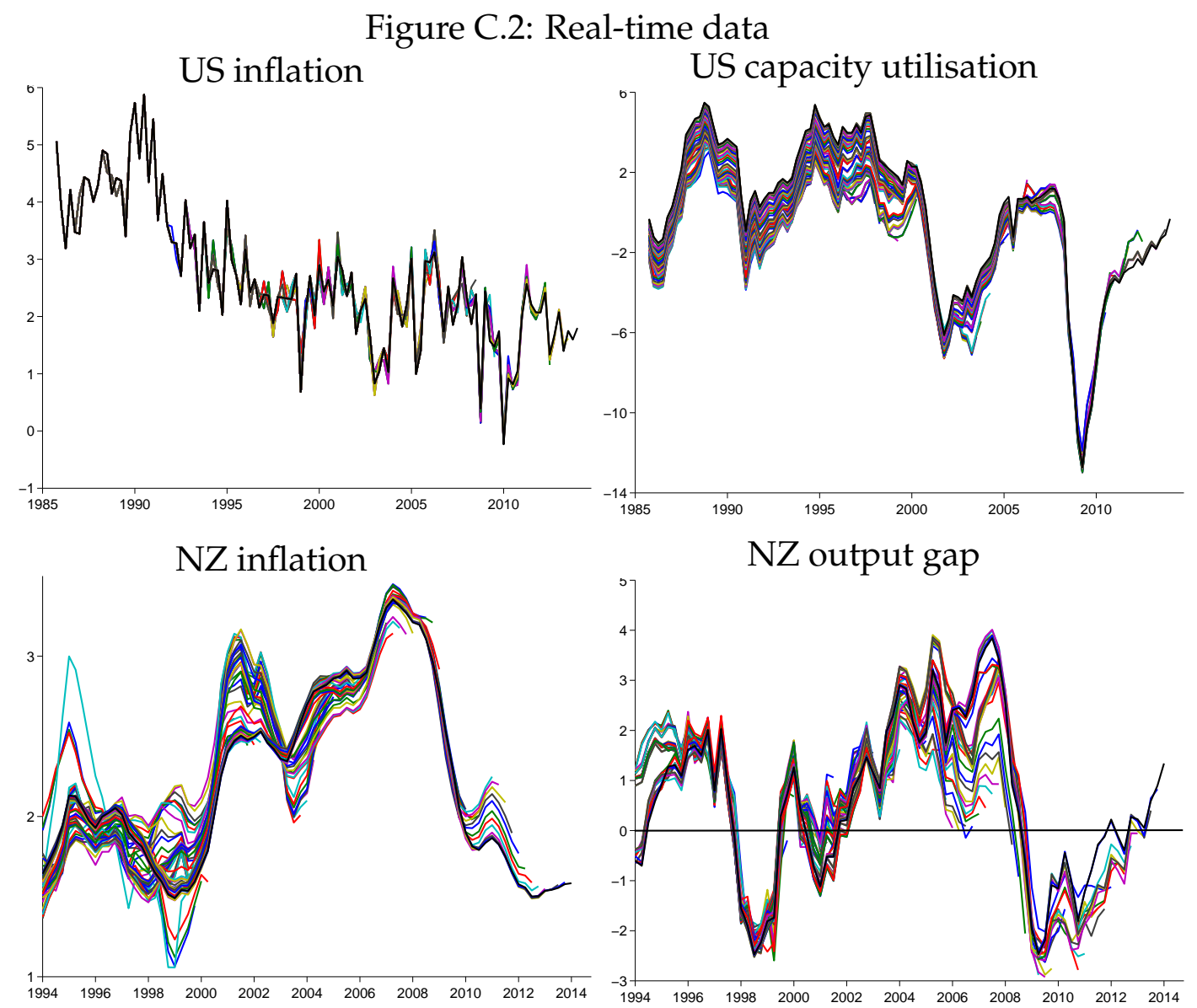